\title{
How to Use the Normalized Hydrophilic-Lipophilic Deviation (HLDN) Concept for the Formulation of Equilibrated and Emulsified Surfactant-Oil-Water Systems for Cosmetics and Pharmaceutical Products
}

\author{
Jean-Louis Salager*, Raquel Antón, Johnny Bullón * (D), Ana Forgiarini and Ronald Marquez \\ Laboratorio FIRP, Universidad de Los Andes, Mérida 5101, Venezuela; rantonsalager@gmail.com (R.A.); \\ anafor.ula@gmail.com (A.F.); marquezronald.ula.ve@gmail.com (R.M.) \\ * Correspondence: jl.salager@gmail.com (J.-L.S.); jbullontorr@gmail.com (J.B.)
}

Received: 23 June 2020; Accepted: 10 July 2020; Published: 14 July 2020

\begin{abstract}
The effects of surfactant molecules involved in macro-, mini-, nano-, and microemulsions used in cosmetics and pharmaceuticals are related to their amphiphilic interactions with oil and water phases. Basic ideas on their behavior when they are put together in a system have resulted in the energy balance concept labeled the hydrophilic-lipophilic deviation (HLD) from optimum formulation. This semiempirical equation integrates in a simple linear relationship the effects of six to eight variables including surfactant head and tail, sometimes a cosurfactant, oil-phase nature, aqueous-phase salinity, temperature, and pressure. This is undoubtedly much more efficient than the hydrophilic-lipophilic balance (HLB) which has been used since 1950. The new HLD is quite important because it allows researchers to model and somehow predict the phase behavior, the interfacial tension between oil and water phases, their solubilization in single-phase microemulsion, as well as the corresponding properties for various kinds of macroemulsions. However, the HLD correlation, which has been developed and used in petroleum applications, is sometimes difficult to apply accurately in real cases involving ionic-nonionic surfactant mixtures and natural polar oils, as it is the case in cosmetics and pharmaceuticals. This review shows the confusion resulting from the multiple definitions of HLD and of the surfactant parameter, and proposes a "normalized" Hydrophilic-Lipophilic Deviation $\left(\mathrm{HLD}_{\mathrm{N}}\right)$ equation with a surfactant contribution parameter (SCP), to handle more exactly the effects of formulation variables on the phase behavior and the micro/macroemulsion properties.
\end{abstract}

Keywords: surfactant-oil-water (SOW) systems; physicochemical formulation; phase behavior; normalized hydrophilic-lipophilic deviation $\left(\mathrm{HLD}_{\mathrm{N}}\right)$; surfactant contribution parameter $(\mathrm{SCP})$; related micro/macro-emulsion properties

\section{Introduction}

Surfactants are amphiphilic molecules going to surfaces and interfaces to produce specific effects. Typical interfaces are the limits between two immiscible phases, e.g., two fluids like water/air and water/oil, or solid/liquid. Surfactants tend to crucially influence the properties of the equilibrated systems (surface and interfacial tension, adsorption, association, bulk solution solubilization, and phase behavior) [1], as well as those of multiphasic dispersions (e.g., macro-, mini-, nano-, and micro-emulsions, foams, and suspensions), which vary with the selected surfactant(s) and with the nature of the other ingredients [2].

The surfactant is generally described according to its chemical formula, e.g., the type and typical characteristics of its hydrophilic and lipophilic group(s), ionic or nonionic head, single or multiple head(s) and tail(s), linear or branched structure of the tail, and pure species or mixtures, for which 
some average tail and average head group may be estimated in some way. However, the formula is not a definite characteristic concerning the effects because different surfactants could produce similar effects and result in similar properties. What is more, surfactants with a very small difference (like a single - $\mathrm{CH}_{3}$ methyl or a simple -OH hydroxyl added somewhere in the molecule) could make it behave very differently.

Surfactants are used in hundreds of products in the classical domestic and industrial applications dealing with interfaces (e.g., detergency and cleaning, personal care products, pharmaceutical and cosmetic vehicles, foods and beverages, paints, corrosion inhibitors, wastewater treatment, paper making, ore separation and concentration, and lubrication) and, since 1975, with the active research-development activities concerning petroleum production and refining.

However, surfactant studies according to application are not always useful because the association between surfactants and other ingredients used in complex systems is far from unique, and can sometimes be contradictory from one case to a very similar one. For instance, the same surfactant can stabilize an emulsion or break it depending on the aqueous and oil phases used, on temperature, and on the way it is handled [3].

The classification according to its behavior in water (i.e., soluble or insoluble, ionic or nonionic) is somewhat useful, but it is often too simple and often insufficient in critical cases. A practical classification must be related to some determinant behavior, or some attained characteristic property of interest, in a water solution or in a multiphase system, such as those containing oil and water, or solid and liquid.

In 1950, the first trial with a semiquantitative classification was proposed by Griffin, who introduced the hydrophilic-lipophilic balance number (HLB) by mixing two surfactants to attain a high stability emulsion result. His original scale was officially using the oleic acid as a very lipophilic amphiphile $(\mathrm{HLB}=1)$ and potassium oleate as a hydrophilic one $(\mathrm{HLB}=20)$, and their mixture with HLB value from 1 to 20 according to their weight average. It has been said that these numbers were not really arbitrary, and that the HLB was firstly taken as $20 \%$ of the weight percent of the hydrophilic part of the surfactant, in particular the ethylene oxide chain in polyethoxylated alcohols. General information is clearly found in Griffin's original proposal [4,5], as well as with many publications in surfactant applications listed in Becher's encyclopedia [6], indicating for HLB the 12-18 range to attain stable $\mathrm{O} / \mathrm{W}$ emulsions and a $4-5$ short interval for $\mathrm{W} / \mathrm{O}$ ones, both depending on the oil phase characterized by a so-called required HLB value. The neutral zone with no stable emulsion was in the 8-12 range on the Griffin scale, while it was in the 6-8 range in a proposal from Davies, which was more theoretical but also quite inexact in practice [7].

It may be said that the HLB proposal from Griffin was helpful to a certain extent to select a surfactant for a given application, particularly related to emulsion type and stability, but that it was quite inaccurate, because it depended on many other properties such as the surfactant molecular weight [8] and on many of its features such as its chemical formula, particularly the nature of the hydrophilic group and the branching of the lipophilic tail, or some other specificities like the aromaticity of the oil, the presence of electrolyte in water, the usual addition of alcohol and other cosurfactants, the temperature, and the pressure. In an article titled "HLB: Is it a valuable concept or a curiosity?", the answer of an author working in a well-known manufacturing company of surfactants was that it was just a curiosity [9].

Consequently, it may be said that HLB is the historical first proposal for characterizing a surfactant, but that it is quite inaccurate for today's formulations used in many different applications, in particular for foods, cosmetics and pharmaceuticals [10].

It is worthwhile mentioning that, in the petroleum-petrochemical industry, the efficient use of surfactants in complex oil-water systems implies a highly precise formulation, and a much more accurate surfactant characterization than in most other domestic and industrial applications. The corresponding high-level knowledge and know-how started to be developed in 1974-1980 to solve the problems found in enhanced oil recovery (EOR) formulation issues. In these applications the interfacial tension 
could change one order of magnitude with a HLB variation of 0.1 unit. Consequently, a usual inaccuracy in Griffin's HLB of \pm 2 units was eliminatory. A required increase in characterization accuracy was generalized to any surfactant-oil-water ternary situation used from many domestic and industrial applications, even if it is not as critical as in EOR. The present review updates the quantification of the surfactant characterization proposed in the 1990's [11], particularly for pharmaceutical applications [12,13].

\section{The Phenomena and Involved Variables in Equilibrated and Emulsified Surfactant-Oil-Water Systems}

The first and simplest way to describe the effect of a surfactant from the physicochemical point of view was first considered to be independent of the nature of the other ingredients. This was performed according to the surfactant's general behavior as far as a property of interest was concerned.

\subsection{Principal Phenomena}

1. Phase behavior in one solvent fluid, i.e., the complete or partial solubility, in particular the concept of cloud point for nonionic surfactants in water that indicates the importance of temperature in the case of polyethoxylated species.

2. Surfactant molecules' self-association in a solvent fluid, e.g., the formation of micelles or other aggregates, either in aqueous or oily phases.

3. The association structure of surfactants with two immiscible fluids, e.g., oil and water, as in an adsorbed single interface layer, or more complex arrangements like microemulsions, liquid crystals, vesicles, liposomes, etc.

\subsection{Particularly Important Properties in Some Applications}

1. Phase behavior, i.e., the occurrence of 1,2 or 3 phases in a surfactant-oil-water (SOW) ternary or in a quaternary system when a second surfactant or a so-called cosurfactant, such as an alcohol, is added.

2. The surface or interfacial tension at the fluid/fluid limit (e.g., air/water or oil/water) that varies with the nature of the ingredients, and their contents.

3. Adsorption of amphiphilic substances, i.e., their location at interface, and its consequences as far as the wettability is concerned.

4. Interfacial effects concerning dispersions with a high surface area, particularly the stability of emulsions, foams, and solid particle suspensions.

The fact is that these physicochemical properties, which depend on the surfactant and sometimes a cosurfactant, also depend on the other ingredients (aqueous brine, oil, additives) and on certain conditions (temperature and pressure). Moreover, it is well known that a good characterization could imply handling not only a single surfactant molecule but also, in practical situations, mixtures of molecules. This is firstly because, in general, manufactured surfactants are not a single substance but a mixture of two or (many) more different types so as to gather advantageous properties, and, secondly, because most commercial surfactants are already a mixture of similar or different species for economic reasons.

The other ingredients, in particular in petroleum, food, detergency, pharmaceutical and cosmetic applications, involve the use of several variables to describe their composition, such as water (from an aqueous solution of sodium chloride to different salts composition as in petroleum reservoir brine, wastewater, or blood). In some applications, substances influencing the $\mathrm{pH}$ are particularly important. As far as the oil phase is concerned, it can vary from pure n-alkane to plant terpenes, edible triglyceride oils, chlorinated solvents, or even crude oils, as well as more or less water-soluble alcohol cosurfactants. In all these cases, the temperature exerts an influence on many different phenomena, and, in petroleum reservoirs and refining units, as well as in system containing dissolved gas, the pressure may also be 
critical. In cosmetic and pharmaceutical applications, it could help dissolving gas in a liquid and then producing a foam by just releasing the pressure.

Furthermore, it may be said that temperature and pressure can influence the occurrence of single or multiple phase behavior in different ways.

Some applications only require an approximate characterization, and thus a simple way to handle the formulation is sometimes enough in practice, as it happened at first with pioneering proposals such as Bancroft's rule in 1915 [14], Langmuir's wedge theory in 1917 [15], and Griffin's hydrophilic-lipophilic balance (HLB) proposed in 1949 with an additional explanation on its use and limits in $1954[4,5]$.

Then, as the used surfactant systems have become more sophisticated, more complete approaches were proposed. The most significant step in that direction took into account many formulation variables, but was still a qualitative description; it was the Winsor's R ratio, proposed a long time ago [16,17], and its extension by Beerbower in 1976 as the cohesive energy ratio (CER) [18] based on the solubility parameters proposed by Hansen in 1967 [19], as well as the geometrical approach of Israelachvili's critical packing parameter (CPP) [20].

Shinoda's phase inversion temperature (PIT) approach proposed in 1964 [21-23] independently described a concept similar to Winsor's $R$ but with a temperature characteristic value. Even if it was limited to systems containing polyethoxylated nonionic surfactants, it was the first numerical approximation, clearly depending on all the system variables.

It was finally during the first years of the intensive research drive in enhanced oil recovery with surfactants in the late 1970's that a more quantitative approach allowed some predictions. This was a systematic one-dimensional formulation scan performed according to Winsor's principle that became the basic experimental method in the petroleum industry [24], including a proposed fundamental basis on chemical potential equations [25].

A study on bi- and multidimensional scans produced an empirical relationship which was interpreted as a physicochemical correlation for the attainment of three-phase behavior, a high solubilization and a minimum interfacial tension [26] for ionic and nonionic surfactants $[27,28]$.

The generality of the correlation for the occurrence of a so-called optimum formulation and related phenomena was expressed as the surfactant affinity difference (SAD) in 1983 [29], and its dimensionless equivalent, so-called hydrophilic-lipophilic deviation (HLD) in 2000 [30].

The state of the art at this time can be found in a general book on interfacial phenomena [1], and in books specifically dealing with microemulsions [31-34], as well as some particular review articles on formulation [11,35-39].

\section{One-Dimensional Scan with Typical Formulation Variables}

The basic technique to study a surfactant-oil-water (SOW) system, i.e., the determination of its phase behavior (and associated interfacial tension and solubilization events), was the one proposed by Winsor 70 years ago [16,40], after determining the variables likely to produce a change in the interactions between the adsorbed surfactant molecules at the interface and the oil and water molecules on both sides of it.

In the most elemental SOW ternary case containing a pure surfactant, an aqueous brine and an immiscible oil, these variables were found to be the following: the surfactant characteristic features depending on at least two different aspects (i.e., its head group hydrophilicity and its tail lipophilicity), the salinity $S$ of the water phase, and the nature of the oil, typically the alkane carbon number $(\mathrm{ACN})$ for the most simple oil case, as well as the temperature and pressure. The content of a minimum of three different substances add two composition variables, to reach a total of eight independent variables. The introduction of a second amphiphile as a different surfactant or an alcohol cosurfactant would complicate the situation with the use of a surfactant-cosurfactant-oil-water, SCOW quaternary diagram, and reach up to 10 variables, a number which makes handling impossible in bi or tridimensional graphs. Fortunately, the number of different cases is less, and there is a combination of the effects. 
In his first proposal [40], Winsor presented an analysis of the physicochemical situation in a SOW system, which presents four types indicated in Figure 1 as reproduced from his original work and compared to the actual aspect in the picture on the right.

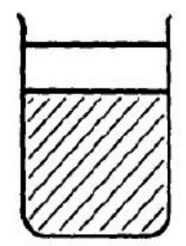

Type I.

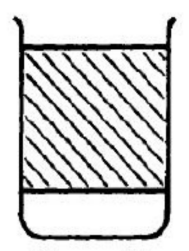

Type II.

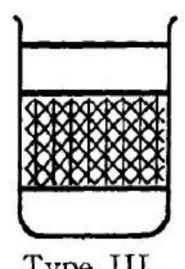

Type III.

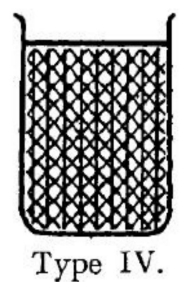

Up to 3 phases

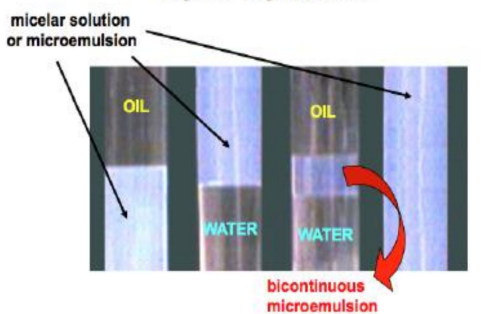

Figure 1. Different types of solubilization in a surfactant-oil-water (SOW) system according to the aspect type and Winsor $R$ ratio: Type I when $R<1$, Type III when $R=1$ and Type II when $R>1$.

The shaded (nontransparent, more or less opacified) phases in Figure 1 contain structures which are large enough to diffuse light, like swollen micelles or inverse micelles (with a typical size of 50-100 nm). They are some kind of extremely small droplets, too small to separate because of dispersive entropic effects. This homogeneous behavior at our visible scale and its associated stability, is why they were not said to be some kind of emulsion by Winsor at the time.

Nevertheless, this solubilizing phase was called first "oleopathic hydromicelle" in type I solubilization [41], and then later "microemulsions" in the three types [42], as clearly reviewed later $[23,43,44]$.

In type I phase behavior, the surfactant exhibits more dominating attractive forces or interactions with the water, and thus solubilizes oil in this phase micelles, with a very low concentration in the excess oil phase (essentially just above the critical micellar concentration CMC), as seen in Figure 2. In type II, it is the same but in the reversed way, when the surfactant has more interactions with the oil phase, thus forming inversed micelles solubilizing water inside, as seen in Figure 2.

In type III, the structured middle phase has an intermediate density because it contains similar amounts of oil and water. Winsor proposed for this middle phase a lamellar, more or less jellylike structure, because of some birefringence, but he mentioned that it was not necessarily a perfectly plane liquid crystal. He suggested that it might be distorted or could contain twisted lamellae with both types of micelles not necessarily spherical, nor really fully organized, but somehow linked or connected, as seen in Figure 2, and that it may be in a permanently changing situation. This was a very early vision from Winsor of the currently accepted bicontinuous microemulsion structure with some chaotic geometry, as nicely proposed by Scriven in his excellent description [43].

Type IV is essentially a case in which there is enough surfactant (a very large concentration in practice, such as more than $20 \%$ ) to cosolubilize both oil and water to produce a single phase. More information is required to know whether this type IV corresponds to one of the other type structures with an excess of surfactant.

In his 1954 book and final review paper [17], Winsor proposed to relate the type of SOW system with the ratio of interactions of the surfactant located at the oil and water limit, i.e., at the interface zone indicated in Figure 2's left scheme, either in a swollen micelle (type I and II) or in the complex middle phase structure (type III). Winsor proposed that the type was defined according to the value of the ratio $\mathrm{R}=\mathrm{Aco} / \mathrm{Acw}$, where the molecular attractive forces Aco and Acw are between the adsorbed surfactant molecule (indicated to be in the interfacial C zone) and the nearby oil (O) and water (W) molecules. Actually C, $\mathrm{O}$ and $\mathrm{W}$ include sometimes-occurring additives like a cosurfactant or alcohol located at the interface and additives located in water (like salt) or oil (like slightly polar species). $\mathrm{R}$ indicates the ratio of the tendency of the interface layer to become convex towards $\mathrm{O}$ to its tendency to become convex towards $W$. When $R=1$ the situation corresponds to an average zero curvature at 
the $\mathrm{O}-\mathrm{W}$ limit, which could be a flat lamellar structure or a complex bicontinuous arrangements of both types of swollen micelles, as schematically indicated in Figure 2 drawing on the right.

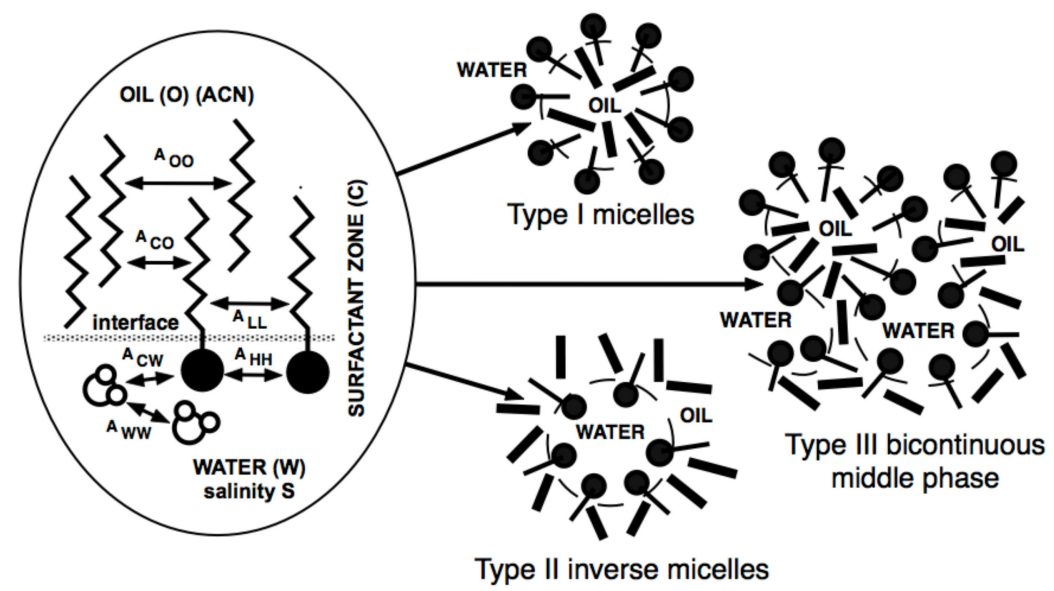

Figure 2. Interactions of the surfactant molecule adsorbed at the oil-water limit with neighboring water and oil molecules found in swollen micelles (Type I) or inverse micelles (Type II), as well as in middle phase lamellae or other complex bicontinuous structure (Type III).

Actually, Winsor proposed in his final review [17], and according to a private suggestion from G. $\mathrm{S}$. Hartley, a supposedly more complete $\mathrm{R}^{\prime}$ relation including the reference interactions when the oil and water are separated, without surfactant, i.e., introducing the Aoo and Aww interactions which tend to oppose the convexity favored by the Aco and Acw attractive interactions. There are thus two expressions called $\mathrm{R}$ and $\mathrm{R}^{\prime}$ here.

$$
\mathrm{R}=\mathrm{Aco} / \mathrm{Acw} \text { and } \mathrm{R}^{\prime}=(\mathrm{Aco}-\mathrm{Aoo}) /(\mathrm{Acw}-\mathrm{Aww})
$$

It should be noted that the $\mathrm{R}$ ratio is only qualitative, since it is not known how many oil and water molecules actually interact with a single surfactant molecule, i.e., what are the coefficients before Aco and Acw, as well as other interactions appearing in R.

An even more complex interaction ratio was discussed a long time after Winsor's proposal by including terms dealing with interactions between neighboring surfactant molecules, both on their hydrophilic head and lipophilic tail zones, e.g., $A_{H H}$ and $A_{L L}$ in Figure 2. As could be seen in a detailed analysis [45] and in a very complete review book [32], this addition could become very complex to analyze, and it is not necessary for the purpose of the present review. Consequently, it is believed that the simplified original $R$ relation or its $R^{\prime}$ alternative are sufficient to easily discuss the basic formulation issues in the following text. What will be used further on is an essentially similar generalized formulation criterion, the so-called hydrophilic-lipophilic deviation (HLD), which is no more than the difference between the numerator and denominator of $\mathrm{R}$, i.e.,

$$
\mathrm{HLD}=\mathrm{Aco}-\mathrm{Acw}
$$

Conceptually, HLD is some kind of logarithmical expression of R, i.e., it is negative (respectively positive) if $\mathrm{R}<1$ (respectively $\mathrm{R}>1$ ). As will be more discussed later [11], HLD has the advantage of being easier to calculate because interaction energies are generally handled as summations and subtractions of chemical potential terms instead of their ratio.

It is worth noting that the $\mathrm{R}=1$ or HLD $=0$ situation, corresponding to type III in Figure 1 , is very easy to be visually detected at the limit between type I and type II. The requirement for that is just to have enough surfactant (e.g., $>0.5 \mathrm{wt} \%$ ) to see some middle phase volume, but not too much of it $(<25 \mathrm{wt} \%)$ to avoid the middle phase invading the whole system as in type IV. 
By continuously changing one of the variables influencing R or HLD, through one of the interactions Aco or Acw, a so-called "formulation scan" is said to be carried out.

For instance, if the length of a surfactant alkyl tail is increased, without changing anything else, then the term Aco is going to increase, thus increasing R and HLD. If the size of a polyethoxylated surfactant head group is increased, it is now the Acw term which is increased, thus R and HLD are decreased. If the second change is carried out to exactly return to the HLD $=0$ situation of three-phase behavior, then their effects are exactly compensated from the numerical point of view. This evolution is easy to understand in such cases, because each selected change only alters monotonically one term in the HLD relation.

It might be somehow more complex if two interaction terms are altered by the change in the scanned variable. For instance, if the size of the n-alkane oil is increased, the Aco term is going to increase, as well as Aoo, because both interactions involve the oil molecule. Since the Aco term depends on the increase of the size of one molecule of oil without changing the size of the surfactant tail, it may be assumed that it varies proportionally to the oil Alkane Carbon Number (ACN). But in Aoo, there are two oil molecules involved and the ACN effect will contribute twice, thus Aoo is likely to vary as $\mathrm{ACN}^{2}$, thus faster than Aco when $\mathrm{ACN}$ increases. Consequently, the R numerator (Aco - Aoo) will increase or decrease depending on the ACN value. It is in general found that if $\mathrm{ACN}$ is large enough (as with liquid alkanes, i.e., if $\mathrm{ACN}>5$ ) the negative term Aoo will dominate Aco, and thus $\mathrm{R}$ and HLD will decrease [32].

When the salinity of the aqueous phase increases, the Acw term decreases because the salt water is a less hydrophilic solvent and it thus results in a lower interaction of the aqueous phase with the surfactant head group. The Aww interaction is also decreasing, and the denominator definitively decreases, and thus R and HLD increase.

When the temperature is changed, most molecular interactions are altered and the discussion is not easy to handle. However, it is experimentally well known that the ionic surfactants are likely to become slightly more water soluble when temperature increases, i.e., Acw generally increases. The opposite occurs with nonionic species whose ethoxylated part are systematically dehydrated when temperature increases, thus becoming less water soluble. As a result, an increase in temperature tends to slightly decrease the R and HLD for ionic surfactants and to strongly increase them for nonionics.

Consequently, it may be said that along any kind of change of a formulation variable, the R or HLD criterion increases or decreases, and that at some point of the scan, a specific $R=1$ or HLD $=0$ value will take place. This occurrence has been called the "optimum formulation" by the people working in enhanced oil recovery, because it is where an (ultra-)low minimum interfacial tension occurs as seen in Figure 3, and thus allows the crude oil displacement to happen because of the considerable modification of the capillary number [24].

This optimum formulation occurring at some scanned variable value, also corresponds to several other interesting events, as will be discussed next, in particular a maximum solubilization of oil and water (best for a microemulsion single phase attainment for pharmaceutical and cosmetics purposes) as seen in Figure 3. It is also seen in this figure that at optimum formulation the partition coefficient of the surfactant between the two excess phases in a type III system is unity. It is worth noting that this is perfectly equivalent to an equal interaction of the amphiphile molecule with the oil and water or very close to its critical micelle concentrations in the excess phases.

If there is no minimum tension nor maximum solubilization in the performed scan, it means that the range is not a proper one to attain somewhere an optimum formulation, i.e., a balance of interactions of the surfactant for oil and water, with the other variables as fixed conditions. In such a case, the surfactant has to be changed for a more hydrophilic or more lipophilic one, or alternatively some other formulation variable, like salinity or temperature, should be changed to attain the optimum somewhere in the selected scan range. The HLD expression presented later in this review will show how to numerically change the different terms to attain the optimum formulation by simply reaching $\mathrm{HLD}=0$. 

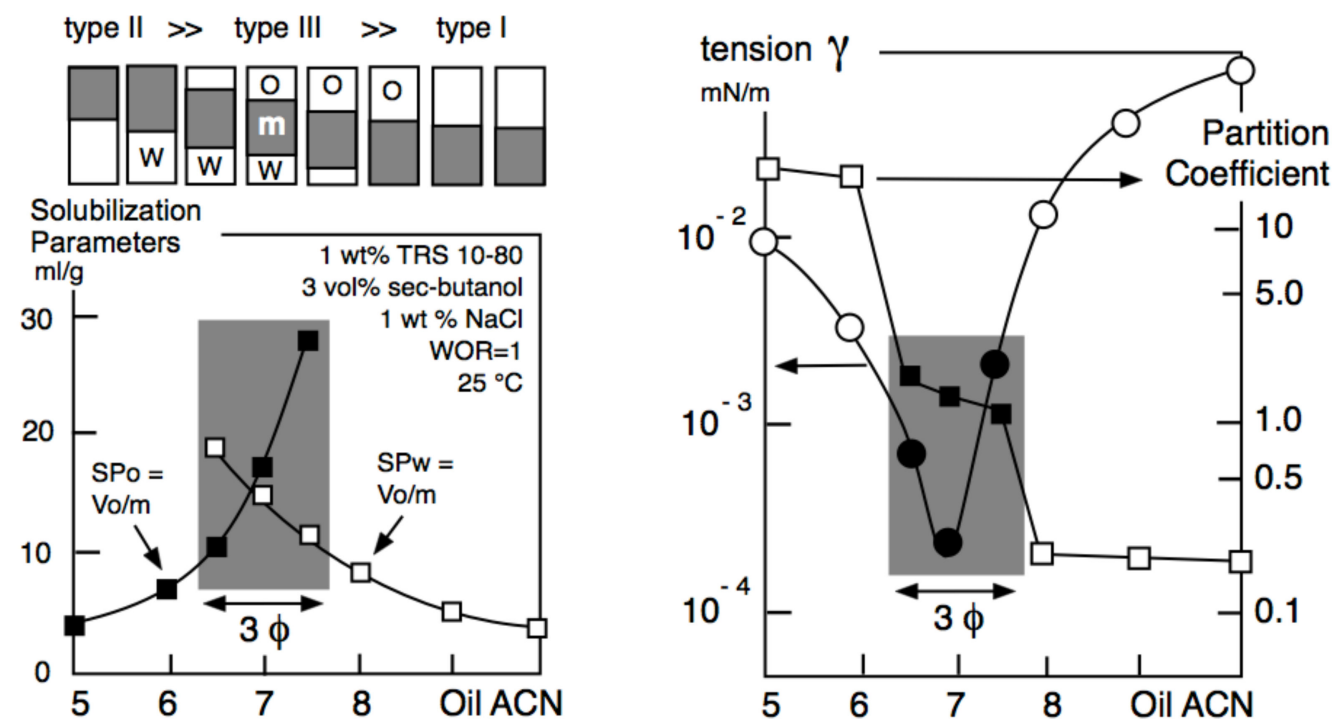

Figure 3. Optimum formulation has been shown in the very first trials [26] to correspond to the minimum interfacial tension and to a unit partition coefficient between oil and water excess phases (right plot), as well as the occurrence of a maximum solubilization, with equal solubilization parameters (SP) in the microemulsion middle phase (left plot).

Let us see now in more details the usual way to describe the phase behavior and the properties of SOW systems. Such systems contain three components, and thus the number of composition variables is three, with two independent ones, e.g., the amount of surfactant and water, with the oil phase being the complement to $100 \%$. Actually, the usual way to give some symmetry to oil and water solvents is to take as the independent variables the concentration of surfactant Cs and the water-to-oil ratio WOR in a triangular plot. According to the influence of many variables concerning the formulation, it is seen that the Winsor's R concept or its equivalent HLD gather many different effects in a single one, which is an overall balance of affinities. The main and most remarkable fact is that the HLD equation has a single concept value that takes into account at least the effect of four physicochemical variables plus temperature and pressure, as well as two composition variables.

It is impossible to make a graph showing the effect of eight variables using a three-dimensional representation graph with Cs, WOR and the generalized formulation. However, it is possible to build a 3D plot shown in Figure 4 (upper left), where the generalized formulation variable is HLD with a monotonous numerical change produced by any (or by several) of its six variables.

Since the usual way to show a graph is a 2D representation, the 3D space is cut by three kinds of planes shown in Figure 4. The first one is the constant formulation cut that results in the so-called Winsor's ternary diagram that allows a decision on the required amount of the SOW ingredients to attain an appropriate phase behavior or property once the formulation is fixed, as seen later.

Then, Figure 4 indicates the constant WOR and constant surfactant concentration cuts, which allow the estimation of the effect of the formulation value in such subspace, particularly at optimum.

Figure 5 schematically indicates (on top) the phase behavior in the Winsor SOW ternary diagrams for three fixed formulation cuts. The cuts correspond to the so-called WI-WIII-WII diagrams according to the Winsor phase behavior type appearing in the multiphase zone, typically at the square point (WOR $=1$ and $\mathrm{Cs} \sim 5 \%$ ). The solubilization (of oil in water SPo and of water in oil SPw) at constant surfactant concentration and WOR $=1$, indicated in Figure 3, is now represented in a different way. It is the minimum surfactant concentration $\mathrm{Cs}^{*}$ required to pass from type III to type IV at WOR $=1$. The two measurements are opposite, as discussed previously [37].

This lower plot in Figure 5 is called the "fish" diagram, even if in the present case the fish is vertical instead of being horizontal as in many studies of nonionic surfactant systems [46-52]. 


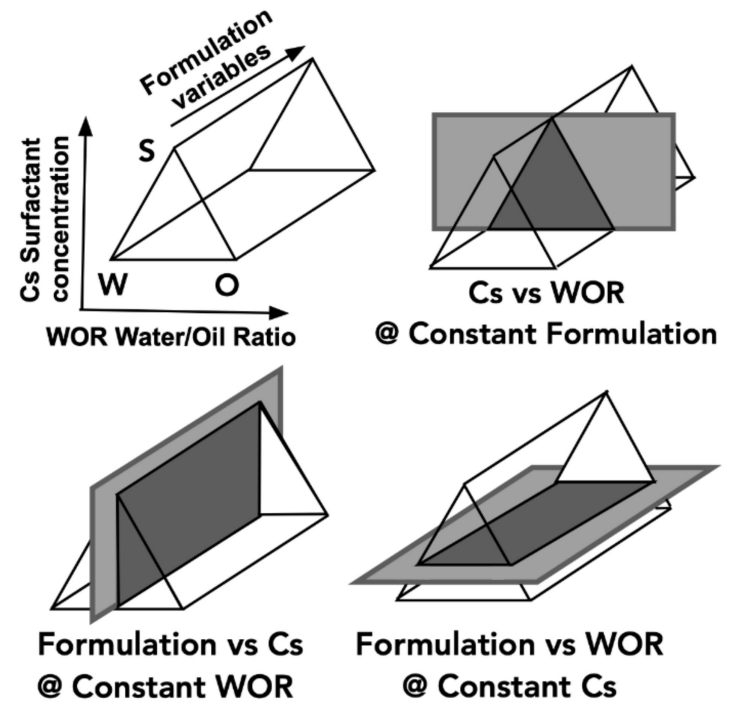

Figure 4. The three-dimensional way to handle the description of a SOW system as a function of the generalized formulation hydrophilic-lipophilic deviation (HLD), as well as constant surfactant concentration (Cs) and water-to-oil ratio (WOR). There are three types of 2D cuts at constant formulation, constant WOR $=1$, and constant concentration of surfactant Cs.

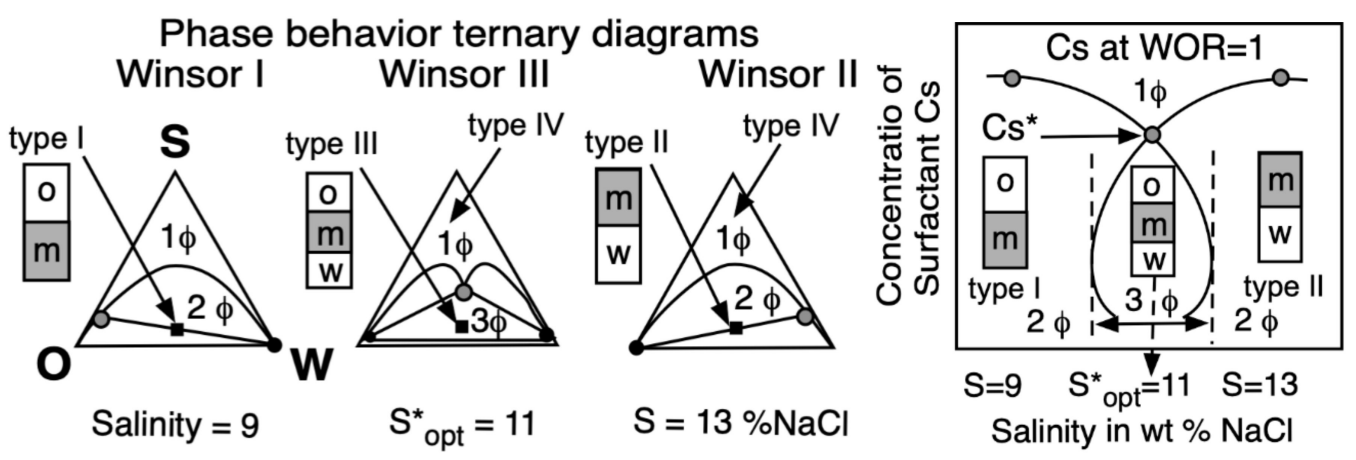

Figure 5. Top: Phase behavior at constant formulation cut for three cases of salinity (Winsor's diagrams). Bottom: Solubilization as $\mathrm{C}_{\mathrm{S}}$ surfactant concentration to attain a single-phase microemulsion at constant $\mathrm{WOR}=1$ cut (vertical fish diagram). In both cases the formulation scan is carried out by a change in salinity.

The optimum formulation (indicated in the present salinity scan at $S^{*}{ }_{\mathrm{opt}}=11$ ) takes place when the minimum concentration of surfactant $\mathrm{Cs}^{*}$ happens.

It can be seen that, close to the optimum formulation (at $\mathrm{S}^{*}=11 \mathrm{wt} \% \mathrm{NaCl}$ in Figure 5), a three-phase behavior happens with a middle-phase microemulsion in equilibrium with excess water and excess oil. These excess phases (black circles) contain a very small concentration of surfactant, slightly above its critical micelle concentrations, as seen essentially to be close to zero in the lower part of the ternary triangle in the Winsor III diagram. At the top of the three-phases triangle (micro-emulsion indicated as a circle point in grey), the better solubilization is attained, i.e., there is a minimum surfactant requirement $\mathrm{Cs}^{*}$ to reach the type IV single phase zone.

This has been extensively reported in review books [32,34,53].

In the three-phase systems there are two interfaces in a test tube, thus two interfacial tensions, so-called $\gamma_{\mathrm{om}}$ and $\gamma_{\mathrm{wm}}$, where $\mathrm{m}$ is the microemulsion middle phase. Optimum formulation, $\mathrm{SP}^{*}$, which happens at the crossing of these two SP curves in Figure 3, indicates the equal solubilization of oil and water in the microemulsion middle phase. 
More detailed information on the tension and solubilization in this WIII diagram may be found elsewhere $[54,55]$. In practice, the range with three-phase behavior in the scan is relatively narrow; it is actually narrower when the minimum tension is lower [56-58].

On the Winsor I diagram (here at lower salinity) $\mathrm{HLD}<0$, i.e., the surfactant has more interactions with the water in which it forms a microemulsion aqueous phase ( $m$ in gray in Figure 5 ) in equilibrium with excess oil, containing practically no surfactant. In the other two-phase Winsor II diagram (here at higher salinity), HLD $>0$ and the surfactant is in an oil microemulsion ( $m$ in gray) in equilibrium with an excess water.

The phase behavior change produced by an increase in brine salinity is usually shown as the diagram transition WI $>$ WIII $>$ WII, as indicated on the top of Figure 5.

The actual phase behavior at the square point in the multiple phase systems is noted in the tube corresponding to the diagrams WI-WIII-WII. Above the microemulsion (gray circle point) in the Winsor III diagram, the behavior is monophasic $(1 \phi)$ and the minimum concentration of surfactant for that is called $\mathrm{Cs}^{*}$ at the tail of the fish.

It has been shown experimentally [24], and explained by means of a microemulsion theoretical model [59], that the interfacial tension $(\gamma)$ varies inversely to the square of the solubilization parameter $\mathrm{SP}$ according to the Chun Huh relation, i.e., $\gamma \mathrm{SP}^{2}=0.30 \pm 0.05 \mathrm{mN} / \mathrm{m}$.

This expression, verified to be followed by many systems close to the optimum formulation, indicates that the optimum formulation to attain a low tension in a scan is also the optimum to solubilize more oil and water into a single phase for a given amount of surfactant. A performance index, called PERFIND and defined as $-\log _{10} \gamma_{\min }$ where $\gamma_{\min }$ is the minimum interfacial tension in a scan, has been recently introduced and is precisely related to the different variables for a very simple system [60].

Thus, at the optimum formulation in any scan, three equivalent events are attained and related, i.e., the lowest tension $\gamma^{*}$, the highest solubilization $\mathrm{SP}^{*}$ or the minimum surfactant concentration $\mathrm{Cs}^{*}$ to make a single phase microemulsion in a fish graph, with numerical equivalence reported elsewhere [37].

In Figure 6, the variation of PERFIND is showed in three different formulation variable scans (surfactant ethoxylation number EON, water salinity S, oil ACN), showing the numerical equivalence of performance index (PERFIND) with other quality criteria like the minimum tension $\gamma^{*}$, the maximum solubility parameter $\mathrm{SP}^{*}$ and the minimum surfactant concentration $\mathrm{C}^{*}$ s to attain a single phase $[11,60]$.

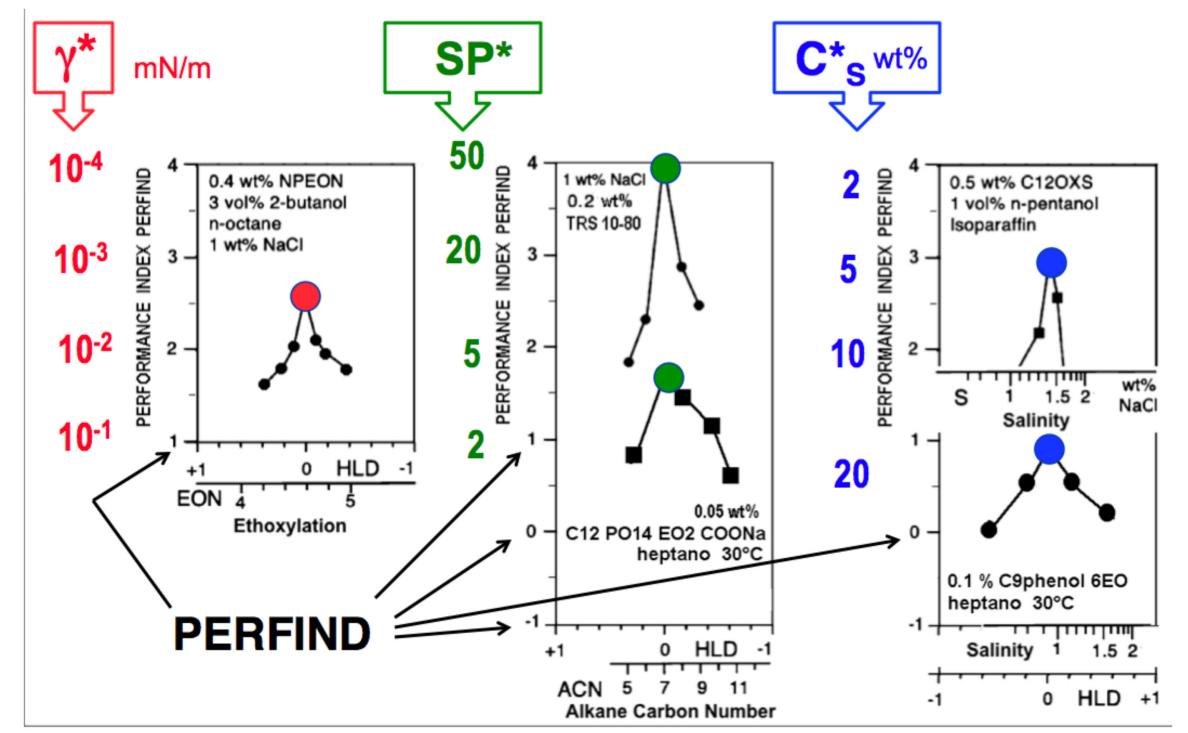

Figure 6. Detection of optimum formulation by different criteria maximizing the performance index PERFIND (minimum interfacial tension $\gamma^{*}$, maximum solubilization parameter SP* and minimum surfactant spending $\mathrm{C}^{*} \mathrm{~s}$ ) to attain a single-phase microemulsion at the tail of the fish diagram. 
It is obvious from Figure 6 that the optimum formulation could be a good solution to cosolubilize oil and water in a single phase microemulsion cream for cosmetic or pharmaceutical applications. It can also be seen that the attained performance for solubilization, even at optimum (HLD =0), could considerably vary with the nature of used ingredients, particularly the surfactant and cosurfactant [60,61].

The detection of the optimum formulation by several experimental measurements is shown in Figure 7 where any scanned variable $\mathrm{V}$ is indicated as being $\mathrm{V}^{*}$ at optimum. The lower horizontal arrows are showing the direction of increasing salinity, surfactant tail length, surfactant head hydrophilicity (e.g., ethylene oxide number for polyethoxylated nonionic), temperature for both ionic and polyethoxylated nonionic surfactants, and pressure.

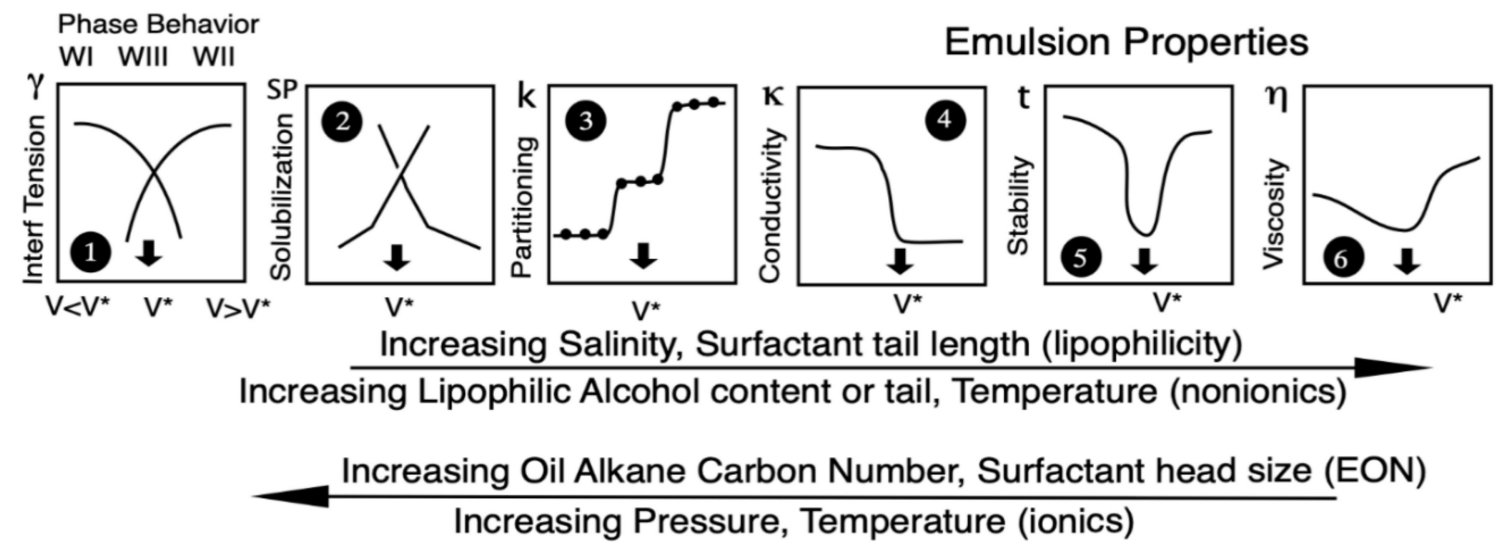

Figure 7. Different occurrences taking place at the optimum value $\left(\mathrm{V}^{*}\right)$ of a single variable scan, whichever the formulation variable $\mathrm{V}$.

It can be seen that the minimum tension, previously mentioned as the way to determine the optimum formulation $\mathrm{V}^{*}$, is at the center of the three-phase behavior (WIII) zone in Figure 7(1) [26]. Then, the solubilization (as the amount of excess phase incorporated in the swollen micelles or in the bicontinuous structure) passes through a maximum in Figure 7(2), and the partition coefficient of the surfactant between oil and water excesses is close to unity in Figure 7(3), as first mentioned very early for anionic surfactants used in enhanced oil recovery $[25,26]$.

An emulsion made by stirring an equilibrated SOW system also exhibits particular characteristics at optimum formulation $[13,62,63]$. It inverts, as indicated by a large change in conductivity in Figure 7(4), where it passes from $\mathrm{O} / \mathrm{W}$ to $\mathrm{W} / \mathrm{O}$, as the phase behavior changes from type I to type II. This easy-to-note emulsion inversion requires a higher conductivity for the water phase, generally because it contains some electrolyte that could be the present ionic surfactant or a salt like $\mathrm{NaCl}$ at a very low concentration, e.g., $0.1 \mathrm{wt} \%$.

The emulsion stability is shown to pass through a very deep minimum in Figure 7(5), i.e., the emulsion becomes very unstable, probably because the surfactant has a lower chemical potential in the microemulsion middle phase than at the oil-water interface, where it has to be to generate stabilization mechanisms. Consequently, it may be said that at optimum formulation, the surfactant seems to be trapped in the microemulsion and that the oil/water mixture dispersed as drops by the stirring would coalesce instantly in practice, as it would be in complete absence of surfactant. This specific emulsion strong instability at optimum formulation has recently been found to match, and thus probably to result from, a very low interfacial rheology elasticity through a low dilational modulus [64-66]. The detection of the minimum stability in emulsified system is besides the quickest way to detect the optimum.

Figure 7(6) additionally shows that the emulsion viscosity is particularly low at optimum formulation, probably because the low tension favors the elongation of the drops when the emulsion is submitted to a shear. However, this viscosity minimum is not as accurate for detecting the optimum as the minimum stability. 
More detailed information about these many specific properties at the optimum formulation of a scan may be found in details in an encyclopedia [3], but what is important here in practice is that this coincidence allows the selection of the best or easiest method to detect the optimum formulation and the best performance.

Before a general discussion, it is worth remarking that attaining an optimum formulation by continuously changing a single variable is an extremely useful and simple method to study systems in different applications. If the water is an aqueous brine, its salinity is a concentration, e.g., some $w t \%$ of some salt like $\mathrm{NaCl}$, or some mixture of several electrolyte species matching a real system like blood. If the oil is not a simple n-alkane, it may be practically described by some equivalent alkane (EACN) [67], which is discussed at the end of the present review. If the brine, the oil, the temperature and pressure are fixed by the application, the variable selected to be scanned to attain an optimum formulation is principally the surfactant (contributing) parameter, so-called SCP in what follows. SCP is actually a generalized term for the surfactant parameter which corresponds to $\sigma / K, \beta / K, C c / K$ or other equivalent in previously proposed relations to attain optimum formulation at HLD $=0$. As will be discussed later, it is not really a characteristic parameter and none of the previously used abbreviations $(\sigma, \beta, C c)$ is appropriate. As a consequence, the SCP term is proposed here for a surfactant parameter with $C$ meaning "contribution" in the present text. Another general term could be proposed in the new future as, for instance, a $\mathrm{SP}_{\mathrm{N}}$ term with $\mathrm{N}$ for "new" or "normalized" surfactant parameter to match with the $H_{L} D_{N}$ generalized expression proposed later to eliminate some confusion.

According to its definition as a concept of lipophilicity/hydrophilicty of a surfactant, SCP (as well as $\sigma, \beta, C_{c}$, etc) increases with its lipophilic tail length [68], and decreases when the head group becomes more hydrophilic, for instance when passing from carboxylate to sulfate, or when increasing the number of ethylene oxide groups (EON) in a nonionic species, with no change in the rest of the molecule.

Consequently, a scan of the SCP (as well as $\sigma, \beta$, Cc etc) variable carried out by changing the surfactant is a practical way to pass through an optimum formulation, either with a surfactant proper modification or with an adequate mixture of two (or more) of them in order to accurately attain the required SCP value producing HLD = 0, as was first proposed in the late 1970's [69]. This optimum formulation is not only useful in pharmaceuticals and cosmetics. It also produces the more efficient solubilization of a plugging drilling fluid [70] in petroleum reservoir perforation, or the more efficient separation of oil drops in waste water treatment, or of water droplets in natural oil dehydration or in petroleum desalting [71,72]. The optimum production of food emulsions like mayonnaise or flavored sauces with stability and rheology issues has also to do with mixing surfactants to adjust formulation.

\section{Multidimensional Scans and Optimum Formulation Events}

When the scanning of one variable is repeated for another system for which another variable is changed, then the effect of a double change is carried out. For instance, in Figure 8 (left plot) a water salinity scan is carried out for typical SOW systems containing surfactant, n-alkane, and some alcohol. The optimum formulation is detected by reaching a minimum interfacial tension (left plot) or a maximum solubilization detected as the minimum surfactant concentration $\mathrm{Cs}^{*}$ to attain the single-phase zone at the fish tail (right plot).

It can readily be seen that a change in water salinity clearly produces an optimum formulation $\mathrm{S}^{*}$ in all the cases in Figure 8 (minimum tension $\gamma$ on the left and minimum Cs on the right), but that the optimum $\mathrm{S}^{*}$ value depends on the oil ACN. Typically, the optimum $\mathrm{S}^{*}$ increases with oil ACN at all other variables constant. 

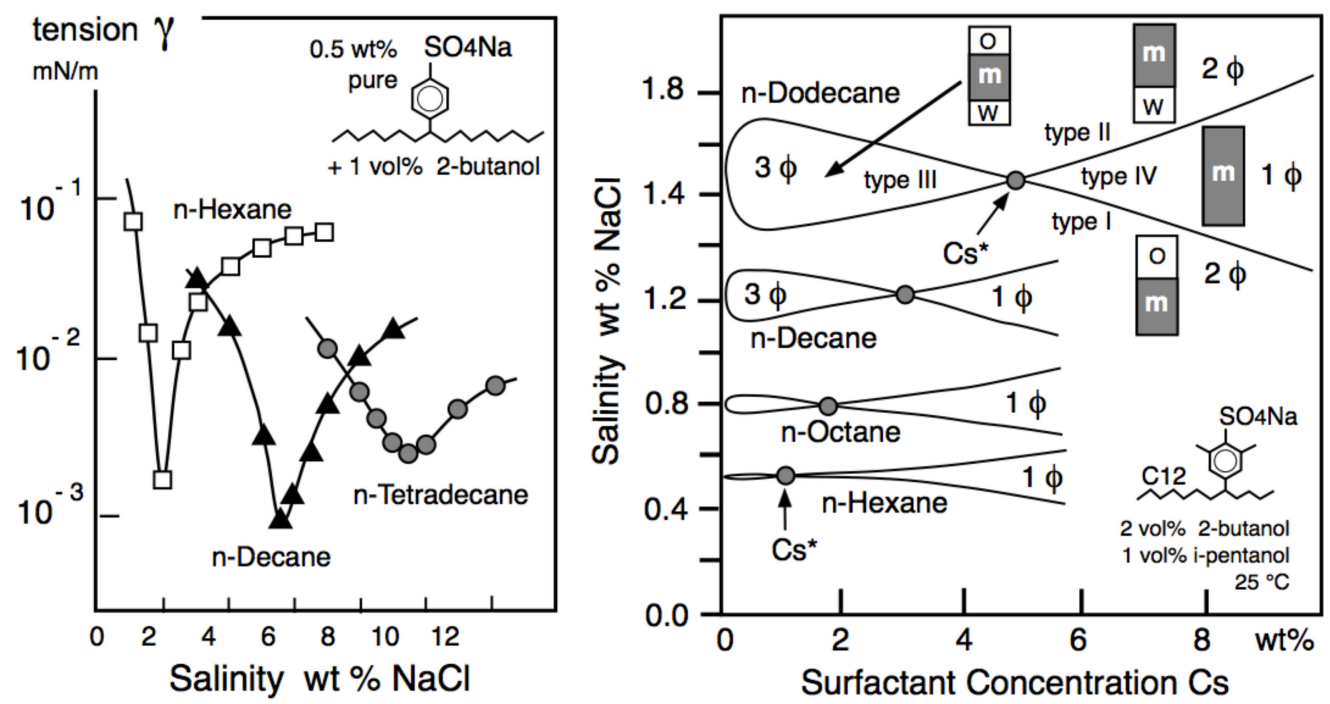

Figure 8. Effects of two formulation variables (water salinity and oil alkane carbon number (ACN)) on interfacial tension with a minimum at optimum (left) and on the best solubilization in a fish diagram as the surfactant concentration $\mathrm{Cs}^{*}$ minimum to attain a single-phase region (right).

Figure 9 displays the variation of the performance (here the solubilization parameters of oil and water $\mathrm{SPo}$ and $\mathrm{SPw}$ ) as a function of the two variables ( $\mathrm{S}$ and $\mathrm{ACN}$ ). The cuts of the surface at different values of ACN (as in Figure 6 middle plot) look like an inverted V, with the maximum solubilization $($ at $\mathrm{SPo}=\mathrm{SPw})$ shown as a thick black line in $3 \mathrm{D}$ indicating the SP solubilization maximum vs $\mathrm{S}$ and ACN.

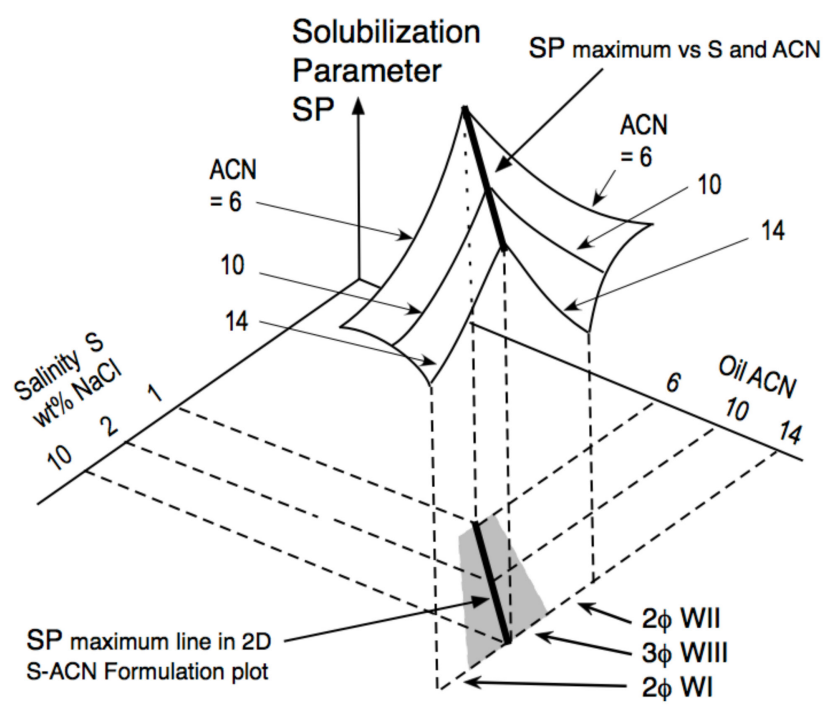

Figure 9. Solubilization as SP parameters (essentially indicating the performance index PERFIND) vs two formulation variables, i.e., water salinity (as $S$ or $\ln S$ ) versus oil ACN.

The projection on the lower S-ACN plane of this 3D black line for solubilization maximum is another black line (called SP maximum line in 2D) which is found in the middle of a grey zone that indicates a three-phase WIII region. The same kind of result is attained if the performance is measured with the interfacial tension, looking for the minimum value to determine the optimum in a scan [60].

Figure 9 shows that the increase in some formulation variable (e.g., $\mathrm{ACN}$ ) produces a transition opposite to the transition generated by the increase of the other variable (e.g., salinity S), thus indicating that they are likely to compensate if they are both increased. In the present case an increase in salinity produces a WI $>$ WIII $>$ WII transition, while an increase in ACN produces the opposite WII $>$ WIII $>$ 
WI transition. As a consequence, appropriate changes of the two at the same time, can maintain the optimum formulation occurrence, at $\mathrm{HLD}=0$.

In practice, the most important result is that this optimum line in a 2D plot (in the S-ACN lower plane) happens to be a straight line, which can be written as Equation (2) for a system containing an anionic surfactant:

$$
\mathrm{LnS}=\mathrm{KACN}+\mathrm{CST}
$$

where CST is a constant depending on values of other (fixed) formulation variables, such as the surfactant head and tail, the eventual presence of alcohol (type and concentration), the temperature, and the pressure. $\mathrm{LnS}$ is the neperian logarithm of the salinity $\mathrm{S}$ in $\mathrm{wt} \% \mathrm{NaCl}$.

Using another ionic surfactant, another temperature, another pressure, and another alcohol content, the same relationship is found with an accordingly different value of the coefficient $\mathrm{K}$ and of the constant CST. In general and for various ionic surfactants, a linear relationship is thus found to exist in general between the salinity variable (expressed as LnS for all ionic surfactants) and the oil ACN, independently of the other variables.

It was found that the $\mathrm{K}$ coefficient could change with the type of surfactant head, as discussed a long time ago [68] and reviewed later in many subsequent articles. It of course also changes if the salinity is expressed in a different scale or in a decimal logarithm, or for a different electrolyte, but the $\mathrm{wt} \% \mathrm{NaCl}$ and neperian logarithm will be kept here so as to avoid confusion with the previous literature.

In other words, a general differential relation of equivalence between the changes of the two formulation variables (here $\mathrm{LnS}$ and $\mathrm{ACN}$ ), as shown in Figure 10, may be written generally as follows for all ionic head surfactant systems.

$$
\mathrm{dLnS}=\mathrm{K} \mathrm{dACN} \text { or } \mathrm{dACN}=\mathrm{K}^{\prime} \mathrm{dLnS} \text { where } \mathrm{K}^{\prime}=1 / \mathrm{K}
$$
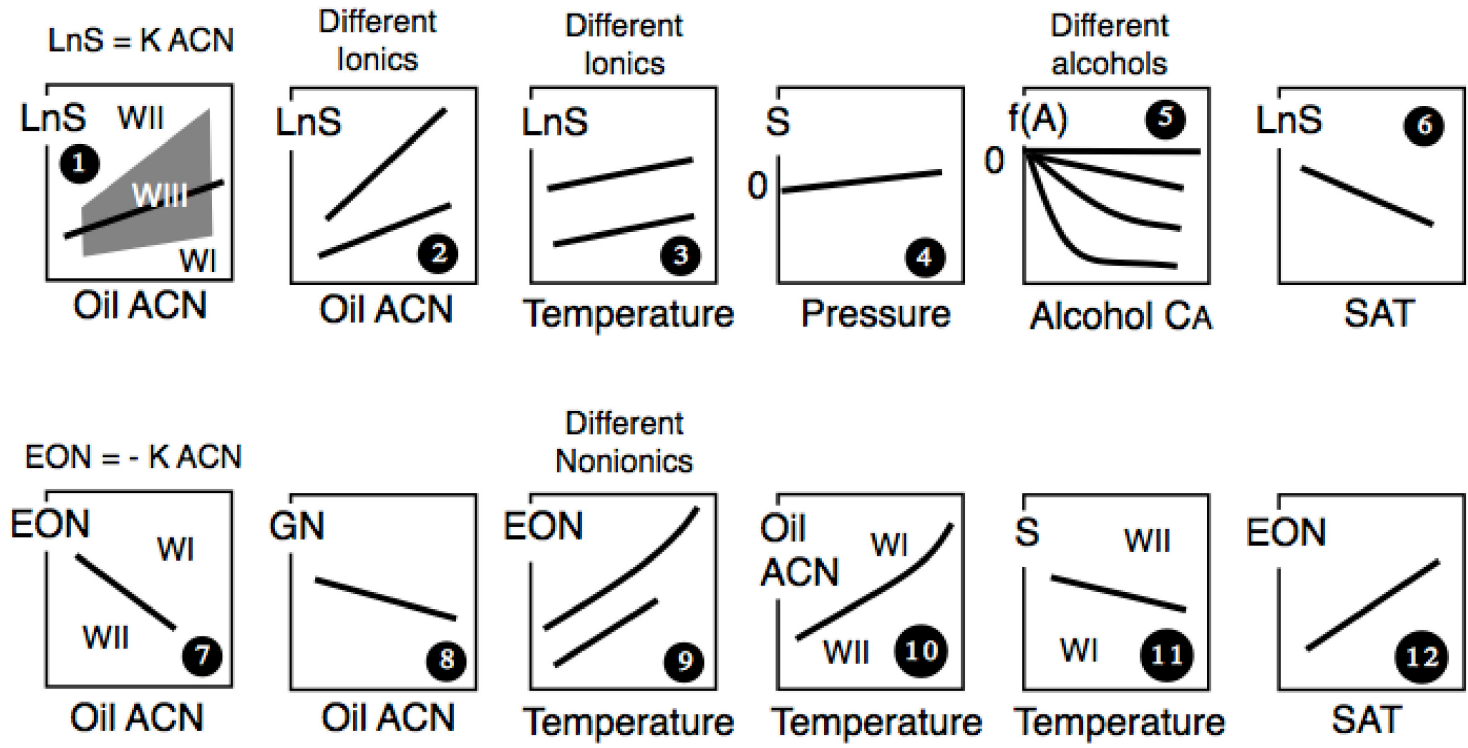

Figure 10. Aspects of a typical (LnS vs ACN) bidimensional scan and other similar cases involving two formulation variables (EON: surfactant ethylene oxide number, GN: surfactant glycerol number, SAT: surfactant alkyl tail carbon number, $\mathrm{C}_{\mathrm{A}}$ : alcohol concentration, $\mathrm{f}(\mathrm{A})=\mathrm{K}_{\mathrm{A}} \mathrm{C}_{\mathrm{A}}$ : alcohol effect).

Many related studies have shown the same basic bidimensional equation, the only difference being that, with nonionic surfactants, it uses a linear salinity term instead of a logarithm (cf. Figure 10).

What is extremely important to make the situation simple is that the same kind of essentially linear relationship (as that illustrated in Figure 10) has been found for all pairs of counterbalancing formulation variables, i.e., brine salinity, oil ACN, surfactant alkyl tail length SAT, ethoxylation 
number EON, or glycerol number GN in nonionics, temperature and pressure. The alcohol effect as a cosurfactant which will be called $\mathrm{f}(\mathrm{A})$ in the complete equation will includes two more variables, e.g., the alcohol's nature and its concentration. Many examples including the values of the different coefficients can be found in the literature [36,73-80], overall with a very general trend, although sometimes with inaccurate data.

It is worth remarking that, with nonionic head surfactants, the salinity effect is much less important than with ionic species, which is why the corresponding variable is expressed as $\mathrm{S}$ instead of LnS. It is also worthwhile mentioning that salinity is an exception, which appears as a logarithm for ionic surfactants. For all the other variables the parameters are the same ones in all the HLD formulation equations. On the other hand, it should be stressed that the $\mathrm{K}$ coefficients have a different value for different surfactants and different pairs of variables, sometimes even with different signs, as, for instance, when the temperature is involved, or when the alcohol is hydrophilic or lipophilic.

After the three original empirical equations for anionic, cationic, and nonionic surfactants, many articles from different research groups and even for many other surfactants $[27,28,51,81,82]$ confirmed this linear variation, thus indicating that the compensation of two formulation variables can be generally written as:

$$
d V_{i}=K_{i j} d V_{j}
$$

where " $\mathrm{i}$ " and " $\mathrm{j}$ " indicate the two compensating variables, and where the $\mathrm{K}$ 's are constant coefficients depending in particular on the type of the surfactant head group.

As discussed hereafter, instead of a unit coefficient before $d V_{i}$ and a $K_{i j}$ before $d V_{j}$, as in Equation (4), the relation can be written in a more general way for any ij pair of two formulation variables $V_{i}$ and $V_{j}$ with two coefficients, i.e., with one coefficient characteristic of each variable as in Equation (5). It is worth noting that Equations (5) and (6) can be multiplied by any coefficient, without any change. In other words, one of the two coefficients can be arbitrarily taken as unity or as any other appropriate value.

$$
K_{i} d V_{i}=K_{j} d V_{j} \text { or } K_{i} d V_{i}-K_{j} d V_{j}=0
$$

This kind of expression has been proposed to represent the equivalence of chemical potential differential dual changes to keep the HLD constant. As corroborated in the literature, the partitioning coefficient of the surfactant between the $\mathrm{W}$ and $\mathrm{O}$ excess phases is found to be unity in simple WIII systems, and thus the standard chemical potentials are equal at optimum formulation [25,30,83,84].

Taking the molecular interaction difference as the surfactant affinity difference (SAD), its dimensionless equivalent HLD (Hydrophilic Lipophilic Difference or Deviation from optimum) may be written as an equation like (4) or (5) [26,27].

When HLD $<0$ (respectively HLD > 0), a Winsor type I (respectively type II) phase behavior is produced, and, at the optimum type III case, HLD $=0$.

By carrying the same argument for all the other pairs of variables, the overall reference chemical potential change in oil and water is as follows for all the variables altering the oil or water phases, where the $\mathrm{K}_{\mathrm{i}}$ are constant coefficients in Equation (6):

$$
\mathrm{dHLD}=\sum \mathrm{K}_{\mathrm{i}} \mathrm{dV} \mathrm{V}_{\mathrm{i}}
$$

By integrating this differential equation that is linear close to an optimum formulation, the following relationship is obtained, where CST is an integration constant.

$$
\mathrm{HLD}=\sum \mathrm{K}_{\mathrm{i}} \mathrm{V}_{\mathrm{i}}+\mathrm{CST}
$$

The constant has the required value to have HLD $=0$ when experimental Vi values at optimum formulation are entered. Since this equation comes from changing variables, a reference state can be arbitrarily taken for each variable consequently written as a variation $\left(\mathrm{V}_{\mathrm{i}}-\mathrm{V}_{\mathrm{i} \text {-ref }}\right)$ with the corresponding 
modification of selection of the CST to make HLD = 0 when the variable values for an experimental optimum formulation are entered.

$$
\mathrm{HLD}=0=\sum \mathrm{K}_{\mathrm{i}}\left(\mathrm{V}_{\mathrm{i}}-\mathrm{V}_{\mathrm{i}-\mathrm{ref}}\right)+\mathrm{CST}
$$

It is clear here that the CST value to be used for HLD $=0$ at optimum formulation, depends on

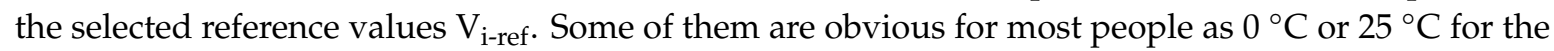
temperature reference, or $\mathrm{S}=0$ (no salt) for nonionic systems. However, $\mathrm{S}=1 \mathrm{wt} \% \mathrm{NaCl}$ or another fixed value is required for ionic systems, since the surfactant is a salt (thus $S=0$ is not possible to reach in practice), and also because there is a logarithmical salinity scale. For the oil, $\mathrm{ACN}_{\text {ref }}=8$ (octane), would result in a reasonable reference, while $\mathrm{ACN}_{\text {ref }}=0$, which is often used because it eliminates a term, is not a very significant selection, since it would mean that the reference alkane would be without any carbon atom, an unreal case. The use of $\mathrm{ACN}=0$ for benzene is not always an accurate assumption.

It is worth remembering that, since the optimum formulation equation is HLD $=0$, it can be multiplied or divided by any number and remain identical. In other words, it means that one of the $\mathrm{K}_{\mathrm{i}}$ coefficients in Equations $(7 \mathrm{a})$ and $(7 \mathrm{~b})$ can be used to divide the equation HLD $=0$, so that the coefficient before a selected variable $\mathrm{V}_{\mathrm{i}}$ would become unity.

The hydrophilic-lipophilic deviation from optimum formulation is formally similar to the empirical equation first proposed in 1979 for alkylbenzene sulfonates and other anionic and cationic surfactants likely to produce very low interfacial tension in EOR [27].

For systems containing ionic surfactants, the correlation was originally written as follows with a unit coefficient in front of the LnS term, essentially because it was the variable that was actually scanned in most experiments [27,32]. For this reason, here it will be called HLD $\mathrm{Lns}_{\mathrm{s}}$

$$
\mathrm{HLD}_{\mathrm{LnS}}=\mathrm{LnS}-\mathrm{K}_{\mathrm{ACN}} \mathrm{ACN}+\sigma=0
$$

$\mathrm{K}$ is the coefficient of $\mathrm{ACN}$, i.e., $(\partial \ln S / \partial \mathrm{ACN})$ in the original correlations (8a). $\mathrm{K}$ was found to be 0.16 for alkylbenzene sulfonates, 0.10 for alkyl carboxylates and sulfates, 0.17 for alkyl ammonium, and 0.19 for alkyl trimethyl ammonium and alkyl pyridinium. For extended surfactants containing a polypropylene oxide intermediate group between the ionic head and the alkyl tail, $\mathrm{K}$ was found to depend on the number of intermediate alkoxylated groups, the ionic group and the tail branching (from 0.05 to 0.14 ) but with no general rule found yet $[76,78,79,82,85,86]$.

The alcohol contribution was originally indicated as an extra term called $-\mathrm{f}(\mathrm{A})$ added in Equation (8b) because it is positive only for very short alcohols like ethanol or propanols and very small. For longer alcohols normally used, it is negative and linear, i.e., $-f(A)=-K_{A} C_{A}$, with $C_{A}$ being the concentration in vol $\%$ and $\mathrm{K}_{\mathrm{A}}$ a negative coefficient whose absolute value increases with the alcohol lipophilicity. As a consequence, for butanol, pentanol, hexanol, etc., the alcohol term is positive. Then both surfactant and cosurfactant term, i.e., $\sigma$ and $-f(A)$, are positive and increase when they are more lipophilic. The $\mathrm{f}(\mathrm{A})$ variation is practically linear with concentration up to a variation of about one unit of LnS, i.e., up to $0.5 \%$ of pentanol and $0.3 \%$ of hexanol. Above it, part of the alcohol leaves the interface and goes to the oil phase and segregates close to interface, hence producing a decrease in $\mathrm{K}_{\mathrm{A}}$. The sec-butanol has practically no effect $\left(\mathrm{K}_{\mathrm{A}} \sim 0\right)$ and the $\mathrm{n}$-butanol has a small negative effect $\left(\mathrm{K}_{\mathrm{A}}=-0.3\right.$ to -0.5$)$ that varies with the surfactant and oil phase.

The following more complete correlation $(8 \mathrm{~b})$ includes the effect of temperature and pressure [87-90]. The temperature effect is small for ionic surfactant, e.g., $\mathrm{K}_{\mathrm{T}} \sim 0.010 \pm 0.005{ }^{\circ} \mathrm{C}^{-1}$ for anionics and about the double for cationics. The pressure effect reported only some time ago [90] has in most cases a very small $K_{p}$ coefficient value in HLD; it is thus generally negligible at ambient conditions.

$$
\mathrm{HLD}_{\mathrm{LnS}}=\mathrm{Ln}\left(\mathrm{S} / \mathrm{S}_{\mathrm{ref}}\right)-\mathrm{K}_{\mathrm{ACN}}\left(\mathrm{ACN}-\mathrm{ACN}_{\mathrm{ref}}\right)+\sigma-\mathrm{K}_{\mathrm{A}} \mathrm{C}_{\mathrm{A}}-\mathrm{K}_{\mathrm{T}}\left(\mathrm{T}-\mathrm{T}_{\mathrm{ref}}\right)-\mathrm{K}_{\mathrm{p}}\left(\mathrm{P}-\mathrm{Pr} \mathrm{rf}_{\mathrm{ef}}\right)=0
$$


It is worth noting that in the very original Equation (8a) in the absence of alcohol, and at reference temperature and pressure, there are only the terms corresponding to the effect of the water salinity (LnS), and of the oil nature (ACN). Thus, the remaining third term must correspond to the surfactant effect. It is important to bear in mind that the selected symbol $\sigma$ for the surfactant effect was not selected as S nor SP to avoid confusion with salinity or solubility parameter.

The term $\sigma$ was arbitrarily defined as the surfactant parameter with a unit coefficient in Equation (8a), thus with a scale corresponding to the scanned variable LnS (where $\mathrm{S}$ is in wt\% $\mathrm{NaCl}$ and $\mathrm{S}_{\text {ref }}=1$ ). Obviously, a $\log _{10} \mathrm{~S}$ term or $\mathrm{LnS}$ with salinity expressed in $\mathrm{mol} / \mathrm{L}$ of $\mathrm{NaCl}$ would give an appropriate similar relationship but with a different numerical value for $\sigma$. Additionally, it is now clear that $\sigma$ also included the integration constant CST and the references for the other variables in Equation (8b), not only $\mathrm{T}_{\text {ref }}$ and $\mathrm{P}_{\text {ref }}$, but also $\mathrm{S}_{\text {ref }}$ (usually 1 ), $\mathrm{ACN}_{\text {ref }}$ and $\mathrm{C}_{\text {Aref }}$ (normally 0 ) and eventually $\sigma_{\text {ref }}$ (which is not really known and is arbitrarily taken as 0 to avoid a semantic confusion).

There is, therefore, no doubt that the $\sigma$ term depends on the surfactant, since nothing else depends on it in the Equation (8a). Nevertheless, it is not a characteristic of the surfactant, because it also includes other effects, and additionally it cannot be measured independently of the other terms, such as the water salinity $\mathrm{S}$, the oil $\mathrm{ACN}$, the temperature and pressure, as well as alcohol content $\mathrm{C}_{\mathrm{A}}$. Such a selection of the surfactant parameter $\sigma$ is clearly confusing. This is why it has to be rectified.

Let's remember that the $\mathrm{K}_{\mathrm{ACN}}$ coefficient in Equation (8a), as well as the other $\mathrm{K}^{\prime} \mathrm{s}$ in Equation (8b), was found to depend on the nature of the surfactant head group.

For usual nonionic surfactants, like the ethoxylated alcohols or alkylphenols, a similar relationship was found. This time, there is a very weak effect of salinity expressed by a simple linear effect bS, where $b$ is in the 0.12-0.16 range depending on the tail branching, if $\mathrm{S}$ is expressed in $\mathrm{wt} \% \mathrm{NaCl}$. The salinity was thus no longer used as the scanned variable to change formulation. It was the average ethoxylation (so-called ethylene oxide number, EON), that was used for scanning the surfactant hydrophilicity. EON is a part of the surfactant parameter called $\beta=\alpha-$ EON in Equation (8c) [28] or $\beta$ $=\alpha-\mathrm{GN}$ in Equation (8d) for nonionic polyglycerol alcohols, where GN is the number of glycerol units [91].

$$
\begin{gathered}
H L D_{E O N}=K_{S} S-K_{A C N} A C N-K_{A} C_{A}+K_{T}\left(T-T_{\text {ref }}\right)-K_{p}\left(P-P_{\text {ref }}\right)+\alpha-E O N=0 \\
H_{L D} D_{G N}=K_{S} S-K_{A C N} A C N-K_{A} C_{A}+K_{T}\left(T-T_{\text {ref }}\right)-K_{p}\left(P-P_{\text {ref }}\right)+\alpha-G N=0
\end{gathered}
$$

$\mathrm{K}_{\mathrm{ACN}}$ is still the coefficient of ACN but with a different meaning in Equations (8c) and (8d), i.e., $\partial \mathrm{EON} / \partial \mathrm{ACN}$ (respectively $\partial \mathrm{GN} / \partial \mathrm{ACN}$ ) and a specific value of about $0.14-0.16$ (respectively 0.10 ) for ethoxylated alcohols and alkylphenols (polyglycerol alcohols respectively).

The temperature effect in nonionic surfactant systems was found to be more significant and with a different sign than with ionics. For ethoxylated alcohols or phenols, the average slope $(\partial \mathrm{EON} / \partial \mathrm{T})$ is found to be about -0.06 , but with some variation as seen in Figure 11 from -0.04 (at low EON $\sim 4$ and $\mathrm{T} \sim 20^{\circ} \mathrm{C}$ ) to -0.08 (at EON $\sim 8$ and $\mathrm{T} \sim 90^{\circ} \mathrm{C}$ ). The slope absolute value tends to decrease about $25 \%$ when the oil ACN increases from hexane to hexadecane [28].

It is worth noting that $\mathrm{K}_{\mathrm{ACN}}$ has a completely different meaning in Equations (9a), (9b) and (9c) including a different sign for ionics and nonionics. It is therefore erroneous to say that it is the same, even if the absolute value more or less coincides for alkyl sulfonates $(+0.16)$ and ethoxylated alcohols (about -0.15$)$ as well as with carboxylates $(+0.10)$ and polyglycerols nonionics $(-0.10)$.

$$
\begin{aligned}
\partial \operatorname{lnS} / \partial \mathrm{ACN} & =\mathrm{K}_{\mathrm{ACN}-\mathrm{LnS}} \\
\partial \mathrm{EON} / \partial \mathrm{ACN} & =\mathrm{K}_{\mathrm{ACN}-\mathrm{EON}} \\
\partial \mathrm{GN} / \partial \mathrm{ACN} & =\mathrm{K}_{\mathrm{ACN}-\mathrm{GN}}
\end{aligned}
$$


With anionic extended surfactants the optimum $S^{*}$ was found to decrease when the number of propylene oxide groups ( $\mathrm{PON}$ ) increases [92-94]. This means that the intermediate PON extension is part of the hydrophobic group. It could be introduced in the HLD Equation ( $8 b)$ as a term like $\mathrm{k}_{\mathrm{PO}} \mathrm{PON}$ with a coefficient of 0.15 . This means that the hydrophobicity added by a PO group in the tail is equivalent to adding half a $-\mathrm{CH}_{2}$ - methylene group. In other words, the polypropylene intermediate group, that contains three carbon atoms, brings a hydrophobicity equivalent to only adding half a carbon in an alkyl group in the tail. This is why the size of an extended surfactant with the same parameter is considerably larger, with no problem of precipitation. It is also the reason why the extended surfactants provide a good solubilization, particularly with polar oils (like natural triglycerides), and why they are good candidates for cosmetics and pharmaceuticals [76,85,92,95-107].

In this $\mathrm{HLD}_{\mathrm{EON}}=0(8 \mathrm{c})$ expression, $\beta$ is the term that includes the nonionic surfactant contribution $(\beta=\alpha-\mathrm{EON})$ as well as the integration constant and the references. It was first introduced as a combination of two variables describing the surfactant structure. The EON is the (average) number of ethylene oxide groups in the surfactant head, that is the usually scanned in nonionic systems, so a $K=-1$ coefficient was taken for EON and thus $K=1$ coefficient for $\beta$ in Equation (8c). The term $\alpha$ indicates the contribution of the tail that is typically described as a linear alkyl group, increasing by about 0.33 units when a carbon atom is added in the tail. However, it also includes the integration constant [68].

Studies carried out with ethoxylated nonionic surfactants by Shinoda and Kunieda [104] used the temperature, as the scanned variable with the corresponding optimum detected by the PIT (phase inversion temperature) which happens at optimum (WIII behavior, minimum tension, maximum solubilization).

This was identical to equation HLD $=0$ using a unit coefficient for the temperature term. However, the temperature is a variable that has an effect on many different interactions, often with an unsure coefficient, very low for ionic surfactant systems, and much greater for ethoxylated nonionics, sometimes with a nonlinear variation for high average EON species of different grades of ethoxylation, as can be seen in Figure 11. It does not seem either to be a proper scan variable for complex systems including ionic-nonionic mixtures which also exhibit a significant variation from linearity. Nevertheless, this nonlinearity is probably due to a fractionation of the mixture species. It must be recalled that a good EON-T and EON-ACN linearity has been found when using very pure ethoxylated surfactants [105]. However, such substances are generally too expensive to be used in commercial products.

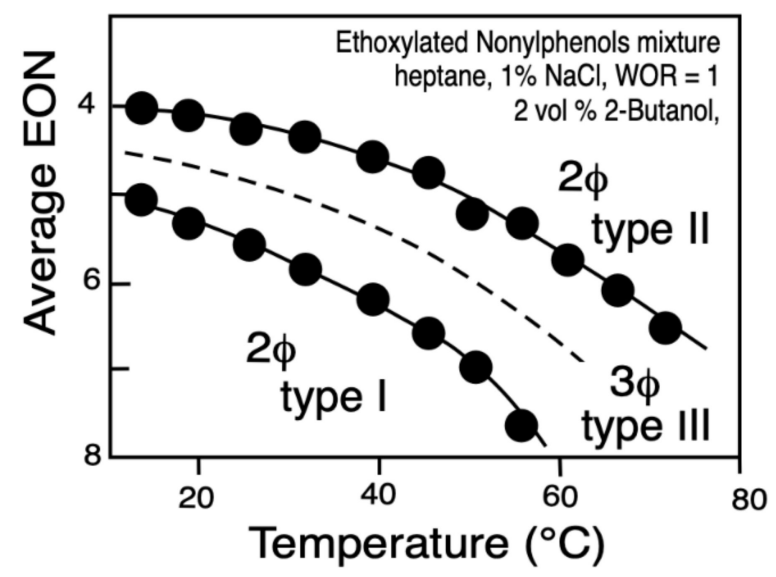

Figure 11. Variation of optimum formulation in the EON-T subspace with commercial mixtures of ethoxylated nonylphenols with $\mathrm{EON}=4$ and $\mathrm{EON}=9$ with a wide distribution.

The very first scans $[69,106]$ used the n-alkane length as the scanning variable, calling it the Nmin. Had it been developed at that time, the ACN term would thus have been the one with a unit coefficient in a multidimensional relation, but such has not been the case for different practical reasons, 
particularly the high cost of long n-alkanes, and the short change in formulation produced in the liquid n-alkane range from 5 to 16.

It is worth remarking that there is now a powerful reason to take a unit coefficient in front of the ACN variable in the HLD equation, even if ACN is not the variable that is actually scanned. It is because ACN happens to be the variable that has exactly the same meaning in all the correlations (8) for ionic and nonionic surfactants systems. Moreover, Figure 2 clearly indicates that the ACN effect only concerns the interactions with the surfactant tail, which is essentially an alkyl standard for most common amphiphiles. Actually, the salinity effect depends on the head group hydration; it thus varies with its structure, a fact which is indicated with different values of the $\mathrm{K}_{\mathrm{LnS}}$ or $\mathrm{K}_{\mathrm{S}}$ coefficient. Furthermore, it is not justified to put a unit coefficient in HLD equation in front of LnS or EON, which are completely different variables, as indicated in Equations $(9 a),(9 b)$ and $(9 c)$. It is the same for the cases of scanning the intermediate propoxylation number, $\mathrm{PON}$, for extended surfactants or for the glycerol number, GN, in alkyl acid ester surfactant. As for the negative $(-1)$ coefficient in front of ACN (instead of +1 ) in equations $8 a-b-c-d$, it is arbitrary. What is justified is to have the same coefficient in front of ACN in all the cases of HLD equations, thus providing the same scale for all the effects.

As a consequence, using a "normalized" $\mathrm{HLD}_{\mathrm{N}}$ with a $(-1)$ coefficient in front of ACN (i.e., equivalent to $\mathrm{HLD}_{\mathrm{ACN}}$ in the previous notation) would make it possible to handle a combination of two or more equations when the surfactants are mixed, particularly when they are ionic and nonionic species.

In order to generalize the HLD equation so as to use it as a single expression, Equations ( $8 b$ ) and (8c) — as well as any similar equation with extended or polyglycerol surfactants-are divided by the coefficient of the variable which has the same meaning, i.e., $\mathrm{K}_{\mathrm{ACN}}$, thus becoming the "normalized" $\mathrm{HLD}_{\mathrm{N}}$, in which the surfactant contributing parameter SCP is also taken with a $(+1)$ coefficient by definition.

It should be remembered that, years ago, the surfactant parameter was proposed to be $\sigma / K_{A C N}$ or $\beta / K_{A C N}$ for appropriate reasons [69], although these were not specifically justified. At that time, it was not stated either that this parameter was not really a critical value for the surfactant effect because it also included the integration constant and the references. To avoid any confusion, the old HLD relations should be divided by the corresponding experimental coefficient $\mathrm{K}_{\mathrm{ACN}}$ as in formula (10) to produce the generalized $H L D_{N}$ relationship (11) valid in all the cases, where the coefficients indicated as lowercase k's have to be introduced according to the experimental data, and to the proper selected references.

$$
\mathrm{HLD}_{\mathrm{N}}=\mathrm{SCP}-\left(\mathrm{ACN}-\mathrm{ACN}_{\mathrm{ref}}\right)+\left[\mathrm{LnS}(\text { or b S })-\mathrm{K}_{\mathrm{A}} \mathrm{C}_{\mathrm{A}} \pm \mathrm{K}_{\mathrm{T}}\left(\mathrm{T}-\mathrm{T}_{\text {ref }}\right)-\mathrm{K}_{\mathrm{p}}\left(\mathrm{P}-\mathrm{P}_{\text {ref }}\right)\right] / \mathrm{K}_{\mathrm{ACN}}=0
$$

The new notation is with a $(+1)$ coefficient in front of the surfactant contribution SCP, a $(-1)$ coefficient in front of $\mathrm{ACN}$, and the new positive coefficients $\mathrm{k}$ 's as the anterior positive K's divided by $\mathrm{K}_{\mathrm{ACN}}$

$$
H L D_{N}=S C P-\left(A C N-A C N_{r e f}\right)+k_{L n S} L n S\left(\text { or } k_{S} S\right)-k_{A} C_{A} \pm k_{T}\left(T-T_{\text {ref }}\right)-k_{p}\left(P-P_{\text {ref }}\right)=0
$$

In the references that are usually selected, the temperature and pressure are ambient values, i.e., $\mathrm{T}_{\text {ref }}=25^{\circ} \mathrm{C}$ and $\mathrm{P}_{\text {ref }}=1$ bar, while the salinity references are $\mathrm{S}=0$ for nonionics, or $\mathrm{S}=1$ for ionic amphiphiles (as well as $\mathrm{S}=1$ for a mixture of ionic and nonionic surfactants), and in most cases without alcohol $\left(C_{A}=0\right)$. In the current Equation (11), the oil reference could be taken as $\mathrm{ACN}_{\text {ref }}=0$, so that, with the previously selected references, the $H L D_{N}=0$ equation can be simply be written as the very simple expression $\mathrm{SCP}=(\mathrm{P}) \mathrm{ACN}$.

The SCP surfactant contribution term has the value in an ACN scan that results in an optimum formulation with the selected references; it is called the preferred alkane carbon number (PACN) in a real or virtual extrapolated ACN scan. Years ago, this optimum ACN was called the EPACNUS 
(as Extrapolated PACN at Unit Salinity and no alcohol) for anionic surfactants, which is a precise, but somewhat anachronistic, definition that is no longer used in the literature [26,74].

We will simply call it PACN, but on the understanding that it includes a set of reference values and an integration constant and that it is thus not a true characteristic of the surfactant. From an exhaustive study with super pure alcohol ethoxylates, and pure n-alkane, in the absence of salt and alcohol, and at atmospheric pressure, EON scans yielded [77,107] the following HLD and HLD N $_{\mathrm{N}}$ equations

$$
\begin{gathered}
\mathrm{HLD}=2.00+0.34 \mathrm{SAT}-\mathrm{EON}-0.15 \mathrm{ACN}+0.05(\mathrm{~T}-25)=0 \\
\mathrm{HLD}_{\mathrm{N}}=13.3+2.25 \mathrm{SAT}-6.67 \mathrm{EON}-\mathrm{ACN}+0.33(\mathrm{~T}-25)=0
\end{gathered}
$$

where the variable with a $(-1)$ coefficient is taken before the EON in Equation (12a) and before the ACN in (12b), and where SAT represents the number of carbons atoms in the surfactant n-alkyl tail, a parameter sometimes called SACN for surfactant alkyl carbon number in the tail. According to the previous equation, the surfactant parameter PACN, including the proper integration constant, could be taken as follows for this kind of system containing ethoxylated n-alcohol, pure n-alkane and pure water, with temperature as the scanned variable [107].

$$
\mathrm{PACN}=\beta / 0.15=13.3+2.25 \mathrm{SAT}-6.67 \mathrm{EON}
$$

The relationship (12b), which includes experimental coefficients, indicates interesting comparisons related to Figure 2 scheme for alcohol ethoxylates with n-alkane oils and pure water. An increase in hydrophilicity (6.67) produced by one more EO group in the head of the surfactant is compensated by adding three methylene $\left(-\mathrm{CH}_{2}-\right)$ groups in its tail $(2.25 \times 3=6.75)$ or by removing 6.6 methylene groups (6.6) in the n-alkane.

In this case, and if SCP only contains two values dealing with the surfactant molecule, i.e., SAT and EON, then the constant is 13.3 in Equation (13). However, if the reference temperature is not $25^{\circ} \mathrm{C}$ but $0{ }^{\circ} \mathrm{C}$, then the CST has to be 12.5. If the reference system were containing some salt or some alcohol, then the CST would be different too. This means that if the constant is introduced in the surfactant parameter, it is obvious that the meaning of this parameter does not only depend on the surfactant specificities, but also on the references for the formulation variables. Since 2000, several studies have shown that the surfactant parameter also changes when the tail structure is altered, e.g., with a benzene or cyclohexane group, or by the introduction of double bounds or branching, as will be discussed later. With this early definition of SCP as PACN with an included CST, it was thus unsuitable and at least confusing to state that the surfactant parameter had to do with the curvature, as found in its naming as Cc (characteristic curvature) in some articles, after the original proposal by Acosta et al. [108], with no more explanation than a better feeling.

Another reason why the Cc name is misleading is also because the curvature has to do with an oil/water interface, even in absence of surfactant; it is thus not a characteristic feature of a surfactant.

Such an anachronism on the introduction of the curvature concept was mentioned in a review book [109], which nonetheless still used the Cc abbreviation, but changed its meaning to surfactant CharacteristiC. This term is also wrong to use the word characteristic because it does not only depend on the surfactant, but also on the selected references for the other variables, and on the CST. Consequently, it is not a characteristic, as salinity is for brine, ACN for an n-alkane oil, and the temperature and pressure for the system conditions. Actually, the HLB defined by Griffin as one-fifth of the weight percentage of its head part could be a more logical surfactant characteristic, because it only depends on the surfactant. However, it is known to be inaccurate because it does not take into account the nature of the hydrophilic part, a fact that is critical for the surfactant behavior. Additionally, the use of curvature to characterize a surfactant could result in conceptual mistakes, when it is textually said that Cc $<0$ or $>0$ means that the surfactant is hydrophilic or lipophilic $[82,99,110]$. 
If it is exact that the lower the SCP, the more hydrophilic the surfactant, a surfactant with a positive $\mathrm{SCP}$ can be hydrophilic if the other variable values result in $\mathrm{HLD}_{\mathrm{N}}<0$ or vice versa.

It is worth remembering that the curvature of the interface has to do with the quality of the system in some applications like attaining a lower tension, increasing the solubilization, or decreasing the emulsion stability, particularly close to optimum formulation.

This is easy to understand since HLD $=\mathrm{Aco}-\mathrm{Acw}=0$ may be produced by having $2-2=$ 0 or $5-5=0$. In the second case, both surfactant interactions indicated in Figure 2 are larger and the micelles are more swollen, either when they are separated in types I and II or aggregated in the bicontinuous structure type III. "More swollen" means a larger size of micelles and a smaller interfacial curvature. It thus requires less surfactant, i.e., it corresponds to a smaller $\mathrm{Cs}^{*}$ and, as a consequence, to a higher PERFIND performance index [60]. Hence, the curvature has to do not with the formulation but with the performance at or close to optimum, as clearly indicated by the net and average curvatures (NAC) model [111].

It could be attractive to separate the CST from the terms strictly depending on the surfactant in SCP. However, this would require the introduction of a reference for the surfactant. Even if Equation (13) for a nonionic surfactant clearly indicates how SCP varies with its head (EON) and tail (SAT), it is also known that other characteristics of the surfactant molecule have an effect, such as the branching in the tail(s), and the presence of double bounds, cycles and other features, such as multiple heads $[82,86,100]$.

These issues are not easy to handle, particularly in complex cases when, for example, the asphaltenes are considered as lipophilic surfactants in the dehydration process [36,112]. It means that the CST does not only depend on references. In a recent article [60], Figures 7 and 8's equivalence with three independent variables exhibits a plane for the Equation (11). Adding the known salinity (S) effect on the ethoxylated nonionics (coefficient $\mathrm{K}_{\mathrm{S}}$ is $0.13 \pm 0.03$ for $\mathrm{wt} \% \mathrm{NaCl}$, but it is 0.10 for $\mathrm{CaCl}_{2}$ and 0.09 for $\mathrm{KCl}$ ), the Equation (11) becomes, with $\mathrm{K}_{\mathrm{S}}=0.13$ :

$$
\mathrm{HLD}_{\mathrm{EON}}=\beta+0.13 \mathrm{~S}-0.15 \mathrm{ACN}+0.05(\mathrm{~T}-25)=0
$$

An equivalence to the previous equation is to take a unit coefficient in front of $\mathrm{ACN}$ by dividing it by $\mathrm{K} \sim 0.15$ for nonionics with a $(-1)$ coefficient before EON or a $(+1)$ before $\beta(=\alpha-\mathrm{EON})$, so that an $\mathrm{HLD}_{\mathrm{N}}$ normalized according to $\mathrm{ACN}$ is:

$$
\mathrm{HLD}_{\mathrm{N}}=\mathrm{HLD}_{\mathrm{ACN}}=6.67 \beta+0.87 \mathrm{~S}-\mathrm{ACN}+0.33(\mathrm{~T}-25)=0
$$

The surfactant term (including the CST which depends on the reference), i.e., PACN, is thus equal to $6.7 \beta$, according to the previous expression of $\mathrm{HLB}_{\mathrm{N}}=0$, which could be written as

$$
\mathrm{HLD}_{\mathrm{N}}=\mathrm{PACN}-\mathrm{ACN}+0.87 \mathrm{~S}+0.33(\mathrm{~T}-25)=0
$$

In such a case illustrated in Figure 12 , the $\mathrm{HLD}_{\mathrm{N}}=0$ plane in the three variables space $(\mathrm{V} 1=\mathrm{ACN}$, $\mathrm{V} 2=\mathrm{S}$ and $\mathrm{V} 3=\mathrm{T}-25$ ) intercepts the $\mathrm{ACN}$ axis, i.e., $\mathrm{S}=0$ and $\mathrm{T}-25=0$, at a $\mathrm{V} 1^{*}=$ value which is the surfactant preferred $\mathrm{ACN}$ with the three selected references, i.e., its PACN. If this value cannot correspond to a real alkane, it is thus an extrapolated value called EACN or a virtual equivalent that could be called EPACN too, a slightly simpler name than the historical EPACNUS.

The logic when two kinds of surfactants are used is to have the same scale for the HLD of all kinds of equations, which means that there should be a unit coefficient in front of the only variable which is exactly the same in both cases, i.e., the oil ACN (or EACN).

For any surfactants the correlation with zero constant and unit coefficient in front of ACN may be written as follows by dividing Equations (8a) and (8b) by the corresponding $\mathrm{K}_{\mathrm{ACN}}$. 


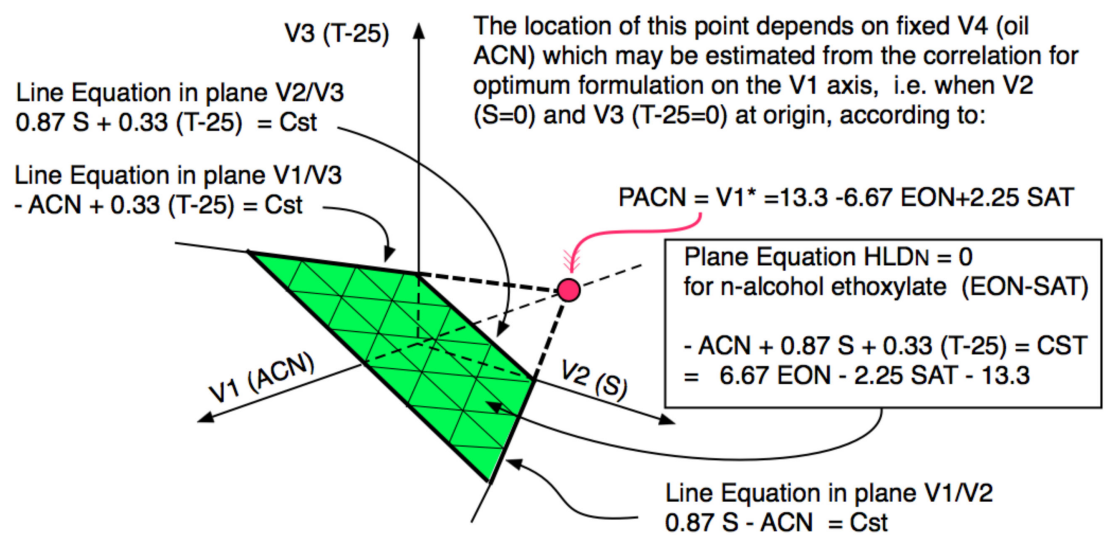

Figure 12. Tridimensional (ACN, T, S) formulation scan with the optimum formulation plane (HLD $=0$ ) is intercepting the $\mathrm{ACN}$ axis at the value of the fourth variable (the preferred alkane carbon number-PACN).

In the ionic surfactant case, the standard reference salinity is taken as unity, i.e., $\mathrm{S}=1 \mathrm{wt} \% \mathrm{NaCl}$, so that $\mathrm{LnS}_{\text {ref }}=0$. The characteristic parameter is then deduced from a reference in which there is no alcohol and at $1 \% \mathrm{NaCl}$ salinity.

$$
\mathrm{HLD}_{\mathrm{N}}=\mathrm{SCP}-\left(\mathrm{ACN}-\mathrm{ACN}_{\mathrm{ref}}\right)+\mathrm{k}_{\mathrm{LnS}} \operatorname{Ln}(\mathrm{S} / 1)-\mathrm{k}_{\mathrm{A}}\left(\mathrm{C}_{\mathrm{A}}-0\right)-\mathrm{k}_{\mathrm{T}}\left(\mathrm{T}-\mathrm{T}_{\mathrm{ref}}\right)-\mathrm{k}_{\mathrm{P}}\left(\mathrm{P}-\mathrm{P}_{\mathrm{ref}}\right)=0
$$

A similar relationship was found for polyethoxylated non-ionic surfactants. There is a very small effect of salinity expressed by a simple linear effect $b S$, where $b$ is a 0.13 coefficient if $S$ is expressed in $w t \% ~ N a C l$ with an ethoxylated species, i.e., when $\mathrm{K}_{\mathrm{ACN}}=0.15$. The HLD $\mathrm{D}_{\mathrm{N}}$ expression is thus essentially the same with a positive sign for the temperature effect and a different salinity reference, which is $S=0$. This is due to the fact that the logical reference with nonionics is no salt since it eliminates a variable, as is the case in many studies [111].

$$
\mathrm{HLD}_{\mathrm{N}}=\mathrm{SCP}-\left(\mathrm{ACN}-\mathrm{ACN}_{\mathrm{ref}}\right)+\mathrm{k}_{\mathrm{S}}(\mathrm{S}-0)-\mathrm{k}_{\mathrm{A}}\left(\mathrm{C}_{\mathrm{A}}-0\right)+\mathrm{k}_{\mathrm{T}}\left(\mathrm{T}-\mathrm{T}_{\mathrm{ref}}\right)-\mathrm{k}_{\mathrm{p}}\left(\mathrm{P}-\mathrm{P}_{\mathrm{ref}}\right)=0
$$

But this different reference produces a small error for comparison with an ionic surfactant case. A same reference of $\mathrm{S}=1 \mathrm{wt} \% \mathrm{NaCl}$ for the nonionic surfactants could thus be recommended. Compared with the usual $S=0$ reference, this results in producing an error of 0.13 on the $\beta$ value or 0.87 on the normalized term $(\beta / \mathrm{K})$, i.e., less than a unity in the $\mathrm{ACN}$ scale, which may be estimated as a negligible inaccuracy.

Studies with different kinds of surfactants have shown the effect of the surfactant tail length, mostly with n-alkyl tails without branching. The surfactant term PACN $(\sigma / K, \beta / K$ or $C c / K)$ indicated later in Figure 13, for pure and commercial products, have been found to vary exactly the same way with the surfactant n-alkyl tail size [68].

It should be remembered that a very general relationship between the surfactant characteristic parameter and the length of its linear alkyl tail was found to be as follows for all the surfactants $[26,30,68]$ :

$$
\mathrm{SCP}=\mathrm{PACN}=\mathrm{PACN}_{0}+2.25 \mathrm{SAT}
$$

where SAT is the surfactant n-alkyl tail carbon number (i.e., the number of carbon atoms in the tail).

This means that for an alkylbenzene sulfonate or an alcohol/alkylphenol-ethoxylate (for which $\mathrm{K}_{\mathrm{ACN}} \sim 0.15-0.16$ ), approximately 0.5 additional carbon atoms in the tail (equal to a molecular weight increase of approximately six units) rises PACN by \pm 1 unit as noted in Equation (16).

The previous equations of $H L D_{N}$ for all surfactants allow to make the following comparisons that give an idea on what is more or less significant in changing the system formulation. 
If the PACN (as the surfactant contributing parameter SCP) is increased by one unit, it means that it is more lipophilic and that the $\mathrm{HLD}_{\mathrm{N}}$ will approximately increase one unit, at everything else constant.

The definition of $\mathrm{HLD}_{\mathrm{N}}$ indicates that this increase in PACN by one unit can be compensated to keep the optimum with an alcohol ethoxylate system by an increase of one unit in the oil ACN, a decrease of $\sim 0.5$ carbon atom in the n-alkyl tail of the surfactant (SAT), a reduction of salinity by $1.2 \mathrm{wt} \% \mathrm{NaCl}$ or a reduction of temperature by $3{ }^{\circ} \mathrm{C}$.

For an anionic surfactant, an increase of PACN of one unit would also correspond to an increase of $\sim 0.5$ carbons in the alkyl tail, and would be compensated by a decrease in LnS of 0.16 for a sulfonate or of 0.10 for a sulfate or carboxylate (or $S$ respectively divided by 2.7 or 1.1 ), and by an increase in temperature of about $10-15^{\circ} \mathrm{C}$.

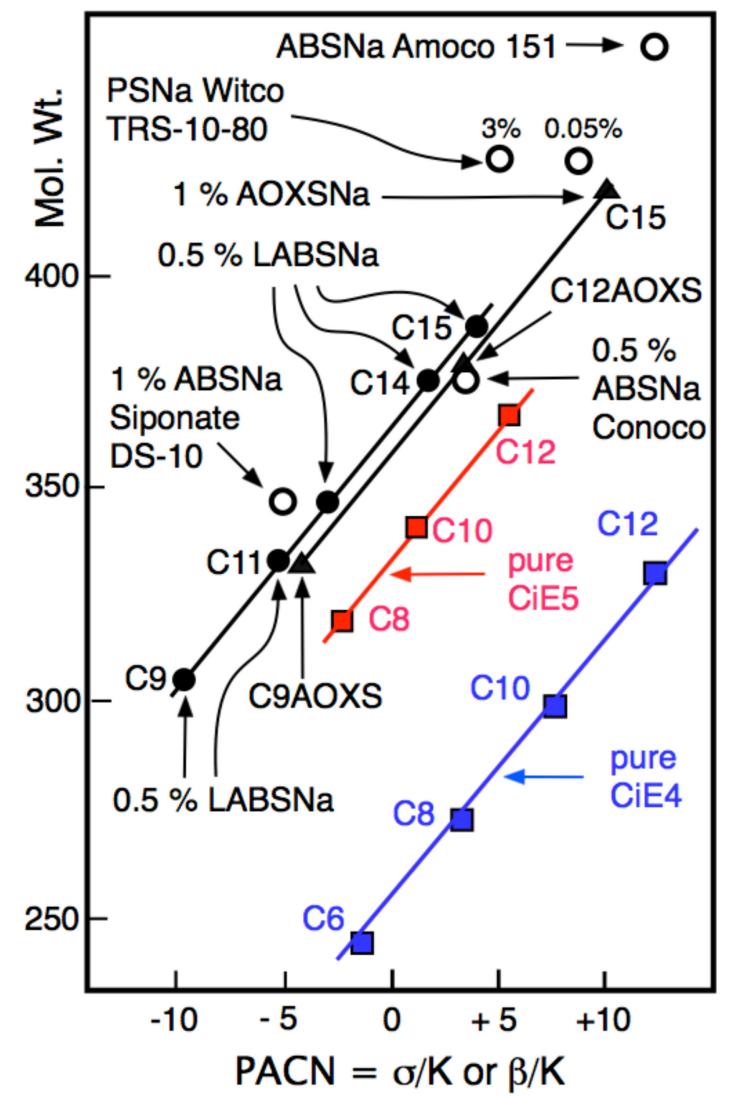

Figure 13. Surfactant characteristic parameters (SCP) as PACN versus molecular weight.

Alcohol contribution in HLD originally mentioned as $f(A)=K_{A} C_{A}$ with $C_{A}$ concentration in $w t \%$, is positive but very small $\left(\mathrm{K}_{\mathrm{A}} \sim+0.5\right)$ for ethanol and propanol, and it is almost zero for sec-butanol which is often used up to $3 \mathrm{wt} \%$ so as to avoid precipitation with anionic surfactants of high molecular weight as petroleum sulfonates. However, there is a significant negative effect on $\mathrm{HLD}_{\mathrm{N}}$ for lipophilic alcohols such as n-butanol, pentanols, hexanols, etc. The linearity effect is satisfied up to $2 \%$ for n-pentanol $\left(\mathrm{k}_{\mathrm{A}}=-7.5+0.5\right)$ and iso-pentanol $\left(\mathrm{k}_{\mathrm{A}}=-6.0 \pm 0.5\right)$, and up to $0.5 \%$ for $\mathrm{n}$-hexanol $\left(\mathrm{k}_{\mathrm{A}}=-15 \pm 2\right)$ with a deviation (decrease in the slope $\mathrm{k}_{\mathrm{A}}$ ) at higher concentration in which the alcohol start partitioning in the oil phase as a lipophilic linker, i.e., a polar oil segregated close to interface [113-115]. For n-butanol the data is not accurate and seems to vary with the surfactants from $\mathrm{k}_{\mathrm{A}}=-1.5$ to -3.0 . For ethoxylated nonionic surfactants, the alcohol cosurfactants have a similar effect but the $\mathrm{k}_{\mathrm{A}}$ have different values, about half those found for the ionic surfactant case, i.e., for 1-pentanol and isopentanol $\left(\mathrm{k}_{\mathrm{A}}=-4\right.$ and -3$)$ and for $\mathrm{n}$-hexanol $\left(\mathrm{k}_{\mathrm{A}}=-8 \pm 1\right)$. 
Figure 13 illustrates this result for pure products series, e.g., the linear alkyl-benzene sulfonates (LABS), the alkyl orthoxylene sulfonates (AOXS) and the ethoxylated n-alcohols (CiEj), which all perfectly follow Equation (16), as indicated by a straight line.

For both ionic and nonionic surfactants, the $\mathrm{PACN}_{0}\left(\sigma_{0} / \mathrm{K}\right.$ or $\left.\beta_{0} / \mathrm{K}\right)$ is the value corresponding to PACN when the SAT is extrapolated to 0 , i.e., when the tail is removed. It was found to depend on the head group, and on the selected references, usually 0 or $1 \%$ wt $\mathrm{NaCl}, 25^{\circ} \mathrm{C}$, no alcohol, and zero $\mathrm{ACN}_{\text {ref }}$ virtual oil. Some values of $\mathrm{PACN}_{0}$ found in the following list (including the first published data [68,116]) in the literature mostly correspond to relatively pure surfactants. However, the indicated values are only approximations ( $\pm 3-4$ units), in general at Cs $=1-2 \mathrm{wt} \%$ and WOR $=1[73,78,100,108,117]$.

In Table 1 the head group is included in the PACN $\mathrm{P}_{0}$ for ionic surfactants and, for nonionics, it appears as a specified number of EO groups, $5 \mathrm{EO}$ or $10 \mathrm{EO}$, inside the $\mathrm{PACN}_{0}$ value. In nonionic surfactants with no specification of head group, the EON (ethylene oxide number) or GN (glycerol group number) appears in the PACN $\mathrm{N}_{0}$ column. In all cases, the surfactant PACN may be calculated from Equation (16) that indicates how to add the contribution of the alkyl tail. No data is indicated for extended surfactants, firstly because the reported $\mathrm{K}$ values are not consistent in the published data (from 0.06 to 0.11 ) on different species, and secondly because it seems to be also altered by the intermediate PON size and also by the presence of some 1-3 EON groups before an ionic head. Additionally, these products are mixtures and their PACN is likely to significantly depend on their concentration. It is thus recommended to make a specific measurement in each case of extended surfactant.

Table 1. Surfactant head contribution parameter $\mathrm{PACN}_{0}$ expressed in $\mathrm{ACN}$ units as in Equation (16).

\begin{tabular}{|c|c|}
\hline Na n-alkyl carboxylate & $\mathrm{PACN}_{0}=-50$ \\
\hline Na n-alkyl sulfate & $\mathrm{PACN}_{0}=-57$ \\
\hline Na alkane sulfonate & $\mathrm{PACN}_{0}=-48$ \\
\hline Na iso-alkyl benzene sulfonate & $\mathrm{PACN}_{0}=-30$ \\
\hline $\mathrm{Na}$ alkyl orthoxylene sulfonate & $\mathrm{PACN}_{0}=-25$ \\
\hline Extended surfactants & no consistent data \\
\hline $\mathrm{Cl}$ n-alkyl ammonium at $\mathrm{pH}=3$ & $\mathrm{PACN}_{0}=-32$ \\
\hline $\mathrm{Cl}$ n-alkyl trimethyl ammonium & $\mathrm{PACN}_{0}=-46$ \\
\hline $\mathrm{Cl}$ n-alkyl pyridinium & $\mathrm{PACN}_{0}=-47$ \\
\hline iso-alkyl phenol ethoxylate & $\mathrm{PACN}_{0}=+23-6.67 \mathrm{EON}$ \\
\hline iso-alkyl phenol + 5 EO & $\mathrm{PACN}_{0}=-10$ \\
\hline n-alcohol ethoxylate & $\mathrm{PACN}_{0}=+13-6.67 \mathrm{EON}$ \\
\hline n-alcohol + 5 EO & $\mathrm{PACN}_{0}=-20$ \\
\hline n-alcohol + $10 \mathrm{EO}$ & $\mathrm{PACN}_{0}=-55$ \\
\hline iso-alcohol ethoxylate & $\mathrm{PACN}_{0}=-2-6.67 \mathrm{EON}$ \\
\hline iso-alcohol + $5 \mathrm{EO}$ & $\mathrm{PACN}_{0}=-35$ \\
\hline iso-alcohol + $10 \mathrm{EO}$ & $\mathrm{PACN}_{0}=-68$ \\
\hline n-alkyl carboxylic acid polyglycerol ester & $\mathrm{PACN}_{0}=+34.5-10 \mathrm{GN}$ \\
\hline
\end{tabular}

When the products are quite pure, a fair coincidence is found even if they are manufactured by different companies. For instance, as can be seen in Figure 13, a PACN value of -4.5 for a sodium linear dodecyl benzene sulfonate with $99 \%$ purity, compares well with another LABS value, which is -3.0. It can thus be asserted that the general tendencies are significant when the surfactant structure, particularly the isomerism, is well defined.

The identical slope in the surfactant series shown in Figure 13 confirms that Equation (16) is quite exact for linear alkyl chains with the head located at the end of the alkyl tail. Nevertheless, it was found that if the tail is not a straight chain, slight differences in structures can notably influence the PACN. This is the case with branched or multiple tails [118-121] and with the introduction of a central intermediate (as for "extended" surfactants with a propylene oxide part in the tail) [76,97,122], or even with simple changes as recently shown for the addition of a single methyl group close to the head $[86,123,124]$. It also confirms that the PACN $(\sigma / K, \beta / K$ or $C c / K)$ has the same increase with an 
additional carbon in the n-alkyl tail, whatever the head and the $\mathrm{K}$ coefficient. This is why the proposed surfactant parameters $(\sigma, \beta$ or $C c)$ in the first HLD equations are not appropriate to characterize the surfactant, and that their values divided by $\mathrm{K}$ [68] must be used as in the new $\mathrm{HLD}_{\mathrm{N}}$.

A double tail occurrence is also important. For instance, a large difference in PACN was found when passing from the $2 \phi C 16$ benzene sulfonate to the $8 \phi C 16$ isomer [125]. This displacement of the benzene attachment point from the second carbon to the center of the C16 linear alkyl tail is equivalent to an increase of 10 units in $\mathrm{PACN}_{0}$, which is the same as adding four more carbon atoms in a linear tail, with the benzene attached in the second carbon.

Moreover, it is worth noting that using $\mathrm{S}=1 \mathrm{wt} \% \mathrm{NaCl}$ reference for nonionics (instead of $\mathrm{S}=0$ ) would introduce a difference of 0.13 in $\beta$ (or 0.9 in PACN), which is relatively small for the ethoxylated n-alcohols. Indeed, such a difference is equivalent to an error of 0.15 on EON, of 0.5 carbon number in the tail (i.e., on SAT), of about one carbon atom in the alkane scan (ACN) and of $3{ }^{\circ} \mathrm{C}$ in the temperature scan. Such a discrepancy is actually small when compared to the effect of the surfactant tail structure, in particular its branching or isomerism that exerts a strong influence, up to 10 times more.

Since the required accuracy for applications like cosmetic and pharmaceutical surfactants is about two PACN units, it can be said that the prediction of the surfactant parameter with a (too) simple HLD equation is, in actual practice, not very accurate unless very pure species are used, which is not feasible because of the cost of such products. Moreover, there is also some error in the characterization of the real oil and water phases, e.g., the EACN of a vegetable product in which some polar ingredients are likely to be segregated at interface $[113,114]$, or an actual aqueous phase containing many anions and cations for which only some initial equivalence has been proposed [75,126].

The previously reported situation emphasizes two crucial aspects. Firstly, there is no doubt that the numerical correlations as Equation (11) with the proper coefficients for each SOW system are generally very useful to make predictions in formulations dealing with applications requiring a much better tool than the simplistic HLB parameter. Secondly, it also indicates that the HLD formulas with only five to six basic variables could still be too approximate in practice for real systems, in particular with mixtures of surfactants or oils that result in interfacial partitioning. Fortunately, a few experimental measurements will make it possible to verify the coefficient values and to have a good predictive $\mathrm{HLD}_{\mathrm{N}}$ equation to describe the formulation.

It can be said that even if real systems are intricate, and actually require more than five to six variables to be described in detail, a high level of formulation understanding allows the use of several skillful tricks to reduce the difficulties in practical cases, and also save a lot of experimental costs.

Before moving on to the last part of this review that deals with the relation between the formulation $\mathrm{HLD}_{\mathrm{N}}$ and the emulsion properties, the third way to describe the phase behavior in the Figure 4 prism is examined. This last cut at constant surfactant concentration (Cs) is important in practice because it exhibits the easier correspondence of formulation with emulsion properties, i.e., on its type, stability, drop size and viscosity, as will be examined below.

Figure 14 shows the aspect of such a cut at constant surfactant concentration Cs. Figure 14 (left diagram) takes place at a usual surfactant concentration in many applications, typically at 2-10\%, for which a type III phase behavior happens at optimum formulation in the central zone. The right side small maps indicate how this phase behavior is affected when the surfactant concentration is smaller or higher.

Figure 14 (left plot) indicates that, with a WOR not far away from unity, i.e., typically with the water or oil content in the $25-75 \%$ range, the phase behavior is very consistent with what has been seen previously, that is, the effect of the formulation variables, particularly as the generalized HLD makes it possible to describe the phase behavior and its associated properties.

A vertical displacement along a change in formulation corresponds to the schemes indicated in Figure 7. It does not significantly vary with WOR, and is thus similar to what is shown with the other cuts in Figure 5. At very low surfactant concentration, the volume in the type III regime tends to be reduced and it disappears close to the CMC concentration. When the concentration is higher than the 
$\mathrm{Cs}^{*}$, the intermediate between types I and II is a single-phase type IV. It is important to bear in mind that this formulation-WOR diagram identifies the same as the other two cuts, but, as will be shown later, it is the best diagram to describe the relation of the formulation with the emulsion properties.
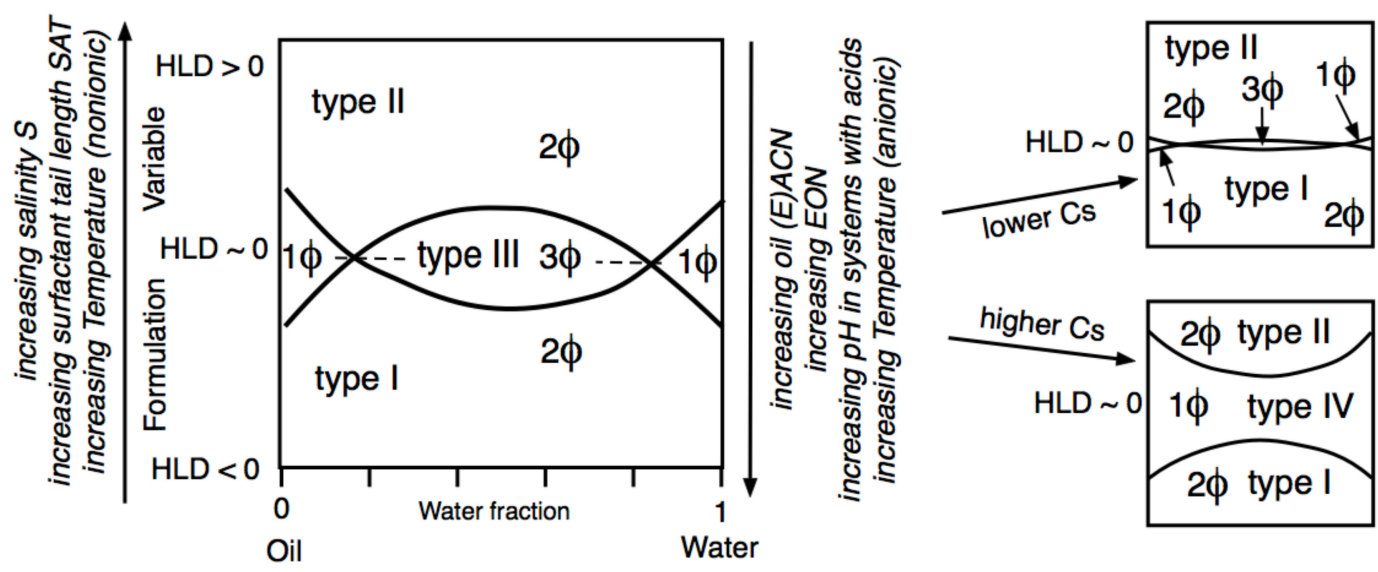

Figure 14. Phase behavior in the formulation-WOR cut of the 3D prism shown in Figure 4.

\section{Relation of HLD Values with Micro-, Mini-, and Macroemulsion Properties}

As a summary, this last part indicates why the value of the generalized HLD expression is crucial to make pharmaceutical and cosmetics products with the properties required for their use, in particular the emulsion's type and stability.

Emulsion persistence has been systematically studied in many reports describing the numerous phenomena involved [127-129]. These should be reviewed by the reader who is not familiar to them. The Bancroft rule and Langmuir wedge theory were proposed in the 1910s. However, it should be stressed that it was in the 1980s only when the generalized HLD $=0$ formulation case was shown to be the most determinant criterion to find an emulsion minimum stability [130-134]. This was a particularly important discovery to break undesirable emulsification as in wastewater treatment and petroleum dehydration, as well as to control biochemical processing involving oil and water. It was only a few years later when some fundamental approaches were proposed to explain this coincidence $[37,64,65]$, which is important when the required property is either a noticeable stability or a strong instability. The following paragraphs review the general phenomena that are explained in more details in chapters dedicated to different applications, particularly in pharmaceuticals and cosmetics [135-139].

The most critical result concerning the use of the HLD formulation concept is what is seen in Figure 15 in which several data about the variation of emulsion stability versus formulation are put together to exhibit the general trends. Similar information can be found in the literature in myriad articles, reviews or books published since 1990.

No matter the ordinate stability scale (from a few minutes to several months to break a large percentage of phase separation of the emulsion and the formulation variable altering HLD in abscissa), the result remains identical. It happens that very close to optimum formulation, say in the narrow $H_{L D}$ interval from -5 to +5 , the emulsions are very unstable, unless they are gels with lamellar crystals or with a very high polymer content. This is extremely important in practice since it implies that a small change in temperature, e.g., from $20^{\circ} \mathrm{C}$ to $35^{\circ} \mathrm{C}$, is enough to break an $\mathrm{O} / \mathrm{W}$ nonionic macroor nanoemulsion when it is placed on the skin. On the contrary, the same increase in temperature can stabilize the same type of emulsion made with a proper ionic surfactant because of the opposite change in stability versus HLD. 


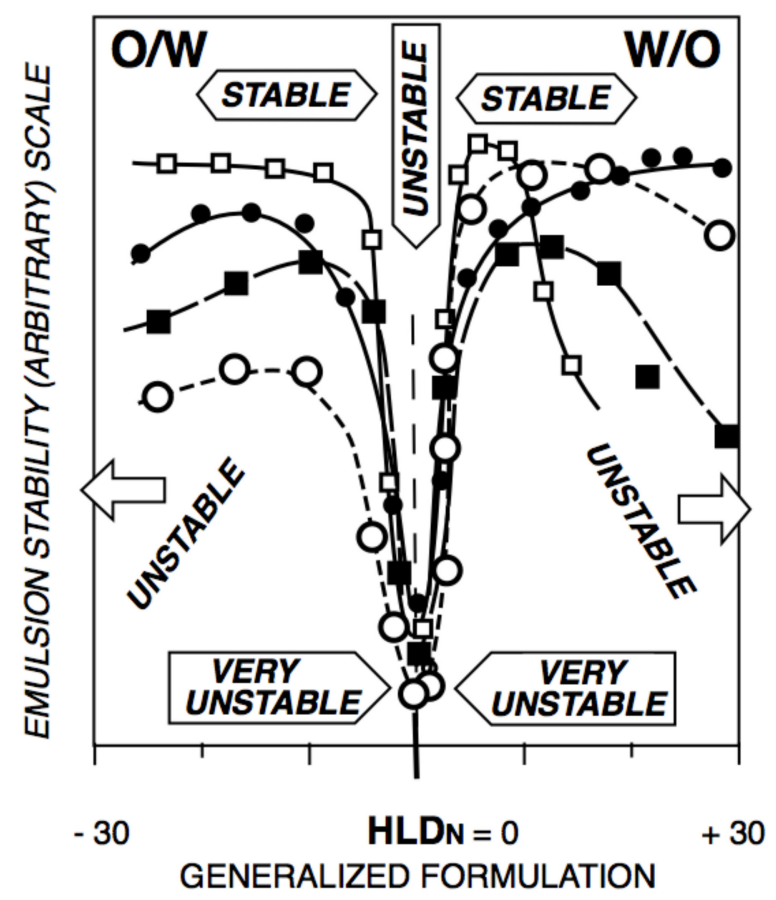

Figure 15. Systematic variations of emulsion stability with the $H L D_{N}$ with different systems.

The handling of HLD by changing one or two variables, enables the emulsion manufacturer to be exactly in the desired stability or instability zone. This is why manipulating the HLD is an extremely useful technique for the practical use of formulation.

Figure 15 clearly exhibits not only a very strong instability at optimum formulation, but it also indicates that, at some distance from $\operatorname{HLD}_{\mathrm{N}}=0$, i.e., in the 10-20 unit range on both sides, there is a stable zone for the two types of emulsions. Of course, this stability zone could be high or very high depending on stabilization phenomena, which have been extensively discussed in the literature. Figure 15 clearly shows that the generalized optimum formulation effect at HLD $\sim 0$ overcomes all stabilization effects $[140,141]$.

Figure 15 also indicates that at more than $20-30 \mathrm{HLD}_{\mathrm{N}}$ units from the optimum on both sides, the stability decreases, sometimes slowly, sometimes quickly. This means that if a high stability is required for an $\mathrm{O} / \mathrm{W}$ (respectively W/O) emulsion, the $\mathrm{HLD}_{\mathrm{N}}$ should be adjusted for a negative (respectively positive) value in the 10-20 unit range, using up to six variables, i.e., with a lot of flexibility. It can be seen from Figure 15 that, depending on the case, the stable zone can be larger or narrower, and higher or lower. What is the best for each application depends on the process in particular, since a small change, for instance $10{ }^{\circ} \mathrm{C}$ in temperature, can produce the emulsion inversion or a displacement in the stability properties, as well as other characteristics like the drop size or the viscosity, as will be quickly discussed below.

The Figure 4 prism cut at constant surfactant concentration Cs has been shown in Figure 16 to exhibit a characteristic phase behavior in different zones. This kind of figure was proposed for the first time by Shinoda and Kunieda [23,31,142-144], always using the temperature as the single formulation variable for nonionic surfactant systems.

It was then used with many formulation variables found in the generalized HLD in a series of papers showing the same phenomenology with other formulation variables [38,145-150].

It is the most significant map to describe how to find out a required emulsion property for a given application. When the formulation (HLD with six variables) is changed or adjusted together with the water/oil composition as seen in Figure 16, the many options of emulsion type and properties appear [151]. 
In Figure 16, the emulsion inversion already seen is a horizontal line at $\mathrm{HLD}_{\mathrm{N}} \sim 0$ with the WIII phase behavior in the WOR central part, i.e., when there is no more than $70-75 \%$ of one of the phases. In this range, the HLD is the unique criterion to attain O/W or W/O types so-called A+ and A- "normal" emulsions in which the continuous phase is the one containing most of the surfactant. In the extreme WOR zones, called B and C, the normal emulsions occur when the HLD matches the occurrence of the continuous phase with most of the surfactant, i.e., $\mathrm{B}+$ (respectively $\mathrm{C}$-), which may be considered as the continuity of the $\mathrm{A}+$ (respectively A-) zone with a high dilution, i.e., a large excess of the external phase.

On the contrary, the B- and C+ zones are said to be "abnormal" because most of the surfactant is not in the emulsion external phase. This is the reason why these zones are exhibiting "multiple" emulsions in some places, with droplets in drops forming the "internal" emulsion, and drops in a continuous phase forming the "external" one. There are two types, i.e., o/W/O in B- and w/O/W in C+, with the low case letter indicating the phase of the smaller droplets inside the drops. The most external emulsion, i.e., $\mathrm{W} / \mathrm{O}$ in $\mathrm{B}-$ and $\mathrm{O} / \mathrm{W}$ in $\mathrm{C}+$ are abnormal (and unstable) while the internal ones, i.e., $\mathrm{o} / \mathrm{W}$ in $\mathrm{B}-$ and $\mathrm{w} / \mathrm{O}$ in $\mathrm{C}+$ are normal and stable, according to the relation between HLD and emulsion type and stability. The formation of multiple emulsion is due to a conflict between the formulation and the composition, and it depends on the way the emulsification process is carried out, in particular it can be made in different steps or produced spontaneously.

The most internal phase in droplets ( $\mathrm{w}$ or $\mathrm{o}$ ) may be identical or different from the continuous phase ( $\mathrm{W}$ or $\mathrm{O}$ ); it thus makes it possible to handle transfer processes from inside to outside or vice-versa which is very useful in pharmaceutical and cosmetic products [152-155].

Figure 16 shows that the emulsion inversion line is mostly horizontal at HLD $\sim 0$ in the WOR central part; the emulsion type thus depends on the formulation only. In this region, there is a so-called "transitional" inversion, which applies to systems that are at equilibrium before emulsification or in some dynamic change in temperature or other formulation variable altering the HLD. The advantage of temperature (which is often used to produce inversion) is that it can be changed in both directions with no memory, including in two opposite steps one after the other, which is not feasible with the other formulation variables.

The two lateral branches of the inversion line, which are mostly vertical, are due to the presence of different mechanisms which are independent from HLD. This type of inversion thus mainly depends on the WOR, with a strong tendency to have the one with the larger proportion as an external phase. This is why the inversion vertical line is on the right or the left side, depending on the HLD favoring a curvature matching a W/O or O/W emulsion. The vertical line position was also found to depend on other conditions which do not appear on this map, such as the mixing apparatus features that can influence the local WOR in the mixed zone, as well as the stirring energy and the intensity of shearing, and the relative viscosity of the phases. This inversion which is so-called "catastrophic" because of its characteristics, is not necessarily the same in the two directions of change, i.e., when adding oil or adding water, and it can involve a hysteresis that tends to increase when the formulation deviates from $\mathrm{HLD}=0$. This hysteresis means that dynamic changes in WOR (i.e., adding water or adding oil when stirring) can produce delays, or somehow push the inversion occurrence, thus displacing its position. As a consequence, these vertical parts on the inversion line can be slanted in one direction or the other depending on the direction of WOR change.

This more complex situation has been studied thoroughly in the past using the Figure 17 map at a second level with a catastrophic cusp hysteresis zone [156], replacing the vertical parts of the inversion lines. For the sophisticated reader, the description of this more complex approach is available elsewhere [157]. It can be used in practice to produce interesting effects like emulsion smaller drops or increased viscosity, as well as stable multiple emulsions [13,151,152]. 


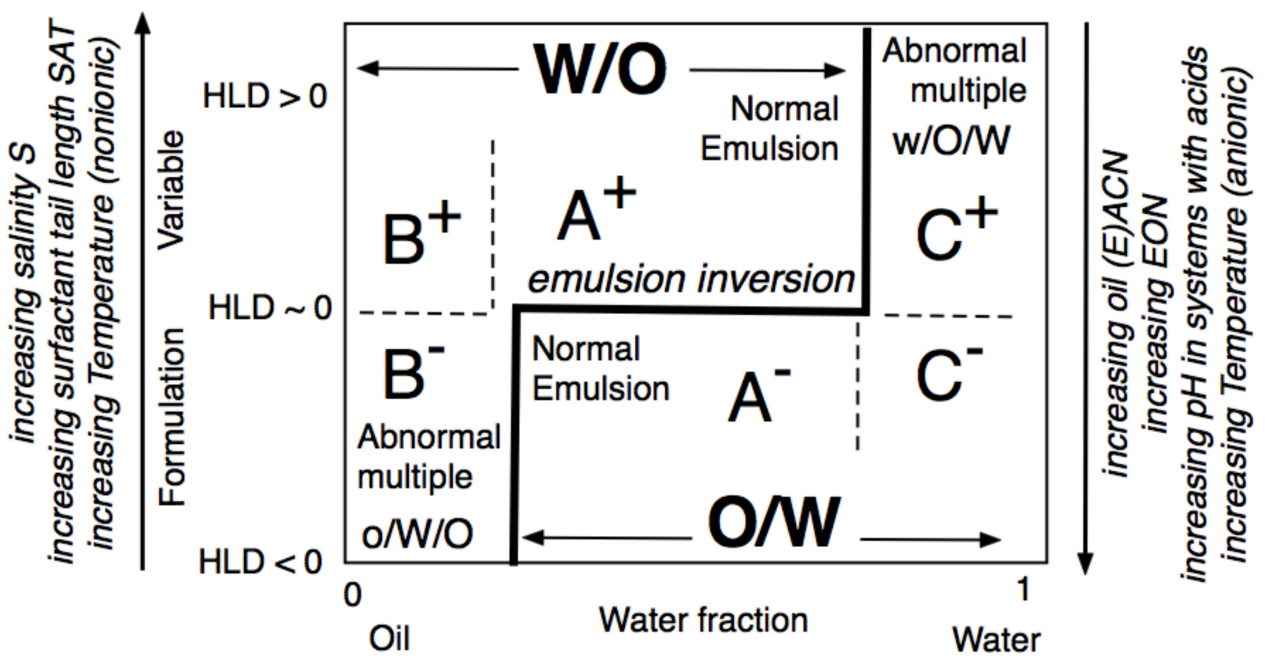

Figure 16. Classical formulation-composition diagram (HLD-WOR) showing the inversion line and emulsion types.

Figure 17 indicates on the same map the main trends about the emulsion stability as well as other crucial properties. First of all, there is a highly unstable emulsion zone close to the horizontal central part of the inversion line at HLD 0. If there is no liquid crystal or a high polymer concentration, the unstable zone is just a matter of minutes of persistence. It can be used for immediately breaking an emulsion when it is in contact with the skin at body temperature. In the case of nonionic surfactants an $\mathrm{O} / \mathrm{W}$ emulsion could be stable at ambient temperature $20-25^{\circ} \mathrm{C}(\mathrm{HLD}<0)$ if the optimum (HLD 0 and instability) is set to be at $35-40{ }^{\circ} \mathrm{C}$

At some distance from optimum, typically at $\mathrm{HLD}_{\mathrm{N}} \sim \pm 10$ both types of emulsions are stable, as clearly seen in Figure 15. Moreover, if the stability tends to decrease when the $H_{L} D_{N}$ gets further away from optimum, it is a slow variation in general and a large change is required for the stability to significantly decrease. Consequently, there is a stability zone which is generally large, e.g., from 10 to 30 units of $\mathrm{HLD}_{\mathrm{N}}$ on each side.

On the contrary, it is worth noting that the stability fall when approaching HLD $=0$ could be very rapid. It is thus important to make sure that an accidental change in formulation (e.g., in temperature) is not going to destabilize the emulsion. Hence, a small safety range is required because of the possible spontaneous evolution that depends on the surfactant too. An ethoxylated surfactant system would exhibit an $\mathrm{O} / \mathrm{W}$ emulsion at $\mathrm{HLD}<0$. It would thus be likely to break if temperature increases, unless the required modification to reach HLD $=0$ is large enough. On the contrary, an ionic surfactant $\mathrm{O} / \mathrm{W}$ emulsion would increase its stability with such a change. The opposite would occur for a W/O emulsion.

At some short distance from HLD $=0$, there is a narrow zone where the emulsion drop size is minimum [156]. This location is close enough to $\operatorname{HLD}_{\mathrm{N}}=0$ where the interfacial tension is minimum, and thus where oil drops made by some mixing tend to elongate and break up easily, and to become smaller. However, it is also close to $\mathrm{HLD}_{\mathrm{N}}=0$ where the emulsion stability is very poor and where coalescence takes place quickly thus increasing the size of the drops. This minimum drop size then comes from the competition between two opposite effects and it may be slightly changed by the stirring process or the phase viscosity ratio.

Then, the exact position in a particular case has to be determined experimentally. However, it is known to be there and it is thus easy to find the best solution in a narrow range of $H L D_{N}$, with a proper formulation variable. Such a determination is often more effective than other frequently used techniques such as an extra strong mixing or a temperature increase to reduce the viscosity. It is important to bear in mind that the viscosity tends to increase with the internal phase ratio of the emulsion (\% vol of internal phase). 
Consequently, in the normal emulsion zones $(\mathrm{A}-$ and $\mathrm{A}+$ ), the higher internal phase volume that happens close to the vertical frontier from normal to abnormal emulsion, is in most cases where the most viscous stable one is produced. It is of course even more viscous if the droplets are smaller at a formulation not far away from $H L D_{N}=0$. It is worth noting that there is a competitive situation between the actual stability and the viscosity $[156,158]$, since being too close to $\operatorname{HLD}_{\mathrm{N}}=0$ could increase the viscosity because of smaller drops, but also be less stable.

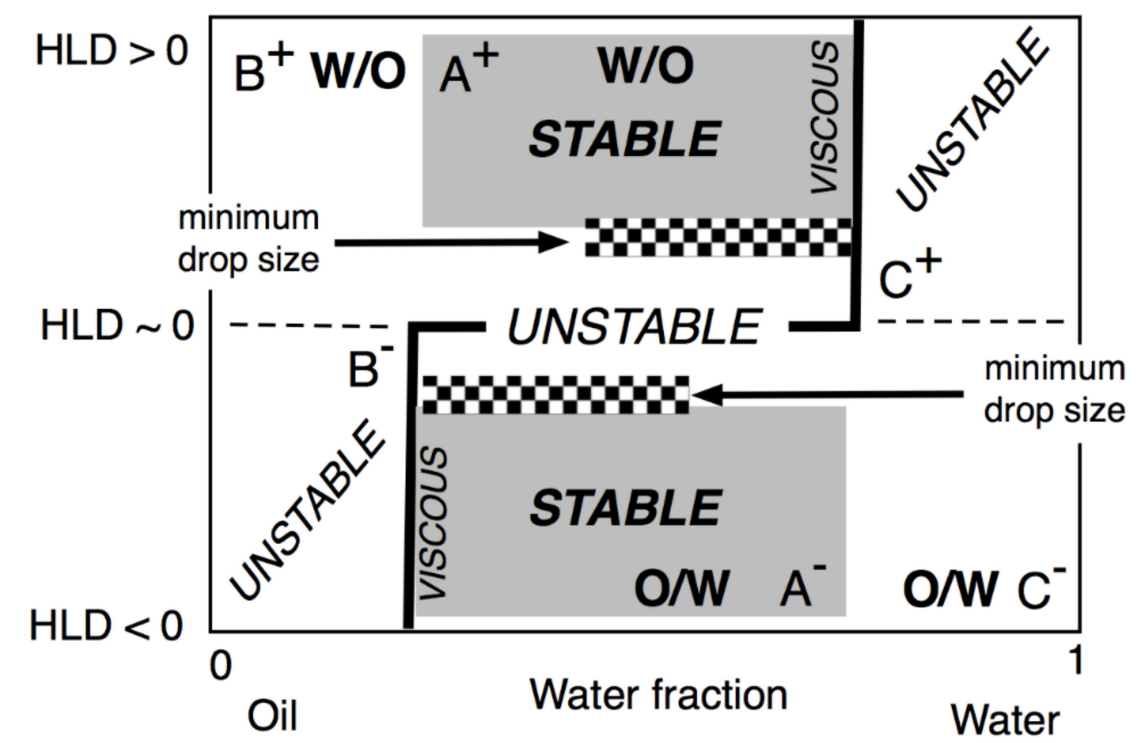

Figure 17. Classical formulation-composition diagram (HLD-WOR) showing the basic properties (stability, drop size and viscosity) as described a long time ago [155].

In any case, this change in property from place to place in this kind of map, indicates that dynamic processes are often a means to benefit from several favorable properties in a path on the map with a number of subsequent steps, often with a horizontal, vertical or slanted crossing of the inversion line $[149,159-164]$. For instance, the original system may be an equilibrated one close to $H L D_{N}=0$, and, it should be noted, not on the other side of the optimum line as many people have suggested to produce an inversion [165] which does not help unless it is necessary to avoid the problem of a too high viscosity ratio between the drop and external phase (like $\eta_{\text {int }}>5 \eta_{\text {ext }}$ ) in the Weber ratio plot [166-168].

Starting at optimum above $\mathrm{Cs}^{*}$ with a single phase type IV is of course a guarantee that the first drops to be formed in a type I or type II phase behavior would be very small, but this requires more surfactant and is thus more expensive.

Being at optimum with a WIII phase behavior is the place where the tension is minimum and where the drop size made by stirring is thus very small too. Then, after starting by making very small drops, the formulation has to be changed to quickly move away from HLD $=0$ to increase the stability. It is, by the way, often interesting to remain some time at the position where the drop size is minimum at a short distance from HLD $=0$, then to "escape" from the fast coalescence zone by quickly changing more the HLD, and instantly passing to where the emulsion is more stable. Adding more internal phase in the normal zone up to be close to the catastrophic inversion vertical line would increase the viscosity and increase the efficiency of the stirring at low shearing. Beware, however, that a very high shearing with an already viscous emulsion could move the vertical inversion line. Even the position of the stirrer in the mixing volume could be important, and could reduce the zone of normal emulsion in the formulation-WOR map [169], which is often an inconvenience. Nevertheless, it is not always the case, because a produced emulsion could be too viscous with $90 \%$ of internal phase. It could thus need to be slightly diluted by adding some external phase. Notwithstanding, such addition could also reduce the emulsion viscosity and stability, unless the added external phase contains a viscous additive like a polymer. It should be noted that the addition of polymer in the external phase added at 
this stage could be much more effective than placing the polymer in the original external phase before the emulsification is carried out.

As can be deduced from these comments, using a sound knowledge of the properties in a general HLD-WOR map, and carrying out a few experiments to generate the corresponding know-how, makes it possible to conduct a few effective trials to obtain an original solution. Now, the possibilities are very numerous because the exact position of the frontiers also depends on some specificities of the surfactant(s), oil(s) and brine, as well as cosurfactants, and polymers.

A chapter on this would be extremely long and costly, and would require a lot of work in the sense that it would imply the publication of years of experimental and confidential research and development. This kind of information is sometimes available in patents, but, quite frequently in such cases, no clear explanation is provided and tricky things are added to confuse the reader rather than to transfer knowledge.

This means that each research and development center which prepares an emulsion with a specific application, such as an $\mathrm{O} / \mathrm{W}$ emulsion cream, a skin treatment, a make-up, a cleaning process, a wettability change, or a vehicle to penetrate the skin and deliver a pharmaceutical product etc., needs to improve its understanding and build up appropriate know-how for its business. This is generally a matter of getting some practical training from a university working with the industrial sector, and of reading specialized journals, not necessarily the most theoretical ones with a higher impact factor which are not particularly dedicated to acquiring working knowledge but to understanding a selected (simple) case. Then the research and development professionals have to start working on that trial after trial, in equilibrated and dynamic processes, and, after 10 years of accumulated experience, they will be able to provide an optimized solution in a few days only.

Some practical chapters have been published without any real secrets, but with some well- known tricky examples $[3,62,63,152]$. They are thus a good start to build up experience.

\section{Additional Advantages and Complications with Complex Systems and Mixtures of Ingredients}

This last section is a quick look at what a formulation researcher must learn in the first 10 years of his/her personal experience, to start beginning to be a specialist. It has to do with the fact that SAD was a concept that allowed putting some basic order in the effect of the formulation, i.e., to have a relatively simple behavior with a unique generalized dimensionless expression. $\mathrm{HLD}_{\mathrm{N}}$ correlation actually includes the contribution of the head and tail of a unique surfactant, the ACN of an n-alkane oil, and the $\mathrm{NaCl}$ salinity of the aqueous phase of a low complexity system, as well as the temperature and pressure. To these six variables, the type and concentration of a cosurfactant like a n-alcohol can be added through the $\mathrm{f}(\mathrm{A})\left(=\mathrm{k}_{\mathrm{A}} \mathrm{C}_{\mathrm{A}}\right)$ term, thus resulting to the contribution of eight variables in a single one, i.e., an extraordinary simplification.

However, this is not sufficient in practice with real surfactant-oil-water cases for nearly all the applications involving oils different from n-alkanes, aqueous phases with ions other than $\mathrm{Na}^{+} \mathrm{Cl}^{-}$, and a large variety of amphiphiles including natural ingredients and their modifications.

\subsection{Equivalent Oil Alkane Carbon Number (EACN)}

The quantitative effect of a new ingredient (surfactant, oil, salt) has been solved by finding an equivalence thanks to the HLD $=0$ equation taking a very pure SOW system and changing two variables, i.e., making a compensative double change. The first change is passing from a well-known case for one variable, e.g., heptane oil with $\mathrm{ACN}=7$, to a new oil like cyclohexane, limonene, or a slightly polar oil including an oxygen atom or an halogen, such as hexylmetacrylate or trichloroethylene, or even a natural mixture like olive oil. This first change is then said to be the first deviation from optimum written as dVi in Equations (5), (6) and (16), in this case it will be dACN. The second step consists in using a second variable to perform a formulation scan, for instance by changing the $\mathrm{NaCl}$ salinity as $\mathrm{dVj}=\mathrm{dLnS}$ with everything else staying constant, in particular a selected anionic surfactant 
for which the K coefficient is known. When the new optimum salinity is known, the $\operatorname{HLD}_{\mathrm{N}}$ equation is written twice, i.e., as follows with the original normalized expression:

$$
\mathrm{ACN}_{1}=(1 / \mathrm{K}) \mathrm{LnS}_{1}+\mathrm{CST} \text { and } \mathrm{ACN}_{2}=(1 / \mathrm{K}) \mathrm{LnS}_{2}+\mathrm{CST}
$$

Then, the CST depending on the values of the other unchanged variables is eliminated by subtraction. The first scan with heptane $\left(\mathrm{ACN}_{1}=7\right)$ has an optimum salinity $S_{1}$ and the one with a second oil $\left(\mathrm{ACN}_{2}\right)$ has an optimum salinity $\mathrm{S}_{2}$, then:

$$
\mathrm{ACN}_{2}=7+(1 / \mathrm{K})\left[\operatorname{Ln}\left(\mathrm{S}_{2}\right)-\operatorname{Ln}\left(\mathrm{S}_{1}\right)\right]
$$

from which the $\mathrm{ACN}_{2}$, which is called the equivalent $\mathrm{ACN}$ (EACN) can be calculated [67]. A lot of data have been reported with various second scans in conditions of detection of the optimum which could be more or less accurate, in particular if the WIII zone is particularly large [170-176].

In a recent review [105], extremely pure nonionic surfactants were used and the optimum was detected in a PIT scan with a very high accuracy on temperature at the $\mathrm{Cs}^{*}$ point (fish tail). Many oil EACN values are reported with different comments on the trends produced by some change in the oil structure. As discussed in this review, the variation of EACN indicates some kind of polarity measurement of the oil, which could be negative even if in this case it has no longer a physical meaning. It was found that the EACN tends to decrease with the occurrence of certain structures like branching, cyclization, and aromatization and with the introduction of polar groups containing oxygen, such as ether, ester, or halogen $[105,145,177]$. These trends, indicated in the data displayed in Table 2 , have been confirmed by the COSMOS model [178].

Table 2. Equivalent oil alkane carbon number (EACN) values for oils with branching, cycles, double and triple bonds.

\begin{tabular}{llll}
\hline Oil & EACN & Oil & EACN \\
\hline Myrcane & 9.5 & p-menthane & 6 \\
Cyclohexane & 2.5 & Cyclohexene & -1 \\
Ethylcyclohexane & 4.5 & Isopropylcyclohexane & 5.5 \\
Benzene & 0 or less & p-cymene & -0.5 \\
Limonene & 1.6 & terpinolene & 0.3 \\
Octyl benzene & 4 & decyl benzene & 6 \\
p-xylene & -2 & 1-decene & 5.5 \\
1-octene & 4 & 1-octyne & -2 \\
1-dodecene & 8 & 1-dodecyne & 2 \\
Squalane (branched C30) & 24 & Dibutyl ether & 3.4 \\
Ethyl myristate & 5 & Ethyl oleate & 7 \\
Hexyl octanoate & 6.2 & Hexyl dodecanoate & 9.3 \\
Hexyl methacrylate & 0 & Isopropylmyristate & 7.5 \\
Miglyol 840-diglyc. C11 & 9 & Miglyol 812 triglyc. C11 & 14 \\
Soya oil triglyceride C18 & 18 & Trilaurin & 16 \\
Triolein & 21 & Tristearin & 24 \\
Glycerol trioctanato & 12.3 & Glycerol tridecanoate & 14 \\
1-Chlorodecane & 3.5 & 1-10 Dichloro decane & 6 \\
\hline
\end{tabular}

When the oil phase contains various substances, a linear mixing rule is generally valid if the species involved are not very different, in particular in their structure and polarity. For instance an hexane-hexadecane mixture perfectly follows a linear equation with the number of carbon atoms in the oil as can be seen in the next equation, where the $X_{i}$ is the fraction (molar in theory but often simply volumetric) of the " $\mathrm{i}$ " species in the mixture.

$$
\mathrm{EACN}_{\mathrm{MIX}}=\sum \mathrm{X}_{\mathrm{i}} \mathrm{EACN}_{\mathrm{i}}
$$


This simple linearity displayed in Figure 18 in a hexane-hexadecane mixture does not apply when the two or more species are very different in their structure, in particular in their polarity. It is the case of the benzene-tetradecane mixture. The EACN of the benzene is estimated to be close to EACN $=0$ by using the prolongation of the n-alkane (dashed) straight line at the experimentally found optimum at $\mathrm{LnS}^{*}=0.30$.

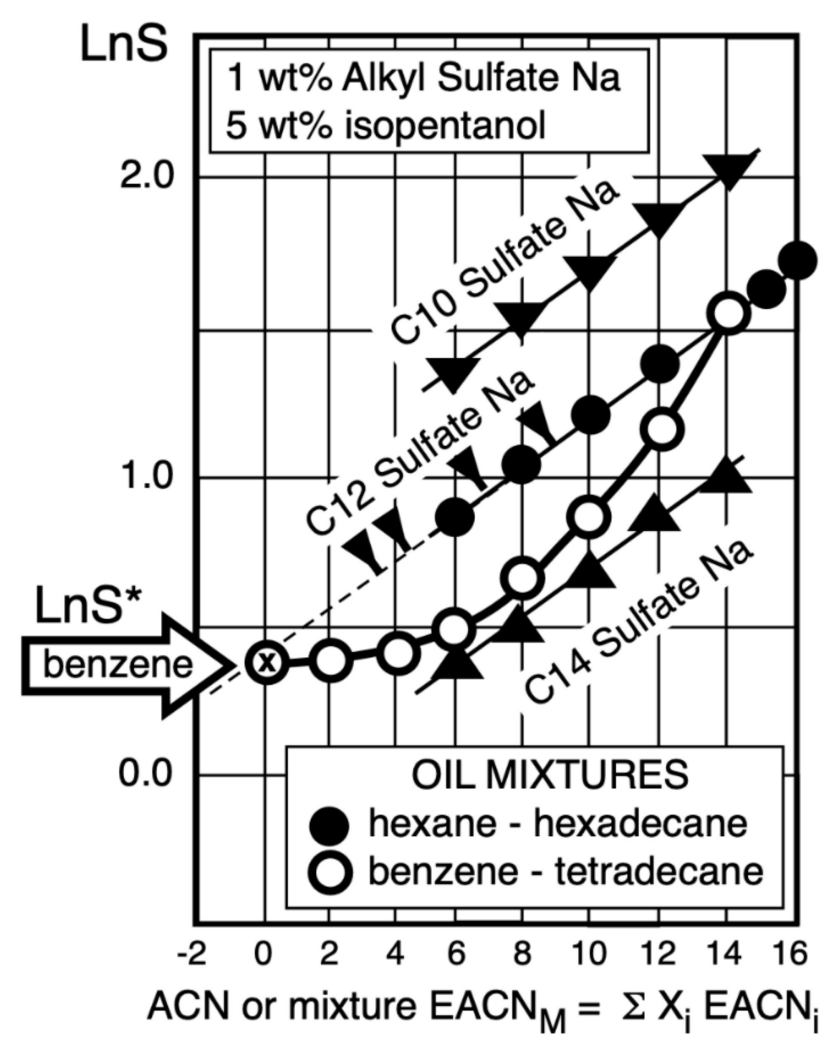

Figure 18. LnS vs ACN and oil mixtures. $\mathrm{LnS}^{*}$ is experimentally determined with pure benzene and placed on the extrapolated LnS*-ACN dashed line for the $\mathrm{C} 12$ sulfate. Xs are the volume fractions in the oil mixtures.

Figure 18 indicates that when some benzene is added to the tetradecane, the LnS* decreases very quickly, certainly because the benzene tends to accumulate close to interface, and results in a strong change $[113,176]$. However, on the other side, when some tetradecane is added to benzene, the oil $\mathrm{LnS}^{*}$ practically does not change because the tetradecane does not go close to the interface, where the benzene occupies almost all the volume. At $50 \%$ of both oils, LnS* is about $0.55(\mathrm{EACN}=2)$ instead of an extrapolated 0.95 for the linear average EACN of $(0+14) / 2=7$.

In pharmaceutical and cosmetic products, in general the oil phase contains a principal solvent like liquid or solid hydrocarbons, such as squalene or other paraffins, and animal or vegetable oils and fats with esters, having a proper melting point and viscosity. They also contain complex polar products like perfumes, antiseptics, preservatives, etc.

The most polar oil molecules have a tendency to be slightly attracted by the aqueous phase. As a consequence, the oil mixture close to interface contains a higher percentage of these polar oil molecules and there is a deviation from linearity, in general with a reduction of the EACN that would characterize the global oil phase mixture according to the content. This mostly happens with cyclic and aromatic hydrocarbons, as shown in Figure 18, or esters oils which tend to segregate close to interface [113]. It is also the case of hydrophobic alcohols like dodecanol, which have been called lipophilic linkers [114] to indicate that they are not really lipophilic cosurfactants like shorter alcohol as hexanol [115], but molecules that should rather be considered as polar oils. 
It should be noted that, in the HLD expression, this intermediate behavior of lipophilic linker can be rendered by a cosurfactant contribution in the $\mathrm{f}(\mathrm{A})$ term or if $\mathrm{f}(\mathrm{A})$ is not used, as a contribution to the surfactant mixture SCP at low concentration or by a modification of the oil EACN at higher ones [179-183].

\subsection{Equivalent Salinity}

In many cases the aqueous phase contains different salts, in particular in a petroleum reservoir, in wastewater, and in blood. The HLD linear variation with salinity as LnS seems to be general for ionic surfactant systems, even if the concentration is not expressed in $\mathrm{wt} \%$ but in $\mathrm{mol} / \mathrm{liter}$, i.e., with another scale, which only changes the salinity term coefficient in the HLD $D_{N}$ expression.

The variation of the negative counter-ion (for instance a change from sodium chloride to sodium sulfate or phosphate) can be taken into account with an equivalence coefficient $2 /(1+Z)$, where $Z$ is the valency of the anions [75]. This term enters the constant in the $H L D_{N}$ equation and the equivalence is easy to handle.

However, this is not the case for the variation of the cation (for instance from sodium to calcium or aluminum chloride) and a general salinity equivalence is not available yet, although some trends have been proposed [103,126,184].

The change in salinity for systems containing nonionic surfactant has been found to be simple with a small coefficient in front of a linear salinity term, as was shown in the initial HLD equation which is also to be corrected if the salt ions change. However, it has not been studied in detail, probably because it is not crucial in practice.

Experimental data are required when using ionic mixtures in the aqueous phase, particularly when the surfactant used contains ionic and nonionic species. In such a case, the reference salinity cannot be taken at $\mathrm{S}=0$ to avoid the problem with a logarithm, but for instance at $1 \mathrm{wt} \% \mathrm{NaCl}$.

\subsection{Equivalent SCP in Surfactant Mixtures}

The use of surfactant mixtures is a very important subject, first because, in many systems, the $\mathrm{S}$, (E)ACN, T and $\mathrm{P}$ values are fixed by the application. A required SCP value can thus be calculated to produce $\mathrm{HLD}=0$ in order to attain optimum formulation or a different goal, for instance $\mathrm{HLD}_{\mathrm{N}} \sim-6$ or -8 to produce an $\mathrm{O} / \mathrm{W}$ small-drop nanoemulsion cream.

Since it is highly unlikely that a commercial product has the proper SCP to exactly attain the goal, a mixture of at least two surfactants is required. Back in 1979, the basic mixing rules were studied at the same time as the SAD/HLD concept for the EOR application [69].

In this early case, the surfactant candidates were typically commercial products containing substances with a similar head group (e.g., sulfonates with $\partial \mathrm{LnS} / \partial \mathrm{ACN}$ slope $\mathrm{K}=0.16$ value) and different tail lengths (alkyl benzene more or less branched), so that the real scanning variable was the surfactant molecular weight, or what was then called the surfactant alkyl tail carbon number (SACN or SAT) with pure species.

For other applications, like cosmetics, several studies were carried out with nonionics made from the same tail structure as n-alcohol or alkylphenol, with different polyethoxylated heads. In these cases, a fairly linear equation was found for the mixture by scanning EON.

These results were written as follows when the optimum was detected by a salinity scan for two or more similar ionic surfactants:

$$
\mathrm{LnS}_{\mathrm{MIX}}=\mathrm{X}_{1} \mathrm{LnS}_{1}+\mathrm{X}_{2} \mathrm{LnS}_{2} \text { or } \mathrm{LnS}_{\mathrm{MIX}}=\sum \mathrm{X}_{\mathrm{i}} \mathrm{LnS}_{\mathrm{i}}
$$

Or with EON scans for ethoxylated nonionics where $\partial \beta / \partial \mathrm{ACN}=-\partial \mathrm{EON} / \partial \mathrm{ACN}$ slope $\mathrm{K}=-0.15$

$$
\mathrm{EON}_{\mathrm{MIX}}=\mathrm{X}_{1} \mathrm{EON}_{1}+\mathrm{X}_{2} \mathrm{EON}_{2} \text { or } \mathrm{EON}_{\mathrm{MIX}}=\sum \mathrm{X}_{\mathrm{i}} \mathrm{EON}_{\mathrm{i}}
$$


This is equivalent to $\mathrm{HLD}_{\mathrm{MIX}}=\sum \mathrm{X}_{\mathrm{i}} \mathrm{HLD}_{\mathrm{i}}$ only if the $\mathrm{K}$ coefficient is the same for all the surfactants used, which is not always true in particular in a mixture of ionics with different Ks in front of $\mathrm{ACN}$, and for ionic/nonionic mixtures where the definitions of $\mathrm{K}$ are different. To avoid this problem, it is absolutely necessary to use the normalized $H L D_{N}$ for such mixtures, and thus the surfactant contribution parameter SCP with the same coefficient as the real or virtual scan variable, i.e., $\mathrm{SCP}=\mathrm{N}_{\mathrm{MIN}}, \sigma / \mathrm{K}, \beta / \mathrm{K}, \mathrm{Cc} / \mathrm{K}, \mathrm{PIT} / \mathrm{K}$ in the first generation of equations. With the normalized $\mathrm{ACN}$ real or virtual scan, $\mathrm{SCP}=\mathrm{PACN}$ according to the $\mathrm{HLD}_{\mathrm{NMIX}}=\sum \mathrm{X}_{\mathrm{i}} \mathrm{HLD}_{\mathrm{Ni}}$

For systems in which the scan corresponds to a mixture of two or more surfactants, the linear mixing rule on the $\mathrm{HLD}_{\mathrm{N}}$ equation where the $\mathrm{ACN}$ coefficient is unity, at the same water salinity, oil ACN, temperature, pressure and same alcohol, is

$$
\operatorname{PACN}_{\mathrm{MIX}}=\sum \mathrm{X}_{\mathrm{i}} \text { PACN }_{\mathrm{i}}
$$

This relationship appears as a straight line in Figure 19a when any of the normalized $H L D_{N}$ parameter to define the surfactant contribution with the corresponding integration constant (SCP) is plotted versus the mixture composition. In many cases and because of some inaccuracy either on the SCP of each surfactant or in the exact content of each species in the mixture, some small deviation is observed, as can be seen in the case illustrated in Figure 19b.
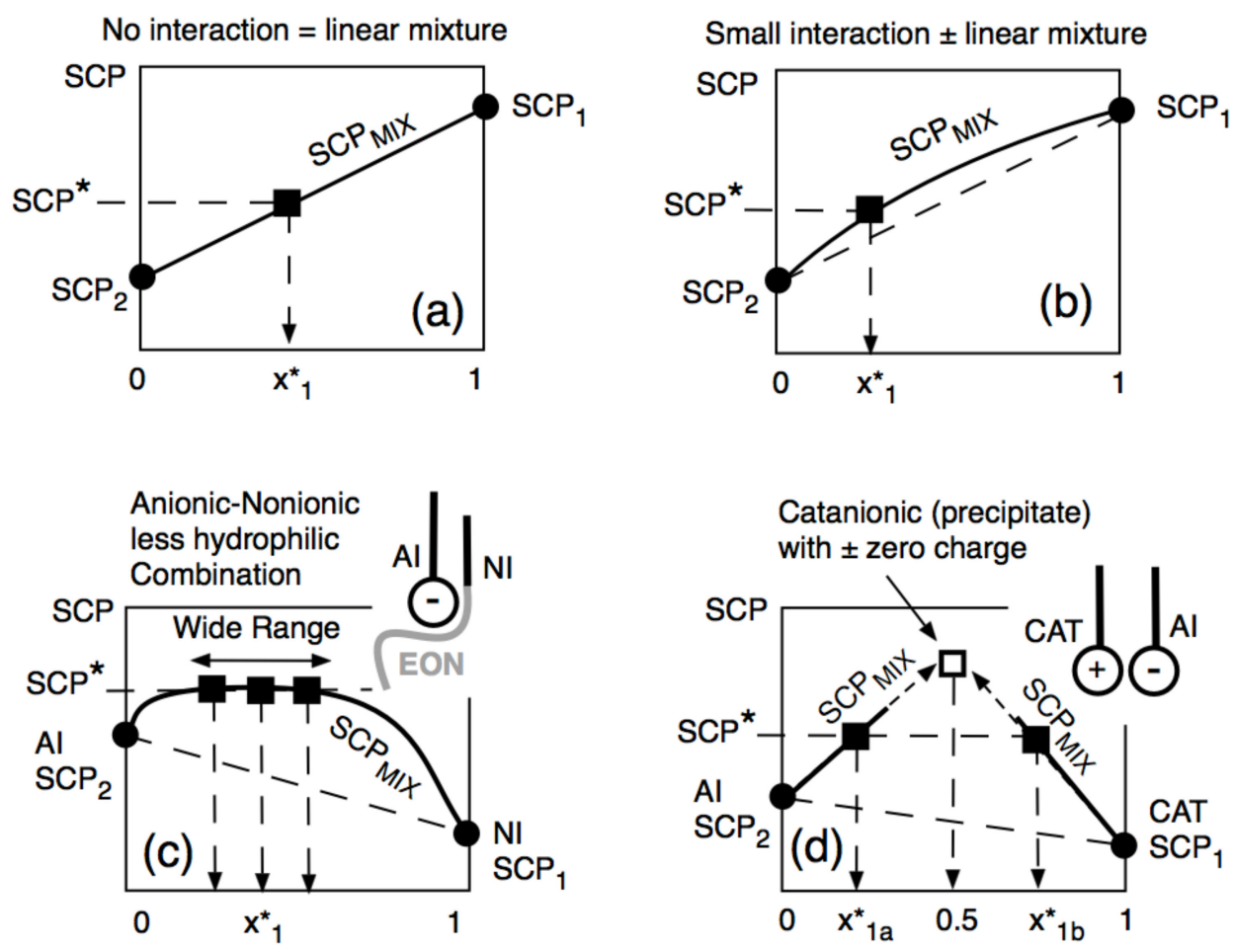

Figure 19. Variation of the surfactant contributing parameter SCP for different kinds of binary surfactant mixtures discussed in the text. (a) no interaction = linear mixture, (b) small interaction \pm linear mixture (c) anionic-nonionic $=$ less hydrophilic interaction and (d) catanionic (precipitate) with \pm zero charge.

\subsection{Problems in Surfactant Mixtures with Interactions and Partitioning of Species}

Now, there is another complication; it is a possibility of interaction between the two surfactant head groups. The linearity of the mixture is then not necessarily satisfied and an excess free energy interaction term appears, for instance as Gex/RT [110].

$$
\operatorname{HLD}_{\mathrm{NMIX}}=\sum \mathrm{X}_{\mathrm{i}} \mathrm{HLD}_{\mathrm{Ni}}+\text { interaction term }
$$


This is the case when mixing an ionic surfactant like sulfate, sulfonate or carboxylate with an ethoxylated nonionic in which the surrounding of the ionic head by the nonionic polyethoxylated chain reduces the hydrophilicity, as shown in Figure 20 inside the box, indicating the scheme of interaction [38].

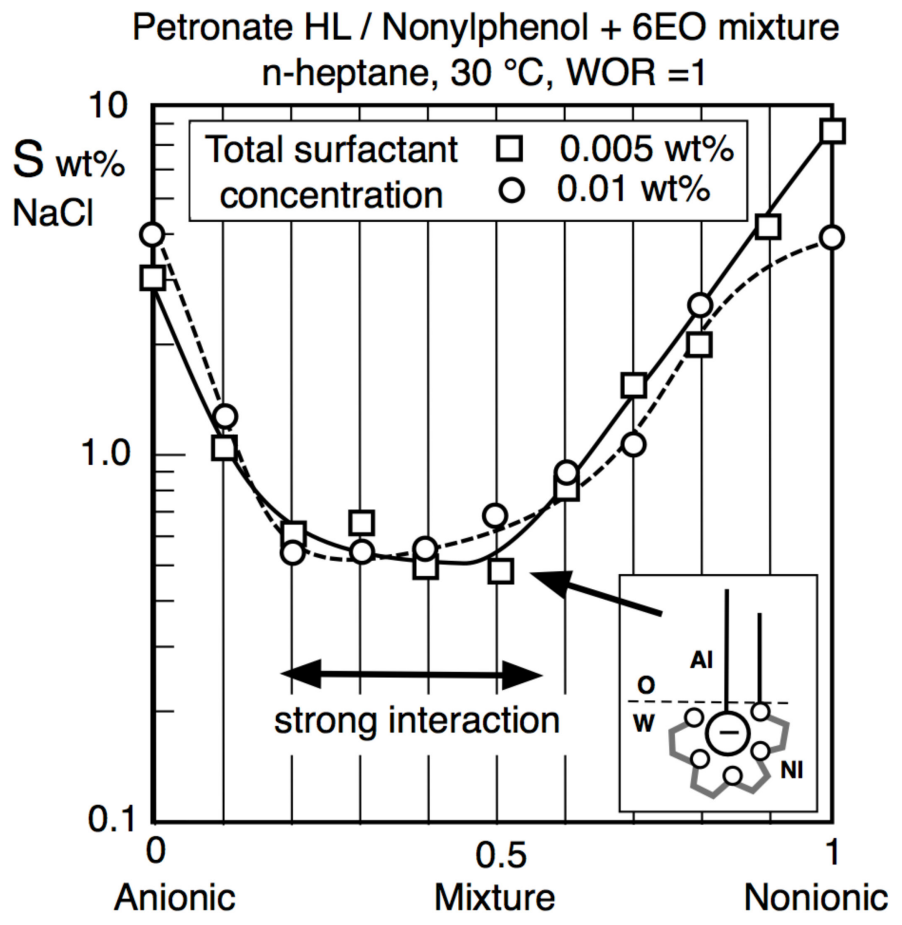

Figure 20. Salinity scan for mixtures of anionic and nonionic surfactants at very low concentration.

Figure 20 clearly shows that the two surfactants in the mixture with $0.01 \mathrm{wt} \%$ total concentration exhibit the same optimum salinity about $4 \mathrm{wt} \% \mathrm{NaCl}$ (circle points). This means that they roughly have the same behavior with an identical PACN according to the $\mathrm{HLD}_{\mathrm{N}}$ equation either for anionic or nonionic systems.

Consequently, and as shown in the first article on surfactant mixture [69], it is not surprising that the $\mathrm{LnS}^{*}\left(\right.$ or $\mathrm{S}^{*}$ ) vs mixture proportion plot does not exhibit a linear (horizontal) variation. What is surprising, though, is that for a mixture of two surfactants with an intermediate hydrophilicity, the optimum $\operatorname{LnS}^{*}$ (or $S^{*}$ ) for the mixture in the central part of the plot is much lower. This means that the mixture is much less hydrophilic than each one of its components. The small drawing showing that the polyethoxylated chain on the nonionic head goes around the anionic head explains the reduction of the interaction with the water molecules, which was called Acw in the Winsor R ratio.

What is more, the interacting surfactants result in a double tail for the more or less aggregated structure, thus in a greater Aco value. Without performing any calculation, it is then clear that the Winsor R ratio and the HLD increased for two reasons. The change in HLD cannot be easily calculated because there is no accurate HLD equation for a mixture of two interacting surfactants, since the frequently proposed simple equation [108] as $\mathrm{HLD}_{\mathrm{MIX}}=\mathrm{X}_{1} \mathrm{HLD}_{1}+\mathrm{X}_{2} \mathrm{HLD}_{2}$ is also wrong, not only because the Gex/RT interaction is missing, but also because in general the HLD $\mathrm{H}_{1}$ and $\mathrm{HLD}_{2}$ equations do not have the same scales because of different Ks. In other words, it is like calculating an average between a temperature of $20^{\circ} \mathrm{C}$ and another one of $60^{\circ} \mathrm{F}$, which is not $40^{\circ}$ in some intermediate degree scale.

This is why there are some errors when comparing the surfactants parameters by using the $\alpha, \beta$ or Cc terms based on the original LnS or EON scans and their mixtures. As a consequence, some information, divulged recently by surfactant companies in order to help their customers [82], 
results in erroneous data for formulating systems that require extreme precision. It is a pity because the extra effort of the manufacturers can be wasted instead of allowing fair comparisons.

It is thus important for academic and industrial researchers to rectify this easy-to-correct confusion. The same kind of mixing rule with ACN actual or virtual scan having the same scale, i.e., with the normalized hydrophilic-lipophilic deviation expression, must then to be applied instead, as expressed below for a linear mixture:

$$
\operatorname{HLD}_{\mathrm{NMIX}}=\mathrm{X}_{1} \mathrm{HLD}_{\mathrm{N} 1}+\mathrm{X}_{2} \mathrm{HLD}_{\mathrm{N} 2}
$$

However, Figure 20 clearly shows, that in some cases there is a very important Gex/RT free energy of interaction to be added, but its calculation would require a scan different from salinity, which should be constant so that $S$ or $\ln S$ remain unchanged during the scan.

Although Figure 20's salinity scan is not the most appropriate one to make calculations with the two $H L D_{N}$ expressions with different salinity terms, it can be said that the mixing of an anionic and nonionic surfactants definitively reduces the $\mathrm{LnS}^{*}$, i.e., it turns the mixture more lipophilic in the central region because of a specific interaction between their head groups. The salinity scan is nevertheless the easiest to carry out in this case, probably more than theoretical advantageous but unavailable in practice ACN scan. Some solution has to be found to translate a simple experiment in an equivalent simple data.

Figure 20 shows another result at very low concentration in which the optimum was accurately detected by the lowest interfacial tension and emulsion low stability. Figure 20 data indeed shows that, when passing from $0.01 \mathrm{wt} \%$ of surfactant to half of it, the optimum salinity decreases for the anionic and increases for the ethoxylated nonionic. In other words, decreasing the concentration makes the anionic at interface less hydrophilic while the opposite occurs for the nonionic [25,185-187].

It can be seen that, in the central part of the graph from $20 \%$ to $50 \%$ of nonionic, there is hardly any change with the surfactant concentration, probably because the two effects in opposite directions are compensated. In such a case, there is a wide mixing zone in which the SCP formulation property does not vary, as can be seen in Figure 19c. This is very interesting in practice because it gives robustness [39] to the use of a mixture, and it is an interesting situation if the actual mixture is not fully controlled, e.g., because of different interfacial adsorptions of the various species.

This is even more so with a mixture of anionic and cationic surfactants, where a new combined species is actually formed with $50 \%$ of each surfactant, i.e., with practically no charge and a double tail combination [188]. In such a mixture the aggregation of two molecules with opposite charges in the head tends to reduce so much the hydrophilicity that the combined "new" molecule precipitates, unless a cosurfactant is added. However, the interesting evidence illustrated in Figure 19d is that the linear mixing rule is found between either the anionic or the cationic and the 50-50 combination which does not exist in solution alone. Recent studies have been presented on this kind of mixing [189], although they do not provide new information with respect to the innovative research presented 25 years ago [188].

The interaction between two surfactants can also be a means to change another property, for instance the optimum temperature introduced as the phase inversion temperature (PIT) of anionic/nonionic mixtures [190]. When the proportion of these surfactants changes their mixture can become more hydrophilic or more lipophilic, and there is a specific one which could be insensitive to temperature, a situation which is important in practice for some applications with more or less linearity effects [137,191-194].

Other cases also involve some complex mechanisms that do not warrant a simple linear mixing rules, like the effect of the $\mathrm{pH}$ (i.e., a logarithmical scale variable which also often changes the salinity) or with alcohol which behaves as cosurfactant at interface or lipophilic linker in oil, and sometimes results in retrograde transition which is a non-monotonous effect [73,195].

In most cases, the surfactant mixture studies involve two species selected to be able to match an HLD $=0$ situation, i.e., one with HLD $>0$ and another with HLD $<0$. However, it has been shown [39] that a mixture with three surfactants makes it possible to complement the HLD $=0$ attainment with 
an improved performance. It is more complex but it provides more flexibility with a surfactant to be efficient in lowering tension or increasing solubilization (like an expensive but efficient extended surfactant), another one which is cheap to reach the appropriate Cs like a branched anionic olefin sulfonate, and a third one, such as a nonionic, which helps to control salinity and temperature effects imposed by the system [38].

Because most commercial surfactants are mixtures, there is a systematic effect on the partitioning of the different species in the three phases at optimum WIII behavior type, i.e., in the interfacial layer which is what corresponds to the middle phase microemulsion and in the excess oil and water phases.

The partitioning of species has to do with a ratio of concentrations, i.e., $\mathrm{Co} / \mathrm{Cw}$, and it depends on the surfactant total amount Cs and of the water-to-oil ratio WOR. The calculation of the partitioning in complex systems, in particular with commercial ethoxylated nonionics with many oligomers has been explained with a pseudophase model [196-198] and measured in details [196,197] in several cases, with some trends clearly defined but with difficulties to perform an exact calculation for real commercial systems, including mixtures of ionics and nonionics.

Back in 1977, basic studies [25,26] showed that in most cases the anionic surfactants tend to partition more in water as their concentration (Cs) decreases; thus their interfacial mixture thus becomes more lipophilic and their PACN increases as Cs decreases. This means that, if all the species have the same head, their average tail length increases at interface when their global Cs decreases.

The opposite was found to happen with ethoxylated nonionic surfactant. When their overall concentration decreases, the less ethoxylated species tends to partition more to oil; their interfacial mixture thus becomes more hydrophilic and their PACN decreases. In other words, if the other formulation variables are the same, and with the same tail, their average EON at interface tends to increase.

Since a change in water and oil amounts in the system will produce a change in partitioning of the different species, a change in WOR will also result in the same phenomenon. With more oil (decrease in WOR) with nonionics there is more partitioning of the most hydrophobic species to oil and thus more hydrophilic species at interface with a decrease in PACN.

With anionic surfactants when more water is included (increase of WOR), there is more partitioning of the hydrophilic species in the water phase, hence more lipophilic species at interface and the PACN increases.

These effects that result from a change in Cs and WOR produce some variation in optimum formulation PACN with the surfactant concentration and with WOR, as well as some twisting of the HLD vs Cs fish diagram and the HLD-WOR with the middle line of the WIII zone somehow slanted.

Figure 21 shows the variation of the position of the interfacial tension minimum (as optimum salinity $S^{*}$ ) versus surfactant concentration for both types of surfactants. i.e., a commercial petroleum sulfonate and an ethoxylated nonyl phenol. The variation of the surfactant concentration is higher than that of the case illustrated in Figure 20, i.e., it represents a reduction of Cs by 10 at a low concentration $(0.01 \mathrm{wt} \%)$ where the effect is more visible.

It can be seen that, for the anionic surfactant, the optimum salinity $\mathrm{S}^{*}$ diminishes from $4.2 \%$ to $3 \%$, thus $\Delta \ln S^{*}=-0.31$, while for the nonionic the optimum salinity $S^{*}$ increases from $4.0 \%$ to $8.5 \%$, with a $\Delta S^{*}=4.5$. When these values are used to calculate the equivalent change $\Delta H L D_{N}$ for both equations, it is found that the $\triangle \mathrm{PACN}$ produced by reducing the Cs from $0.01 \%$ to $0.001 \%$ is -3.8 for the nonionic which becomes more hydrophilic and +1.9 for the anionic, which becomes more lipophilic. If the proper calculation is carried out to find out what is the mixture that would produce a compensation of the two effects to avoid the change in PACN with the change in Cs, it is found that it is $35 \%$ of the nonionic.

A close look at Figure 20, which is for the same system, confirms that it is just around 30-40\% of nonionic, and that there is hardly any variation of the optimum formulation, both versus the mixture composition and versus the surfactant concentration. 


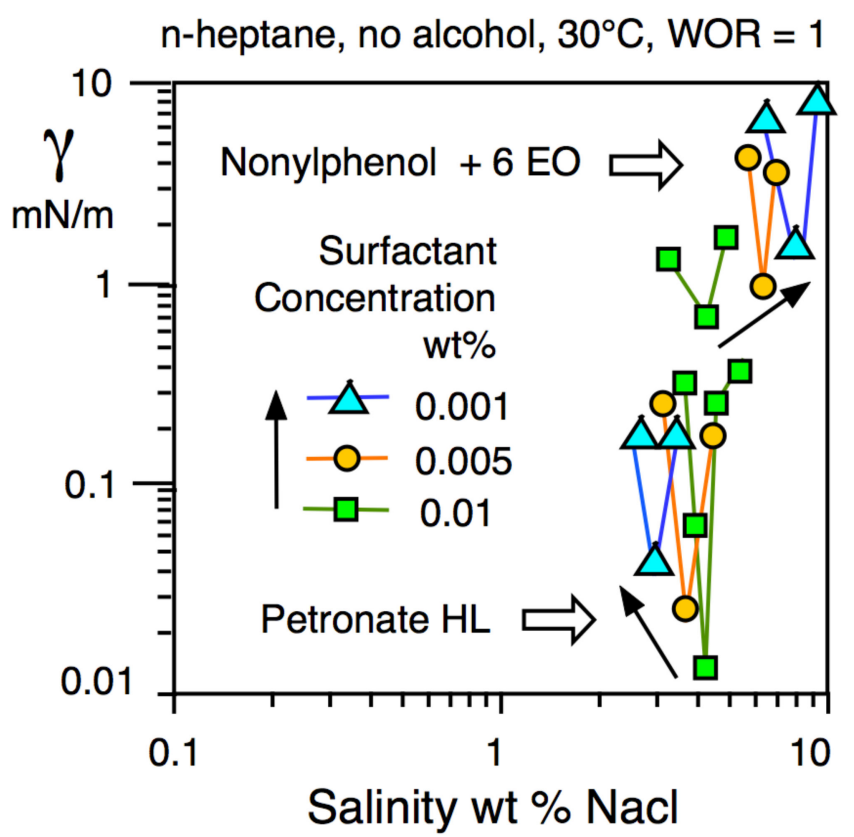

Figure 21. Variation of optimum salinity versus surfactant concentration for ionic and nonionic systems.

Thus a simple experimentation produces a result that is attractive in practice to find a robust formulation as in the case illustrated in Figure 19c, not only because the formulation can vary (e.g., the temperature change when a cream is placed on the skin), but also when the surfactant concentration diminishes (because of adsorption) or increases with the WOR change (because of evaporation of the water). It is worth noting that this nonlinear association tends to increase the SCP or PACN, i.e., to make the mixture more lipophilic $[187,196,197]$.

The fact that this distortion due to a change in Cs or WOR disappears with extremely pure surfactants (and oil) [50] is easy to understand qualitatively, but it cannot be used in real practice because it is costly. A modeling of the nonlinearity effect is also important for understanding the results in simple cases, but not for practical situations in which there are many more than two surfactants and two oils.

As a consequence, it is necessary to use the know-how related to the Cs and WOR effects on interfacial $\mathrm{HLD}_{\mathrm{N}}$ but it is useless to make some theoretical predictions, and it is much simpler to carry out a few appropriate experiments.

Kunieda showed that, with a mixture of two different surfactants, a hydrophilic one and a lipophilic one, the transformation of Winsor SOW bidimensional diagram in a $\mathrm{S}_{1} \mathrm{~S}_{2} \mathrm{OW}$ tridimensional diagram explains the effect of $\mathrm{Cs}$ and WOR resulting in a variation of interfacial partitioning. It actually shows that the HLD $=0$ plane is slanted inside the 3D pyramid [142,198].

It is worthwhile mentioning that the nonlinearity of a mixture effect is not necessarily an inconvenience, since it could be used in cases in which a mixture change can take place in certain applications. For instances spreading a cream on the skin would in general result in a change in temperature, and thus of formulation with the corresponding effect, in particular in emulsion property. As a product is applied on the skin, the adsorption of some substances would result in a change in surfactant concentration at the oil/water drop interface, thus to interfacial formulation.

Another change that would happen spontaneously is the evaporation of the water phase, thus causing a change in WOR, as well as in surfactant overall concentration. All these naturally occurring changes are likely to alter the $\mathrm{HLD}_{\mathrm{N}}$ and, as a consequence, the phase behavior and the emulsion properties. Even if this means that things are extremely complex, it also means that some expertise about the effects of the spontaneously formulation changes would make it possible to successfully solve problems. 
The same happens when an emulsion is formed in a way to provide specific properties by using a dynamic process passing quickly or slowly in some zones in Figures 16 and 17's maps, in particular when crossing the inversion horizontal line at HLD 0 [152,158,166,199], or the vertical branches by changing the WOR $[3,200]$. It has been recently shown that some tricky results may be obtained by crossing just at the corner of the inversion to take advantage of both cases, and additionally to the hysteresis feature, which is addressed elsewhere.

An even more complex process could be produced by crossing several times the inversion line by adding oil or water because of a distortion on the inversion line, as can be seen in some publications, which are not easy to follow [164].

\section{Conclusions}

In a real system formulation problem, the typical formulation variables (i.e., S, ACN, SCP, f(A), $\mathrm{T}$ and $\mathrm{P}$ ) must be dealt with to attain a single-phase microemulsion or a macro- and nanoemulsion for pharmaceutical and cosmetic vehicles with the desired properties of emulsion type, stability, viscosity, dispersion size, etc. [61,63].

Since the nature of oil and brine and their complex composition could result in considerable changes in the description parameters for SCP, EACN and S at interface, the $\mathrm{HLD}_{\mathrm{N}}$ formula with three or four variables must be handled numerically, avoiding the purely empirical trial and error methods that would cost time and money.

Consequently, a thorough understanding of how to attain the required $\mathrm{HLD}_{\mathrm{N}}$ formulation is necessary to assimilate the basic practical know-how presented here. Then, and after several years of learning more and of improving practice, the next levels of expertise would allow the researcher to solve problems after conducting a few experiments only, a striking result when it is known that over a dozen of variables must quite frequently be tested.

Several practical chapters, more advanced and more exhaustive than the present review, have been published. Some of them are mentioned here $[3,32,34,60,62,63,92,105,152]$. Additionally, some advanced specific effects are divulged every week, either because of the university's desire for more publications, the journal seeking a higher impact factor, or the commercial considerations of the surfactant manufacturer. They indicate that in real SOW systems with mixtures of various surfactants, various oils, and probably various electrolytes, linear simple equations like HLD no longer describe the reality, even if the current mistakes are corrected, which is very likely to be the most urgent thing to be done with $\mathrm{HLD}_{\mathrm{N}}$.

Although they do not contain top miraculous secrets, the available findings sometimes include some tricky examples of formulation engineering, and are thus a good start in building up experience, of course after the understanding of the present review for formulation beginners in many different applications.

Funding: This review received no specific external funding.

Acknowledgments: The authors would like to thank Jean-Marie Aubry from University of Lille (France) for helpful and enlightening discussions on the confusing situation related to the different HLD definitions and to the different surfactant parameter names that appeared in the last few decades.

Conflicts of Interest: The authors declare no conflict of interest.

\section{References}

1. Rosen, M.J. Surfactants and Interfacial Phenomena, 3rd ed.; John Wiley \& Sons: Hoboken, NJ, USA, 2004. [CrossRef]

2. Rosen, M.J.; Dahanayake, M. Industrial Utilization of Surfactants. Principles and Practice; AOCS Press: Urbana, IL, USA, 2000; ISBN 893997111. 
3. Salager, J.L.; Bullon, J.; Pizzino, A.; Rondon-Gonzalez, M.; Tolosa, L. Emulsion Formulation Engineering for the Practitioner. In Encyclopedia of Surface and Colloid Science, 2nd ed.; Somasundaran, B., Ed.; Taylor \& Francis: London, UK, 2010; Volume 1, Section 1; pp. 1-6. [CrossRef]

4. Griffin, W.C. Classification of Surface Active Agents by HLB. J. Soc. Cosmet. Chem. 1949, 1, 311-326.

5. Griffin, W.C. Calculation of HLB values of nonionic surfactants. J. Soc. Cosmet. Chem. 1954, 5, $249-256$.

6. Becher, P. Hydrophilic-lipophilic balance: An updated bibliography. In Encyclopedia of Emulsion Technology; Becher, P., Ed.; Marcel Dekker: New York, NY, USA, 1985; Volume 2, Chapter 8.

7. Davies, J.T. A quantitative kinetic theory of emulsion type I: Physical chemistry of the emulsifying agent. In Gas/Liquid and Liquid/Liquid Interfaces. Proceedings of the 2nd International Congress of Surface Activity; Butterworths: London, UK, 1957; Volume 1, pp. 426-438.

8. Marszall, L. Dependence of hydrophilic-lipophilic balance of nonionic surfactants on the size of the molecule. Kolloid Z Z Polym. 1973, 251, 609-610. [CrossRef]

9. Balson, T.G. HLB: Is it a valuable concept or a curiosity? In Industrial Applications of Surfactants IV; Karsa, D.R., Ed.; Royal Society of Chemistry: London, UK, 1999; pp. 175-192.

10. Ontiveros, J.F.; Pierlot, C.; Catte, M.; Molinier, V.; Salager, J.L.; Aubry, J.M. A simple method to assess the hydrophilic lipophilic balance of food and cosmetic surfactants using the phase inversion temperature of C10E4/n-octane/water emulsions. Colloids Surf. A 2014, 458, 32-39. [CrossRef]

11. Salager, J.L. Quantifying the concept of physico-chemical formulation in surfactant-oil-water systems. Progr. Colloid Polym. Sci. 1996, 100, 137-142. [CrossRef]

12. Salager, J.L. Formulation concepts for the emulsion makers. In Pharmaceutial Emulsions and Suspensionfs; Nielloud, F., Marti-Mestres, G., Eds.; Marcel Dekker: New York, NY, USA, 2000; Chapter 2; pp. $19-72$. [CrossRef]

13. Salager, J.L. Emulsion properties and related know-how to attain them. In Pharmaceutial Emulsions and Suspensionfs; Nielloud, F., Marti-Mestres, G., Eds.; Marcel Dekker: New York, NY, USA, 2000; Chapter 3; pp. 73-125. [CrossRef]

14. Bancroft, W.D. The Theory of Emusification VI. J. Phys. Chem. 1915, 19, 275-309. [CrossRef]

15. Langmuir, I. The constitution and fundamental properties of solids and liquids. J. Am. Chem. Soc. 1917, 39, 1848-1906. [CrossRef]

16. Winsor, P. Solvent Properties of Amphiphilic Compounds; Butterworth: London, UK, 1954.

17. Winsor, P. Binary and multicomponent Solutions of amphiphilic compounds. solubilization and the formation, structure, and theoretical significance of liquid crystalline solutions. Chem. Rev. 1968, 68, 1-40. [CrossRef]

18. Holtzscherer, C.; Candau, F. Application of the cohesive energy ratio concept (CER) to the formation of polymerizable microemulsions. Colloids Surf. 1988, 29, 411-423. [CrossRef]

19. Hansen, C. The Three Dimensional Solubility Parameter-Key to Paint Component Affinities: I.; Solvents, Plasticizers, Polymer, and Resins. J. Paint Technol. 1967, 39, 104-117.

20. Israelavilich, J.N. The science and applications of emulsions-An overview. Colloids Surf. A 1994, 91, 1-8. [CrossRef]

21. Shinoda, K.; Arai, H. The correlation between phase inversion temperature in emulsion and cloud point in solution of nonionic emulsifier. J. Phys. Chem. 1964, 68, 3485-3490. [CrossRef]

22. Shinoda, K.; Arai, H. The effect of phase volume on the phase inversion temperature of the emulsions stabilized by nonionic surfactants. J. Colloid Interface Sci. 1967, 25, 429-431. [CrossRef]

23. Shinoda, K.; Kunieda, H. Conditions to produce so-called microemulsions: Factors To increase the mutual solubility of oil and water by solubilizer. J. Colloid Interface Sci. 1973, 42, 381-387. [CrossRef]

24. Reed, R.L.; Healy, R.N. Some physicochemical aspects of microemulsion flooding-A review. In Improved Oil Recovery by Surfactant and Polymer Flooding; Shah, D.O., Schechter, R.S., Eds.; Academic Press: New York, NY, USA, 1977; pp. 347-383.

25. Wade, W.H.; Schechter, R.S.; Morgan, J.C.; Jacobson, J.K.; Salager, J.L. Interfacial tension and Phase Behavior of Surfactant Systems. Paper SPE 6844 presented in Proceedings 52nd Fall Meeting Society of Petroleum Engineering, Denver (1977). Soc. Petroleum Eng. J. 1978, 18, 242-252. [CrossRef]

26. Salager, J.L. Physico-Chemical Properties of Surfactant-Water-Oil Mixtures: Phase Behavior, Microemulsion Formation and Interfacial Tension. Ph.D. Thesis, University of Texas, Austin, TX, USA, 24 December 1977.

27. Salager, J.L.; Morgan, J.; Schechter, R.S.; Wade, W.H.; Vasquez, E. Optimum formulation of surfactant-oil-water systems for minimum tension and phase behavior. Soc. Pet. Eng. J. 1979, 19, 107-115. [CrossRef] 
28. Bourrel, M.; Salager, J.L.; Schechter, R.S.; Wade, W.H. A correlation for phase behavior of nonionic surfactants. J. Colloid Interface Sci. 1980, 75, 451-461. [CrossRef]

29. Salager, J.L.; Miñana-Perez, M.; Perez-Sanchez, M.; Ramirez-Gouveia, M.; Rojas, C. Surfactant-Oil-Water systems near the affinity inversion-Part III: The two kinds of emulsion inversion. J. Dispers. Sci. Technol. 1983, 4, 313-329. [CrossRef]

30. Salager, J.L.; Marquez, N.; Graciaa, A.; Lachaise, J. Partitioning of ethoxylated octylphenol surfactants in microemulsion-oil-water systems: Influence of temperature and relation between partitioning coefficient and physicochemical formulation. Langmuir 2000, 16, 5534-5539. [CrossRef]

31. Shinoda, K.; Kunieda, H. Phase properties of emulsions: PIT and HLB. In Encyclopedia of Emulsion Technology; Basic Theory; Becher, P., Ed.; Marcel Dekker: New York, NY, USA, 1983; Volume 1, pp. 337-367.

32. Bourrel, M.; Schechter, R.S. Microemulsions and Related Systems: Formulation, Solvency, and Physical Properties; Marcel Dekker: New York, NY, USA, 1988.

33. Kunieda, H.; Solans, C. How to prepare microemulsions: Temperature insensitive microemulsions. In Industrial Applications of Microemulsions; Marcel Dekker: New York, NY, USA, 1997; ISBN 9780824797959.

34. Stubenrauch, C. (Ed.) Microemulsions: Background, New Concepts, Applications and Perspectives; Wiley-Blackwell: Oxford, UK, 2009. [CrossRef]

35. Shinoda, K.; Lindman, B. Organized surfactant systems: Microemulsions. Langmuir 1989, 3, 135-149. [CrossRef]

36. Salager, J.L.; Forgiarini, A.; Bullon, J. How to attain ultralow interfacial tension and three-phase behavior with surfactant formulation for enhanced oil recovery: A review. Part 1. Optimum formulation for simple surfactant-oil-water ternary systems. J. Surfactants Deterg. 2013, 16, 449-472. [CrossRef]

37. Salager, J.L.; Forgiarini, A.; Marquez, L.; Manchego, L.; Bullon, J. How to attain ultralow interfacial tension and three-phase behavior with surfactant formulation for enhanced oil recovery: A review. Part 2. Performance improvement trends from Winsor's premise to currently proposed inter- and intramolecular mixtures. J. Surfactants Deterg. 2013, 16, 631-663. [CrossRef]

38. Salager, J.L.; Forgiarini, A.; Rondon, M. How to attain ultralow interfacial tension and three-phase behavior with surfactant formulation for enhanced oil recovery: A review. Part 3. Practical procedures to optimize the laboratory research according to the current state of the art in surfactant mixing. J. Surfactants Deterg. 2017, 20, 3-19. [CrossRef]

39. Salager, J.L.; Anton, R.E.; Arandia, M.A.; Forgiarini, A. How to attain ultralow interfacial tension and three-phase behavior with surfactant formulation for enhanced oil recovery: A review. Part 4. Robustness of optimum formulation zone through the insensibility to some variables and the occurrence of complex artifacts. J. Surfactants Deterg. 2017, 20, 987-1018. [CrossRef]

40. Winsor, P. Hydrotropy, solubilization and related emulsification processs. Trans. Faraday Soc. 1948, 44, 376-382. [CrossRef]

41. Hoar, T.P.; Schulman, J.H. Transparent water-in-oil dispersions: Oleopathic hydromicelle. Nature 1943, 182, 102-103. [CrossRef]

42. Schulman, J.H.; Stoeckenius, W.; Prince, L.M. Mechanism of formation and structure of microemulsions by electron microscopy. J. Phys. Chem. 1959, 63, 1677-1680. [CrossRef]

43. Scriven, L.E. Equilibrium bicontinuous structures. Nature 1976, 263, 123-125. [CrossRef]

44. Clausse, M.; Peyrelasse, J.; Heil, J.; Boned, C.; Lagourette, B. Bicontinuous structure zones in microemulsions. Nature 1981, 293, 636-638. [CrossRef]

45. Bourrel, M.; Verzaro, F.; Chambu, C. Effect of oil type on solubilization by amphiphiles. Soc. Pet. Eng. Reserv. Eng. 1987, 2, 41-53. [CrossRef]

46. Kahlweit, M.; Strey, R. Phase Behavior of ternary systems of the type H20-oil-nonionic amphiphile microemulsions. Angew. Chem. Intern. Ed. Engl. 1988, 24, 654-668. [CrossRef]

47. Kahlweit, M.; Strey, R.; Firman, P. Search for Tricritical points in ternary systems: Water-Oil-Nonionic amphiphile. J. Phys. Chem. 1986, 90, 671-677. [CrossRef]

48. Lade, O.; Beizai, K.; Sottmann, T.; Strey, R. Polymerizable nonionic microemulsions: Phase Behavior of $\mathrm{H} 2 \mathrm{O}-n$-alkyl methacrylate-n-alkyl polyethylene glycol ether (CiEj). Langmuir 2000, 16, 4122-4130. [CrossRef]

49. Lee, J.M.; Lim, K.H. Changes in two-phase emulsion morphology in temperature-amphiphile concentration or fish diagram for ternary amphiphile/oil/water systems. J. Colloid Interface Sci. 2005, 290, 241-249. [CrossRef] [PubMed] 
50. Pizzino, A.; Molinier, V.; Catte, M.; Salager, J.L.; Aubry, J.M. Bidimensional analysis of the phase behavior of a well-defined surfactant (C10E4)/oil (n-Octane)/water-temperature system. J. Phys. Chem. B 2009, 113, 16142-16150. [CrossRef] [PubMed]

51. Pizzino, A.; Molinier, V.; Catte, M.; Ontiveros, J.F.; Salager, J.L.; Aubry, J.M. Relationship between phase behavior and emulsion inversion for a well-defined surfactant (C10E4)/n-octane/water ternary system at different temperatures and water/oil ratios. Ind. Eng. Chem. Res. 2013, 52, 4527-4538. [CrossRef]

52. Burauer, S.; Sachert, T.; Sottmann, T.; Strey, R. On microemulsion phase behavior and the monomeric solubility of surfactant. Phys. Chem. Chem. Phys. 1999, 1, 4299-4306. [CrossRef]

53. Solans, C.; Kunieda, H. (Eds.) Industrial Applications of Microemulsions; Marcel Dekker: New York, NY, USA, 1997.

54. Kahlweit, M.; Lessner, E.; Strey, R. Phase behavior of quaternary systems of the type $\mathrm{H}_{2} \mathrm{O}$-oil-nonionic surfactant inorganic electrolyte. J. Phys. Chem. 1984, 88, 1937-1944. [CrossRef]

55. Strey, R. Microemulsion microstructure and interfacial curvature. Colloid Polym. Sci. 1994, 272, $1005-1019$. [CrossRef]

56. Graciaa, A.; Fortney, L.N.; Schechter, R.S.; Wade, W.H.; Yiv, S. Criteria for structuring surfactants to maximize solubilization of oil and water: Part 1-Commercial nonionics. Soc. Pet. Eng. J. 1982, 22, 743-749. [CrossRef]

57. Barakat, Y.; Fortney, L.; Schechter, R.S.; Wade, W.H.; Yiv, S.H.; Graciaa, A. Criteria for structuring surfactants to maximize solubilization of oil and water. II. Alkyl benzene sodium sulfonates. J. Colloid Interface Sci. 1983, 92, 561-574. [CrossRef]

58. Barakat, Y.; Fortney, L.; Schechter, R.S.; Wade, W.H. Alpha-Olefin sulfonates for oil recovery. In Proceedings of the 2nd European Symposium on Enhanced Oil Recovery, Paris, France, 8-10 November 1982.

59. Huh, C. Interfacial tensions and solubilizing ability of a microemulsion phase that coexists with oil and brine. J. Colloid Interface Sci. 1979, 71, 408-426. [CrossRef]

60. Salager, J.L.; Manchego, L.; Marquez, L.; Bullón, J.; Forgiarini, A. Trends to attain a lower interfacial tension in a revisited pure alkyl polyethyleneglycol surfactant-alkane-water ternary system. Basic concepts and straightforward guidelines for improving performance in enhanced oil recovery formulations. J. Surf. Deterg. 2014, 17, 199-213. [CrossRef]

61. Salager, J.L.; Forgiarini, A.; Bullón, J. Surfactant formulation guidelines to reach an ultralow interfacial tension for enhanced oil recovery. In Topics in Colloidal Aggregation and Interfacial Phenomena; Garcia-Sucre, M., Lozsan, A., Castellanos-Suarez, A., Toro-Mendoza, J., Eds.; Research Signpost: Kerala, India, 2012; Chapter 5; pp. 125-160. ISBN 9788130804910.

62. Salager, J.L.; Marquez, L.; Mira, I.; Peña, A.; Tyrode, E.; Zambrano, N. Principles of emulsion formulation engineering. In Adsorption and Aggregation of Surfactants in Solution; Surfactant Science Series; Mittal, K.L., Shah, D.O., Eds.; Marcel Dekker: New York, NY, USA, 2003; Volume 109, Chapter 24; pp. 501-524. [CrossRef]

63. Salager, J.L.; Forgiarini, A.M.; Bullón, J. Progress over a century of designing emulsion properties—Emerging phenomenological guidelines from generalized formulation and prospects to transmute the knowledge into know-how. In Surfactant Science and Technology: Retrospects and Prospects; Romsted, L.S., Ed.; CRC Press: Boca Raton, FL, USA, 2014; Chapter 18; pp. 459-487. [CrossRef]

64. Marquez, R.; Forgiarini, A.; Fernandez, J.; Langevin, D.; Salager, J.L. New interfacial rheology characteristics measured using a spinning-drop rheometer at the optimum formulation of a simple surfactant-oil-water system. J. Surf. Deterg. 2018, 21, 611-623. [CrossRef]

65. Marquez, R.; Forgiarini, A.; Langevin, D.; Salager, J.L. Instability of emulsions made with surfactant-oil-water systems at optimum formulation with ultralow interfacial tension. Langmuir 2018, 34, 9252-9263. [CrossRef]

66. Marquez, R.; Anton, R.E.; Vejar, F.; Salager, J.L.; Forgiarini, A. New Interfacial Rheology Characteristics Measured using a Spinning Drop Rheometer at the Optimum Formulation. Part 2. Surfactant-Oil-Water systems with a high volume of middle phase microemulsion. J. Surf. Deterg. 2019, 22, 177-188. [CrossRef]

67. Cash, L.; Cayias, J.L.; Fournier, G.; MacAllister, D.; Shares, T.; Schechter, R.S.; Wade, W.H. The application of low interfacial tension scaling rules to binary hydrocarbon mixtures. J. Colloid Interface Sci. 1977, 59, 39-44. [CrossRef]

68. Salager, J.L.; Anton, R.E.; Anderez, J.M.; Aubry, J.M. Formulation des micro-émulsions par la méthode HLD. Tech. Ing. Vol. Génie Procédés 2001, 157, 1-20.

69. Salager, J.L.; Bourrel, M.; Schechter, R.S.; Wade, W.H. Mixing rules for optimum phase-behavior formulations of surfactant/oil/water systems. Soc. Pet. Eng. J. 1979, 19, 271-278. [CrossRef] 
70. Quintero, L.; Jones, T.A.; Clark, D.E.; Gabrysch, A.D.; Forgiarini, A.; Salager, J.L. Single Phase Microemulsions And in Situ Microemulsions for Cleaning Formation Damage. U.S. Patent 8,091,646 B2, 10 January 2012.

71. Delgado-Linares, J.G.; Pereira, J.; Rondón, M.; Bullón, J.; Salager, J.L. Breaking of water-in-crude oil emulsions. 6. Estimating the demulsifier performance at optimum formulation from both the required dose and the attained instability. Energy Fuels 2016, 30, 5483-5491. [CrossRef]

72. Delgado, J.G.; Alvarado, J.G.; Vejar, F.; Forgiarini, A.; Bullón, J.; Salager, J.-L. Breaking of water-in-crude oil emulsions. 7. Demulsifier performance at optimum formulation for various extended surfactant structures. Energy Fuels 2016, 30, 7065-7073. [CrossRef]

73. Anton, R.E.; Anderez, J.M.; Bracho, C.; Vejar, F.; Salager, J.L. Practical surfactant mixing rules based on the attainment of microemulsion-oill-water three-phase behavior systems. In Interfacial Processes and Molecular Aggregation; Narayanan, R., Ed.; Springer: Berlin/Heidelberg, Germany, 2008; Volume 218, pp. 83-113. [CrossRef]

74. Bourrel, M.; Salager, J.L.; Schechter, J.L.; Wade, W.H. Properties of amphiphile oil-water systems at optimum formulation for phase behavior. In Proceedings of the 53rd Annual Fall Technical Conference Society Petroleum Engieneers, Preprints Paper SPE 7450, Houston, TX, USA, 1-3 October 1978. [CrossRef]

75. Anton, R.E.; Salager, J.L. Effect of the electrolyte anion on the salinity contribution formulation of anionic surfactant microemulsions. J. Colloid Interface Sci. 1990, 1540, 75-81. [CrossRef]

76. Witthayapanyanon, A.; Acosta, E.; Harwell, J.H.; Sabatini, D.A. Formulation of ultralow interfacial tension systems using extended surfactants. J. Surf. Deterg. 2006, 9, 331-339. [CrossRef]

77. Salager, J.L.; Anton, R.E.; Sabatini, D.A.; Harwell, J.H.; Acosta, E.; Tolosa, L.I. Enhancing solubilization in microemulsion-State of the art and current trends. J. Surf. Deterg. 2005, 8, 3-21. [CrossRef]

78. Witthayapanyanon, A.; Harwell, J.H.; Sabatini, D.A. Hydrophilic-Lipophilic deviation (HLD) method for characterizing conventional and extended surfactants. J. Colloid Interface Sci. 2008, 325, 259-266. [CrossRef]

79. Solairaj, S.; Britton, C.; Lu, J.; Kim, D.H.; Weerasooriya, U.; Pope, G. New correlation to predict the optimum surfactant structure for EOR. Paper SPE 154262. In Proceedings of the 18th SPE Improved Oil Recovery Symposium, Tulsa, OK, USA, 14-18 April 2012. [CrossRef]

80. Bourrel, M.; Koukounis, C.; Schechter, R.S.; Wade, W.H. Phase and interfacial tension behavior of nonionic surfactats. J. Dispers. Sci. Technol. 1980, 1, 13-35. [CrossRef]

81. Anton, R.E.; Garces, N.; Yajure, A. A correlation for three-phase behavior of cationic surfactant-oil-water systems. J. Dispers. Sci. Technol. 1997, 18, 539-555. [CrossRef]

82. Nguyen, T.T.; Morgan, C.; Poindexter, L.; Fernandez, J. Application of the Hydrophilic-Lipophilic Deviation concept to surfactant characterization and surfactant selection for enhanced oil recovery. J. Surf. Deterg. 2019, 22, 983-999. [CrossRef]

83. Torrealba, V.A.; Johns, R.T. Partition coefficient relations in surfactant-oil-brine systems for improved description of microemulsion phase behavior. In Proceedings of the SPE EOR Conference at Oil and Gas West Asia, Muscat, Oman, 26-28 March 2016. [CrossRef]

84. Torrealba, V.; Johns, R. Coupled interfacial tension and phase behavior model based on micellar curvatures. Langmuir 2017, 33, 13603-13614. [CrossRef]

85. Miñana-Perez, M.; Graciaa, A.; Lachaise, J.; Salager, J.L. Solubilization of polar oils in microemulsion systems. Progr. Colloid Polym. Sci. 1995, 98, 177-179. [CrossRef]

86. Hammond, C.; Acosta, E.; Jakobs-Sauter, B. Effect of hydrocarbon branching on the packing of extended surfactants at oil-water interfaces. In Proceedings of the 5th World Congress on Emulsion, Lyon, France, 12-14 October 2010.

87. Fotland, P.; Skauge, A. Ultralow interfacial tension as a function of pressure. J. Dispers. Sci. Technol. 1986, 7, 563-579. [CrossRef]

88. Skauge, A.; Fotland, P. Effect of pressure and temperature on the phase behavior of microemulsions. Soc. Pet. Reserv. Eng. 1990, 5, 601-608. [CrossRef]

89. Austad, T.; Strand, S. Chemical flooding of oil reservoir. 4. Effects of temperature and pressure on the middle phase solubilization parameters close to optimum flood conditions. Colloid Surf. A 1996, 108, $243-252$. [CrossRef]

90. Ghosh, S.; Johns, R.T. An equation-of-state model to predict surfactant/oil/brine-phase behavior. Soc. Pet. Eng. J. 2016, 21, 1106-1125. [CrossRef] 
91. Chailloux, N.; Nardello-Rataj, V.; Salager, J.L.; Aubry, J.M. Propriétés amphiphiles des tensioactifs de la famille du monolaurate de polyglycérol et application à la préparation de microémulsions à base d'esters gras. Ol. Corps Gras Lipides 2003, 10, 382-386. [CrossRef]

92. Salager, J.L.; Forgiarini, A.; Marquez, R. Extended surfactants including an alkoxylated central part intermediate producing a gradual polarity transition-A review of the properties used in applications such as enhanced oil recovery and polar oil solubilization in microemulsions. J. Surfactants Deterg. 2019, 22, 935-972. [CrossRef]

93. Miñana-Pérez, M.; Graciaa, A.; Lachaise, J.; Salager, J.L. Solubilization of polar oils with extended surfactants. Colloids Surf. A 1995, 100, 217-224. [CrossRef]

94. Aoudia, M.; Wade, W.H.; Weerasooriya, V. Optimum microemulsions formulated with propoxylated Guerbet alcohol and propoxylated tridecyl alcohol sodium sulfates. J. Dispers. Sci. Technol. 1995, 16, 115-135. [CrossRef]

95. Charoensaeng, A.; Sabatini, D.A.; Khaodhiar, S. Solubilization and adsolubilization of polar and nonpolar organic solutes by linker molecules and extended surfactants. J. Surfactants Deterg. 2009, 12, $209-217$. [CrossRef]

96. Velasquez, J.; Scorzza, C.; Vejar, F.; Forgiarini, A.; Anton, R.E.; Salager, J.L. Effect of the temperature and other variables on the optimum formulation of anionic extended surfactants-alkane-brine systems. J. Surfactants Deterg. 2010, 13, 69-73. [CrossRef]

97. Forgiarini, A.M.; Scorzza, C.; Velasquez, J.; Vejar, F.; Zambrano, E.; Salager, J.-L. Influence of the mixed propoxy/ethoxy spacer arrangement order and of the ionic head group nature on the adsorption and aggregation of extended surfactants. J. Surfactants Deterg. 2010, 13, 451-458. [CrossRef]

98. Klaus, A.; Tiddy, G.J.T.; Rachel, R.; Trinh, A.P.; Maurer, E.; Touraud, D.; Kunz, W. Hydrotrope-Induced inversion of salt effects on the cloud point of an extended surfactant. Langmuir 2011, 27, 4403-4411. [CrossRef] [PubMed]

99. Zarate, S.; Troncoso, A.B.; Acosta, E. The cloud point of alkyl ethoxylates and its prediction with the hydrophilic-lipophilic difference (HLD) framework. Langmuir 2015, 31, 12000-12008. [CrossRef] [PubMed]

100. Hammond, C.E.; Acosta, E. On the characteristic curvature of alkyl-polypropylene oxide sulfate extended surfactants. J. Surfactants Deterg. 2012, 15, 157-165. [CrossRef]

101. Chen, J.; Hu, X.Y.; Fang, Y.; Liu, H.H.; Xia, Y.M. Comparative study of conventional/ethoxylated/extended n-alkylsulfate surfactants. Langmuir 2019, 35, 3116-3125. [CrossRef]

102. Miñana-Perez, M.; Graciaa, A.; Lachaise, J.; Salager, J.L. Systems containing mixtures of extended surfactants and conventional nonionics. Phase behavior and solubilization in microemulsion. In Proceedings of the 4th World Surfactants Congress, Barcelona, Spain, 3-7 June 1996. Proceedings 2:226-234, Edited for AEPSAT by Roger de Llúria, Barcelona, Spain.

103. Vera, R.; Salazar, F.; Marquez, R.; Forgiarini, A. How the influence of different salts on interfacial properties of surfactant-oil-water systems at optimum formulation matches the Hofmeister series ranking. J. Surfactants Deterg. 2020, 23, 603-615. [CrossRef]

104. Kunieda, H.; Shinoda, K. Phase behavior in systems of nonionic surfactant-water-oil around the hydrophile-lipophile balance-temperature (HLB-Temperature). J. Dispers. Sci. Technol. 1982, 3, 233-244. [CrossRef]

105. Aubry, J.M.; Ontiveros, J.F.; Salager, J.L.; Nardello-Rataj, V. Use of the normalized hydrophiliclipophilic-deviation (HLDN) equation for determining the equivalent alkane carbon number (EACN) of oils and the preferred alkane carbon number (PACN) of nonionic surfactants by the fish-tail method (FTM). Adv. Colloid Interface Sci. 2020, 276, 102099. [CrossRef] [PubMed]

106. Cayias, J.L.; Schechter, R.S.; Wade, W.H. Modeling crude oils for low interfacial tension. Soc. Pet. Eng. J. 1976, 16, 351-357. [CrossRef]

107. Sottmann, T.; Strey, R. Ultralow interfacial tension in water-n-alkane-surfactant systems. J. Chem. Phys. 1997, 106, 8606-8615. [CrossRef]

108. Acosta, E.; Yuan, J.S.; Bhakta, A.S. The characteristic curvature of ionic surfactants. J. Surfactants Deterg. 2008, 11, 145-158. [CrossRef]

109. Abbott, S. Surfactant Science: Principles and Practice; Creative Commons BY-ND: Mountain View, CA, USA, 2015; ISBN 9781605954844. Available online: http://www.stevenabbott.co.uk/practical-surfactants/the-book.php (accessed on 14 July 2020). 
110. Acosta, E.; Bhakta, A.S. The HLD-NAC model for mixtures of ionic and nonionic surfactants. J. Surfactants Deterg. 2009, 12, 7-19. [CrossRef]

111. Acosta, E.; Szekeres, E.; Sabatini, D.A.; Harwell, J. Net-Average curvature model for solubilization and supersolubilization in surfactant microemulsions. Langmuir 2003, 19, 186-195. [CrossRef]

112. Hayes, M.; Bourrel, M.; El-Emary, M.; Schechter, R.S.; Wade, W.H. Interfacial tension and phase behavior of nonionic surfactants. Soc. Pet. Eng. J. 1979, 19, 349-356. [CrossRef]

113. Graciaa, A.; Lachaise, J.; Cucuphat, C.; Bourrel, M.; Salager, J.L. Interfacial segregation of an ethyl oleate/hexadecane oil mixture in microemulsion systems. Langmuir 1993, 9, 1473-1478. [CrossRef]

114. Salager, J.L.; Graciaa, A.; Lachaise, J. Improving solubilization in microemulsions with additives. 3. Lipophilic linker optimization. J. Surfactants Deterg. 1998, 1, 403-406. [CrossRef]

115. Bourrel, M.; Chambu, C. The rules for achieving high solubilization of brine and oil by amphiphilic molecules. Soc. Pet. Eng. J. 1983, 23, 327-338. [CrossRef]

116. Salager, J.L. Microemulsions. In Handbook of Detergents_Part A: Properties; Surfactant Science Series; Broze, G., Ed.; Marcel Dekker: New York, NY, USA, 1999; Volume 82, Chapter 8; pp. 253-302. [CrossRef]

117. Budhathoki, M.; Hsu, T.P.; Lohateeraparp, P.; Roberts, B.L.; Shiau, B.-J.; Harwell, J.H. Design of an optimal middle phase microemulsion for ultra high saline brine using hydrophilic lipophilic deviation (HLD) method. Colloids Surf. A 2016, 488, 36-45. [CrossRef]

118. Doe, P.H.; El-Emary, M.; Wade, W.H.; Schechter, R.S. Surfactants for producing low interfacial tensions: II. Linear alkylbenzene-sulfonates with additional alkyl substituents. J. Am. Oil Chem. Soc. 1978, 55, 505-512. [CrossRef]

119. Doe, P.H.; El-Emary, M.; Wade, W.H.; Schechter, R.S. Surfactants for producing low interfacial tensions: III. Di and tri n-alkylbenzenesulfonates. J. Am. Oil Chem. Soc. 1978, 55, 513-520. [CrossRef]

120. Doe, P.H.; El-Emary, M.; Wade, W.H. The influence of surfactant structure on low interfacial tension. In Chemistry of Oil Recovery; ACS Series 91; Johansen, R.T., Berg, R.L., Eds.; American Chemical Society: Washington, DC, USA, 1979; pp. 17-34. [CrossRef]

121. Salager, J.L.; Anton, R.E. Ionic microemulsions. In Handbook of Microemulsion Science and Technology; Kumar, P., Mittal, K.L., Eds.; Marcel Dekker: New York, NY, USA, 1999; Chapter 8; pp. 247-280, ISBN 08247-1979-4.

122. Acosta, E.; Kiran, S.; Hammond, C.E. The HLD-NAC model for extended surfactant microemulsions. J. Surfactants Deterg. 2012, 15, 495-504. [CrossRef]

123. Schechter, R.S.; Wade, W.H.; Weerasooriya, U.; Weerasooriya, V.; Yiv, S. Synthesis and performance of isomer-free secondary alkane sulfonate surfactants. J. Dispers. Sci. Technol. 1985, 6, 223-235. [CrossRef]

124. Johansson, I. Does hydrophobe branching make a surfactant more or less hydrophilic? Spec. Chem. Mag. 2004, 11, 38-40.

125. Doe, P.H.; Wade, W.H.; Schechter, R.S. Alkylbenzene sulfonates for producing low interfacial tension between hydrocarbons and water. J. Colloid Interface Sci. 1977, 59, 525-531. [CrossRef]

126. Trotter, B.; Baradaran, S.; Kadhum, M.; Shiau, B.; Harwell, J. Specific ion effects in Winsor III microemulsions. In Proceedings of the AOCS Annual Meeting, Orlando, FL, USA, 30 April-4 May 2017.

127. Jeffreys, G.; Davies, A.C. Coalescence of liquid droplets and liquid dispersión. In Recent Advances in Liquid-Liquid Extraction; Hansen, C., Ed.; Pergamon Press: Oxford, UK, 1971; pp. 495-584. [CrossRef]

128. Jones, T.J.; Neustadter, E.L.; Whittingham, K.P. Water-In-Crude oil emulsion stability and emulsion destabilization by chemical demulsifiers. J. Can. Pet. Technol. 1978, 17, 100-108. [CrossRef]

129. Walstra, P. Formation of emulsions. In Encyclopedia of Emulsion Technology; Becher, P., Ed.; Marcel Dekker: New York, NY, USA, 1983; Chapter 2; pp. 57-127.

130. Bourrel, M.; Graciaa, A.; Schechter, R.S.; Wade, W.H. The relation of emulsion stability to phase behavior and interfacial tension of surfactant systems. J. Colloid Interface Sci. 1979, 72, 161-163. [CrossRef]

131. Salager, J.L.; Quintero, L.; Ramos, E.; Anderez, J.M. Properties of surfactant/oil/water emulsified systems in the neighborhood of the three-phase transition. J. Colloid Interface Sci. 1980, 77, 288-289. [CrossRef]

132. Milos, F.S.; Wasan, D.T. Emulsion stability of surfactant systems near the three-phase region. Colloids Surf. 1982, 4, 91-96. [CrossRef]

133. Vinatieri, J.E. Correlation of emulsion stability with phase behavior in surfactant systems for tertiary oil recovery. Soc. Pet. Eng. J. 1980, 20, 402-406. [CrossRef]

134. Anton, R.E.; Salager, J.L. Emulsion instability in the three-phase behavior region of surfactant-alcohol-oil-brine systems. J. Colloid Interface Sci. 1986, 111, 54-59. [CrossRef] 
135. Rieger, M.M.; Rhein, L.D. (Eds.) Surfactants in Cosmetics, 2nd ed.; Surfactant Science Series; Marcel Dekker: New York, NY, USA, 1997; Volume 68, ISBN 0824798058.

136. Barel, A.O.; Paye, M.; Maibach, H.I. Handbook of Cosmetic Science and Technology; Marcel Dekker: New York, NY, USA, 2001. [CrossRef]

137. Schueller, R.; Romanowski, P. Multifunctional Cosmetics; Marcel Dekker: New York, NY, USA, 2003; ISBN 9780203911044.

138. Tadros, T. (Ed.) Encyclopedia of Colloid and Interface Science; Spinger: Berlin/Heidelberg, Germany, 2013; ISBN 9783642206665.

139. Sivamani, R.K.; Jagdeo, J.R.; Elsner, P.; Maibach, H.I. (Eds.) Cosmeceuticals and Active Cosmetics, 3rd ed.; CRC Press, Taylor \& Francis: Boca Raton, FL, USA, 2016.

140. Tadros, T.F.; Vincent, B. Emulsion stability. In Encyclopedia of Emulsion Technology; Basic Theory; Becher, P., Ed.; Marcel Dekker: New York, NY, USA, 1983; Volume 1, pp. 129-285.

141. Zapryanov, Z.; Malhotra, A.K.; Aderangi, N.; Wasan, D.T. Emulsion stability: An analysis of the effects of bulk and interfacial properties on film mobility and drainage rate. Intern. J. Multiph. Flow 1983, 9, 105-129. [CrossRef]

142. Shinoda, K.; Saito, H. The effect of temperature on the phase equilibria and the types of dispersions of the ternary system composed of water, cyclohexane and nonionic surfactant. J. Colloid Interface Sci. 1968, 26, 70-74. [CrossRef]

143. Kunieda, H.; Shinoda, K. Evaluation of hydrophyle-lipophile balance (HLB) of nonionic surfactants. I. Multisurfactant systems. J. Colloid Interface Sci. 1985, 107, 107-121. [CrossRef]

144. Kunieda, H.; Ishikawa, N. Evaluation of hydrophyle-lipophile balance (HLB) of nonionic surfactants. II. Commercial surfactant systems. J. Colloid Interface Sci. 1985, 107, 122-128. [CrossRef]

145. Anton, R.E.; Castillo, P.; Salager, J.L. Surfactant-Oil-Water systems near the affinity inversion-Part IV: Emulsion Inversion Temperature. J. Dispers. Sci. Technol. 1986, 7, 319-329. [CrossRef]

146. Miñana-Perez, M.; Jarry, P.; Perez-Sanchez, M.; Ramirez-Gouveia, M.; Salager, J.L.; Lopez-Castellanos, G.; Miñana-Perez, M. Surfactant-Oil-Water systems near the affinity inversion. Part 4. Emulsions with viscous hydrocarbons. J. Dispers. Sci. Technol. 1990, 11, 397-407. [CrossRef]

147. Salager, J.L.; Lopez-Castellanos, G.; Miñana-Perez, M.; Parra, C. Surfactant-Oil-Water systems near the affinity inversion. Part 7. Phase inversion and emulsions with polar oils. J. Dispers. Sci. Technol. 1991, 12, 59-67. [CrossRef]

148. Anton, R.E.; Rivas, H.; Salager, J.L. Surfactant-Oil-Water systems near the affinity inversion. Part 10. Emulsions made with anionic-nonionic surfactant mixtures. J. Dispers. Sci. Technol. 1996, 17, 553-566. [CrossRef]

149. Mendez, Z.; Anton, R.E.; Salager, J.L. Surfactant-Oil-Water systems near the affinity inversion. Part 11. pH sensitive emulsions containing carboxylic acids. J. Dispers. Sci. Technol. 1999, 20, 883-892. [CrossRef]

150. Perez, M.; Zambrano, N.; Ramirez, M.; Tyrode, E.; Salager, J.L. Surfactant-Oil-Water Systems near the affinity Inversion. 12. Emulsion Drop Size versus Formulation and Composition. J. Dispers. Sci. Technol. 2002, 23, 55-63. [CrossRef]

151. Salager, J.L.; Anton, A.; Aubry, J.M. Formulation des émulsions par la méthode HLD. Tech. Ing. Vol. Génie Procédés 2006, 158, 1-15.

152. Salager, J.L. Emulsion phase inversion phenomena. In Emulsions and Emulsion Stability, 2nd ed.; Sjoblöm, J., Ed.; Taylor \& Francis: London, UK, 2006; Chapter 4; pp. 184-225.

153. Aserin, A. (Ed.) Multiple Emulsions-Technology and Applications; Wiley: Hoboken, NJ, USA, 2008; ISBN 9780470170939.

154. Frenkel, M.; Shwartz, R.; Garti, N. Multiple Emulsions. I. Stability: Inversion, apparent and weighted HLB. J. Colloid Interface Sci. 1983, 94, 174-178. [CrossRef]

155. Garti, N. Double emulsions-Scope, limitations and new achievements. Colloids Surf. A 1997, 123, $233-246$. [CrossRef]

156. Salager, J.L. Phase transformation and emulsion inversion on the basis of catastrophe theory. In Encyclopedia of Emulsion Technology; Becher, P., Ed.; Marcel Dekker: New York, NY, USA, 1988; Volume 3, Chapter 2; pp. 79-134. 
157. Salager, J.L. Applications of catastrophe theory to surfactant-oil-brine equilibrated and emulsified systems. In Surfactants in Solution; Mittal, K.L., Bothorel, P., Eds.; Plenum Press: New York, NY, USA, 1987; Volume 4, pp. 439-448. [CrossRef]

158. Miller, D.J.; Henning, T.; Grunbein, W. Phase inversion of W/O emulsions by adding hydrophilic surfactant-A technique for making cosmetics products. Colloids Surf. A 2001, 183, 681-688. [CrossRef]

159. Salager, J.L.; Anton, R.E.; Bracho, C.; Briceño, M.I.; Peña, A.; Rondon, M.; Salager, S. Attainment of emulsion properties on design. A typical case of formulation engineering. Récent Progrès Génie des Procédés. 1999, 13, 133-140.

160. Salager, J.L.; Forgiarini, A.; Lopez, J.C.; Marfisi, S.; Alvarez, G. Dynamics of near-zero energy emulsification. In Proceedings of the 6th World Surfactant Congress CESIO, Berlin, Germany, 21-23 June 2004.

161. Perazzo, A.; Preziosi, V.; Guido, S. Phase inversion emulsification: Current understanding and applications. Adv. Colloid Interface Sci. 2015, 222, 581-599. [CrossRef]

162. Salager, J.L.; Forgiarini, A.; Marquez, L.; Peña, A.; Pizzino, A.; Rodriguez, M.P.; Rondon-Gonzalez, M. Using emulsion inversion in industrial processes. Adv. Colloid Interface Sci. 2004, 108, 259-272. [CrossRef]

163. Tyrode, E.; Mira, I.; Zambrano, N.; Marquez, N.; Rondon-Gonzalez, M.; Salager, J.L. Emulsion catastrophic inversion from abnormal to normal morphology. 3. Conditions for triggering the dynamic inversion and application to industrial processes. Ind. Eng. Chem. Res. 2003, 42, 4311-4318. [CrossRef]

164. Forster, T.; Schambil, F; von Rybinski, W. Production of fine dispersed and long-term stable oil-in-water emulsions by the phase inversion temperature. J. Dispers. Sci. Technol. 1992, 13, 183-193. [CrossRef]

165. Forster, T.; Von Rybinsky, W.; Wadle, A. Influence of microemulsion phases on the preparation of fine -dispersed emulsions. Adv. Colloid Interface Sci. 1995, 58, 119-149. [CrossRef]

166. Cansellier, J.P.; Poux, M. Procédés d'émulsification-Méchanismes de formation des émulsions. Tech. Ing. 2000, 152, 1-12.

167. Schubert, H.; Armbruster, H. Prinzipien der Herstellung und stabilität von emulsionen. Chem. Ing. Tech. 1989, 61, 701-711. [CrossRef]

168. Grace, H.P. Dispersion phenomena in high viscosity inmiscible fluid systems and aplication of static mixers as dispersion devices in such systems. Chem. Eng. Commun. 1982, 14, 225-277. [CrossRef]

169. Salager, S.E.; Tyrode, E.C.; Celis, M.T.; Salager, J.L. Influence of the stirrer initial position on emulsion morphology. Making use of the local water-to-oil ratio concept for formulation engineering purpose. Ind. Eng. Chem. Res. 2001, 40, 4808-4814. [CrossRef]

170. Kunieda, K.; Miyajima, A. Effect of the mixing of oils on the Hydrophile-Lipophile-Balanced (HLB) temperature in a water/nonionic surfactant/oil system. J. Colloid Interface Sci. 1989, 128, 605-607. [CrossRef]

171. Nardello, V.; Chailloux, N.; Poprawski, J.; Salager, J.L.; Aubry, J.M. HLD concept as a tool for the characterization of cosmetic hydrocarbon oils. Polym. Intern. 2003, 52, 602-609. [CrossRef]

172. Queste, S.; Salager, J.L.; Strey, R.; Aubry, J.M. The EACN scale for oil classification revisited thanks to fish diagrams. J. Colloid Interface Sci. 2007, 312, 98-107. [CrossRef]

173. Bouton, F.; Durand, M.; Nardello-Rataj, V.; Serry, M.; Aubry, J.M. Classification of terpene oils using the fish diagrams and the equivalent alkane carbon (EACN) scale. Colloids Surf. A 2009, 338, 142-147. [CrossRef]

174. Bouton, F.; Durand, M.; Nardello-Rataj, V.; Borosy, A.P.; Quellet, C.; Aubry, J.M. A QSPR model for the prediction of the "fish-tail" temperature of CiE4/water/polar hydrocarbon oil systems. Langmuir 2010, 26, 7962-7970. [CrossRef]

175. Tchakalova, V.; Fieber, W. Classification of fragrances and fragrance mixtures based on interfacial solubilization. J. Surfactants Deterg. 2012, 15, 167-177. [CrossRef]

176. Ontiveros, J.F.; Pierlot, C.; Catte, M.; Molinier, V.; Pizzino, A.; Salager, J.L.; Aubry, J.M. Classification of ester oils according to their equivalent alkane carbon number (EACN) and asymmetry of fish diagrams of $\mathrm{C}_{10} \mathrm{E}_{4}$ /ester oil/water systems. J. Colloid Interface Sci. 2013, 403, 67-76. [CrossRef]

177. Baran, J.R.; Pope, G.A.; Schultz, C.; Wade, W.H.; Weerasooriya, V.; Yapa, A. Toxic spill remediation of chlorinated hydrocarons via microemulsion formation. In Surfactants in Solutions; Chattopadhay, A.K., Mittal, K.L., Eds.; Marcel Dekker: New York, NY, USA, 1996; pp. 393-411.

178. Lukowicz, T.; Illous, E.; Nardello-Rataj, V.; Aubry, J.M. Prediction of the equivalent alkane carbon number (EACN) of aprotic polar oils with COSMO-RS sigma-moments. Colloids Surf. A 2018, 536, 53-59. [CrossRef]

179. Rondon, M.; Bouriat, P.; Lachaise, J.; Salager, J.L. Breaking of water-in-crude oil emulsions. Part 1: Physico-chemical phenomenology of demulsifier action. Energy Fuels 2006, 20, 1600-1604. [CrossRef] 
180. Rondon, M.; Pereira, J.C.; Bouriat, P.; Graciaa, A.; Lachaise, J.; Salager, J.L. Breaking of water-in-crude oil emulsions. 2: Influence of asphaltene concentration and diluent nature on demulsifier action. Energy Fuels 2008, 22, 702-707. [CrossRef]

181. Pereira, J.C.; Delgado, J.G.; Scorzza, C.; Rondon, M.; Salager, J.L. Breaking of water-in-crude emulsions. 4. Estimation of the demulsifier surfactant performance to destabilize the asphaltenes effect. Energy Fuels 2011, 25, 1045-1050. [CrossRef]

182. Salager, J.L.; Forgiarini, A. Emulsion stabilization, breaking and inversion: Advantage or inconvenience in flow assurance. Energy Fuels 2012, 2, 4027-4033. [CrossRef]

183. Gjayour, A.; Acosta, E. Characterizing the oil-like and surfactant-like behavior of polar oils. Langmuir 2019, 35, 15038-15050. [CrossRef]

184. Vlachy, N.; Jagoda-Cwiklik, B.; Vácha, R.; Touraud, D.; Jungwirth, P.; Kunz, W. Hofmeister series and specific interactions of charged headgroups with aqueous ions. Adv. Colloid Interface Sci. 2009, 146, 42-47. [CrossRef]

185. Graciaa, A.; Lachaise, J.; Sayous, J.G.; Grenier, P.; Yiv, S.; Schechter, R.S.; Wade, W.H. The Partitioning of complex surfactant mixtures between oil/water/microemulsion phases at high surfactant concentrations. J. Colloid Interface Sci. 1983, 93, 474-486. [CrossRef]

186. Graciaa, A.; Lachaise, J.; Bourrel, M.; Osboren-Lee, I.; Schechter, R.S.; Wade, W.H. Partitioning of nonionic and anionic surfactant mixtures between oil/microemulsion/water phases. Soc. Pet. Eng. Reserv. Eng. 1987, 2, 305-314. [CrossRef]

187. Graciaa, A.; Anderez, J.M.; Bracho, C.; Lachaise, J.; Salager, J.L.; Tolosa, L.; Ysambertt, F. The selective partitioning of the oligomers of polyethoxylated surfactant mixtures between interface and oil and water bulk phases. Adv. Colloid Interface Sci. 2006, 123, 63-73. [CrossRef] [PubMed]

188. Antón, R.E.; Gómez, D.; Graciaa, A.; Lachaise, J.; Salager, J.L. Surfactant-Oil-Water systems near the affinty inversion. Part 9. Optimum formulation and of mixed anionic-cationic systems phase behavior. J. Dispers. Sci. Technol. 1993, 14, 401-416. [CrossRef]

189. Li, X.; Kunieda, H. Catanionic surfactants: Microemulsion formation and solubilization. Current Opin. Colloid Interface Sci. 2003, 8, 327-336. [CrossRef]

190. Kunieda, H.; Hanno, K.; Yamaguchi, S.; Shinoda, K. The three-phase behavior of a brine/ionic surfactant/nonionic surfactant/oil system: Evaluation of the hydrophile-llipophile balance (HLB) of ionic surfactant. J. Colloid Interface Sci. 1985, 107, 129-137. [CrossRef]

191. Anton, R.E.; Graciaa, A.; Lachaise, J.; Salager, J.L. Surfactant-Oil-Water system near the affinity inversion. Part 8. Optimum formulation and phase behavior of mixed anionic-nonionic system versus temperature. J. Dispers. Sci. Technol. 1992, 13, 565-579. [CrossRef]

192. Lukowicz, T.; Maldonado, R.; Molinier, V.; Aubry, J.M.; Nardello-Rataj, V. Fragrance solubilization in temperature insensitive aqueous microemulsions based on synergistic mixtures of nonionicand anionic surfactants. Colloids Surf. A 2014, 458, 85-95. [CrossRef]

193. Ontiveros, J.F.; Pierlot, C.; Catte, M.; Salager, J.L.; Aubry, J.M. Determining the Preferred Alkane Carbon Number (PACN) of nonionic surfactants using the PIT-slope method. Colloids Surfaces A 2018, 536, 30-37. [CrossRef]

194. Ontiveros, J.F.; Pierlot, C.; Catte, M.; Molinier, V.; Salager, J.L.; Aubry, J.M. Structure-Interfacial properties relationship and quantification of the amphiphilicity of well-defined ionic and nonionic surfactants using the PIT-slope method. J. Colloid Interface Sci. 2015, 448, 222-230. [CrossRef]

195. Salager, J.L.; Marquez, N.; Anton, R.E.; Graciaa, A.; Lachaise, J. Retrograde Transition in the Phase Behavior of surfactant-oil-water systems produced by an alcohol scan. Langmuir 1995, 11, 37-41. [CrossRef]

196. Arandia, M.A.; Forgiarini, A.; Salager, J.L. Resolving an enhanced oil recovery challenge: Optimum formulation of a surfactant-oil-water system made insensitive to dilution. J. Surfactants Deterg. 2010, 13, 119-126. [CrossRef]

197. Hirasaki, G.J. Interpretation of the change in optimal salinity with overall surfactant concentration. Soc. Pet. Eng. J. 1982, 22, 971-982. [CrossRef]

198. Kunieda, H.; Yamagata, M. Three-Phase behavior in a mixed nonionic surfactant system. Colloid Polym. Sci. 1993, 271, 997-1004. [CrossRef] 
199. Engels, T.; Forster, T.; von Rybinski, W. The influence of coemulsifier type on the stability of oil-in-water emulsions. Colloids Surf. A 1995, 99, 141-149. [CrossRef]

200. Marquez, R.; Bullon, J.; Marquez, L.; Cardenas, A.; Briceño, M.I.; Forgiarini, A. Rheological changes of parenteral emulsions during phase-inversion emulsification. J. Dispers. Sci. Technol. 2008, 29, 621-627. [CrossRef] 